\title{
Meta-organization of Translation Centers Revealed by Proximity Mapping of Endoplasmic Reticulum Ribosome Interactors
}

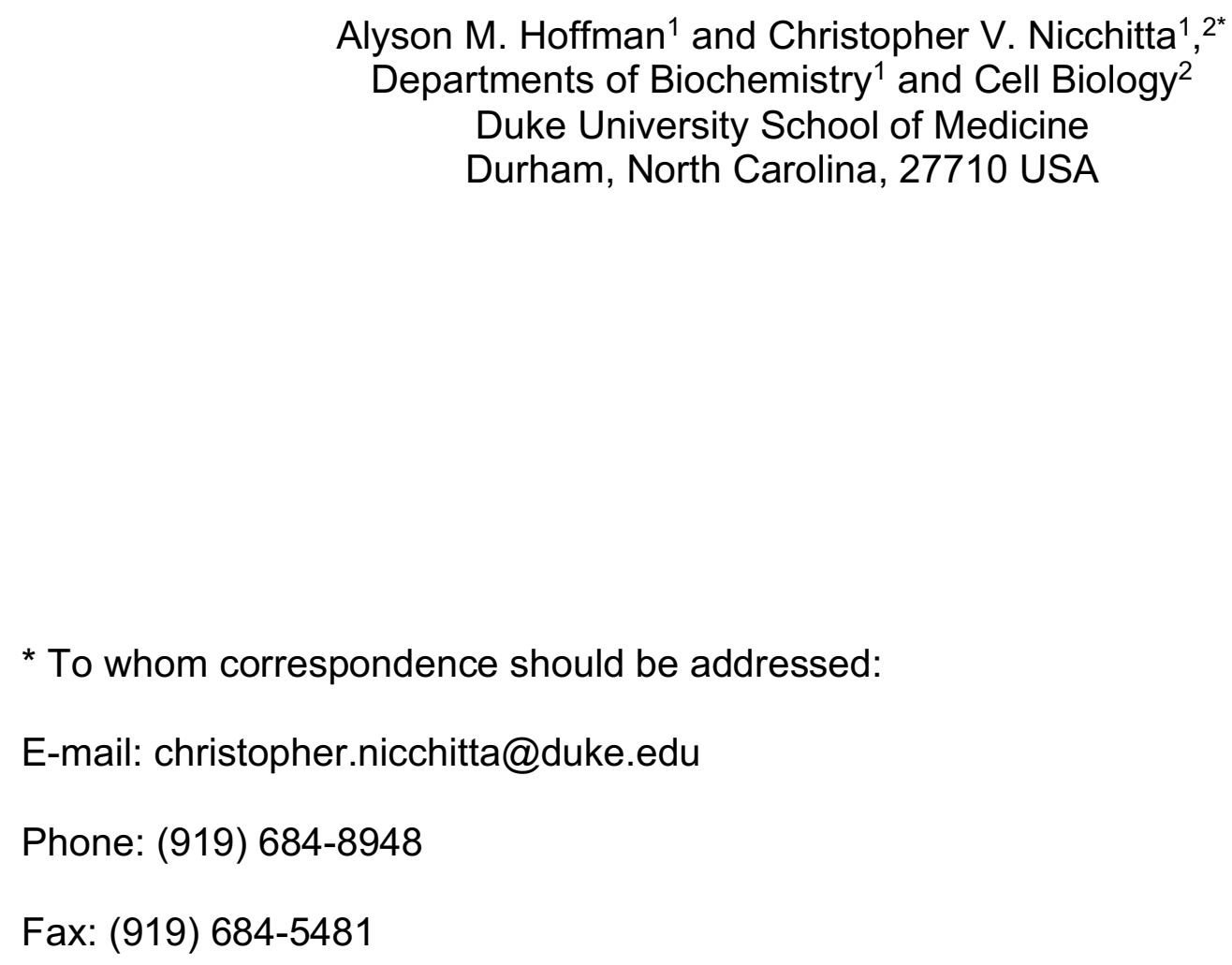




\section{Abstract:}

48 The endoplasmic reticulum (ER) is a nexus for mRNA localization and translation; the

49

50

51

52

53

54

55

56

57

58

59

60

61

62

63

64

molecular organization of these processes remains however largely undefined. To gain insight into mechanisms supporting a diverse ER translational landscape, we utilized BiolD labeling to study the protein neighborhoods of the Sec61 translocon, specifically Sec61 $\beta$, an established ribosome interactor, and ER proteins (Ribophorin I, LRRC59, and Sec62) previously implicated in ribosome association. Divergent protein interactomes enriched for distinct GO functions were identified for the four reporters, within a cohort of shared interactors. Efficient BiolD tagging of ribosomes was only observed for the Sec61 $\beta$ and LRRC59 reporters. RNA-seq analyses of the Sec61ß- and LRRC59-labeled ribosomes revealed divergent enrichments in mRNAs and identified a transcriptome-wide role for the ER in proteome expression. These data provide evidence for a mesoscale organization of the ER and suggest that such organization provides a mechanism for the diversity of translation on the ER. 


\section{Introduction:}

The endoplasmic reticulum (ER) is a highly heterogeneous organelle composed of both rough and smooth membrane domains, distinguished by the presence or absence of bound ribosomes, a contiguous sheet and tubular membrane organization, and a diversity of primary cellular functions including secretory/membrane protein biogenesis, lipid biosynthesis, and calcium storage (English \& Voeltz, 2013; Fawcett, 1966; Lynes \& Simmen, 2011; Schwarz \& Blower, 2016). In addition to these defining features, the ER engages in membrane-membrane communication with different organelles, including mitochondria, endosomes, and the plasma membrane (English \& Voeltz, 2013; Helle et al., 2013; Valm et al., 2017). The sites of organelle-ER communication are marked by multi-protein assemblies that define areas of regional specialization, e.g., mitochondrialassociated membranes (MAMs), and provide evidence for the spatial organization of the membrane proteome as a biochemical/biophysical mechanism to accommodate the various structural and functional properties of this critical organelle (de Brito \& Scorrano, 2010; Hung et al., 2017; Jing et al., 2015; Vance, 2014).

In addition to a dedicated function in secretory/membrane protein biogenesis, recent and past studies examining the subcellular distribution of mRNAs between the cytosol and ER compartments have revealed a transcriptome-wide role for the ER in proteome expression (Mueckler and Pitot 1981; Diehn et al. 2000; Diehn et al. 2006; Stephens and Nicchitta 2008; Jan, Williams, and Weissman 2014; Chartron, Hunt, and Frydman 2016; Voigt et al. 2017; Reid and Nicchitta 2012). The high enrichment in ER localization and translation of secretory/membrane protein-encoding mRNAs further validates the 
established function of the ER in secretory and membrane protein biogenesis (Reid and Nicchitta 2012; Jan, Williams, and Weissman 2014; Chartron, Hunt, and Frydman 2016). An unexpected yet consistent finding in these studies is the comparatively modest enrichment of cytosolic mRNAs on free, cytosolic ribosomes (Reid and Nicchitta 2012; Jan, Williams, and Weissman 2014; Chartron, Hunt, and Frydman 2016). Given that eukaryotic transcriptomes are substantially weighted to cytosolic protein-encoding mRNAs, such modest enrichments indicate a broad representation of these mRNAs on the ER and suggest a global role for the ER in transcriptome expression (Diehn et al., 2006; Mueckler \& Pitot, 1981; Reid \& Nicchitta, 2015; Voigt et al., 2017). Although a function for the ER in the translation of cytosolic protein-encoding mRNAs has been under investigation for many decades, more recent biochemical and structural biology studies of the ribosome-Sec61 translocon, composed of Sec61 $\alpha$, Sec61 $\beta$ and Sec61 $\gamma$ subunits, would suggest that such a function is unlikely (Becker et al., 2009; Pfeffer et al., 2014, 2015; Prinz, Behrens, Rapoport, Hartmann, \& Kalies, 2000; Schaletzky \& Rapoport, 2006; Voorhees, Fernández, Scheres, \& Hegde, 2014). The Sec61 translocon serves as a ribosome receptor and translocation channel, where the ribosomal protein exit channel resides in close physical apposition to the translocon channel entrance site. Thus, Sec61 translocon-associated ribosomes are presumed to be dedicated to the translation of secretory and membrane protein-encoding mRNAs. Recent work supports additional mechanisms of supporting ER-localized translation, where translation of cytosolic proteinencoding mRNAs on the ER could be accommodated by Sec61 translocon-independent ribosome association mechanisms (Cui, Zhang, and Palazzo 2012; Voigt et al. 2017; Reid and Nicchitta 2012; Stephens and Nicchitta 2008; Potter and Nicchitta 2000). In support 
112 of this view, a number of ER resident membrane proteins other than the Sec61 translocon

113 have been proposed to function as ribosome receptors, including the

114 oligosacharyltransferase (OST) subunit Ribophorin I, LRRC59 (p34), and p180 (RRBP1)

115 (Harada, Li, Li, \& Lennarz, 2009; Kreibich, Freienstein, Pereyra, Ulrich, \& Sabatini, 1978;

116 Savitz \& Meyer, 1990; Tazawa et al., 1991). Although these proposed ribosome receptors

117 have been shown to display high binding affinity to ribosomes in vitro, very little is known

118 regarding the potential diversity of ribosome-ER protein interactions in vivo.

Here we utilized BiolD in vivo proximity mapping as a means to investigate the interactomes of a subset of proposed ribosome receptors. These data revealed a higher order (mesoscale) organization of the ER, where the BiolD reporters reside in stable protein environments with clear GO functional enrichments, consistent with the organization of the ER membrane into discrete translation centers. Of the four candidates examined, only two, Sec61 $\beta$ and LRRC59, efficiently labeled ER-bound ribosomes. Intriguingly, RNA-seq analysis of ribosomes from the two distinct sites revealed both enriched and shared transcriptome cohorts. These data are consistent with a higher order organization of the translation functions of the ER into translation centers, which we define as enriched assemblies of interacting proteins, associated ribosomes, and bound mRNAs. In addition, these data suggest mechanisms whereby the ER could serve a 131 broad role in proteome expression. 


\section{Results:}

\section{Experimental Overview:}

Recent reports identify a transcriptome-wide function for ER-associated ribosomes in proteome expression (Reid and Nicchitta 2012; Voigt et al. 2017; Jan, Williams, and Weissman 2014; Chartron, Hunt, and Frydman 2016). Given the central role of the Sec61 translocon as both the protein-conducting channel and ribosome receptor for membrane and secretory proteins (Gorlich, Prehn, Hartmann, Kalies, \& Rapoport, 1992; Voorhees et al., 2014), we postulated that ER membrane proteins other than the Sec61 translocon participate in ribosome-ER interactions, as a mechanism to support transcriptome expression on the ER (Pfeffer et al., 2015; Reid \& Nicchitta, 2015; Voorhees et al., 2014). To test this hypothesis, we used a BiolD proximity labeling approach, where BioID chimera of known or proposed ribosome interacting proteins were used to map both ER protein-ribosome and proximal ER membrane protein interactions (Figure 1A,B). Briefly, BiolD uses a mutant bacterial biotin ligase $\left(B_{i r} A^{*}\right)$ that releases an unstable, aminereactive biotin intermediate (biotin-AMP) from the active site; biotin-AMP can then react with near-neighbor proteins and thus provide in vivo protein-protein spatial interaction information (Roux, Kim, Raida, \& Burke, 2012). As schematically illustrated in Figure 1A, ER membrane protein-BioID chimera constructs were engineered, inducible HEK293 FlpIn cell lines generated, and interactomes studied by biotin addition followed by subcellular fractionation and proteomic analyses of biotin-tagged proteins. As noted above, prior studies have established the Sec61 translocon as a ribosome receptor and so Sec61 $\beta$ BiolD was selected to report on the Sec61 translocon interactome (Deshaies, Sanders, Feldheim, \& Schekman, 1991; Levy, Wiedmann, \& Kreibich, 2001; Pfeffer et al., 2015). 
155 Ribophorin I, a component of the OST, is vicinal to translocating nascent chains, has been proposed to function as a ribosome receptor, and was found to be a Sec61 translocon interactor, thus complementing the Sec61 $\beta$-BiolD interactome screen (Harada et al., 2009; Kreibich et al., 1978; Wild et al., 2018). Sec62, though relatively unstudied in mammalian systems, is orthologous to yeast Sec62, which participates in posttranslational translocation, and in mammalian systems has been demonstrated to function in ribosome binding, with binding interactions mapped to regions adjacent to the ribosome exit tunnel (Lang et al., 2012; Müller et al., 2010). LRRC59, also relatively unstudied, was identified as a ribosome binding protein through biochemical reconstitution approaches and chemical crosslinking, where it was demonstrated to reside near large ribosomal subunits (Ichimura et al., 1993; Tazawa et al., 1991). An in vivo function for LRRC59 in ribosome binding has not been established, although anti-LRRC59 IgG and Fab inhibit ribosome binding and protein translocation in vitro (Ichimura et al., 1993). These four Ribophorin I, and little studied proteins lacking a defined function in mammalian cells, e.g., LRRC59 and Sec62, to provide an expanded understanding of the molecular organization of the ER. of the ribosome interactor-BiolD chimera introduced above, reporter cell lines were induced for 16 hours with biotin supplementation and the subcellular reporter expression 
biotin labeling patterns examined by staining with a streptavidin-AF647conjugate (Figure 2A). A cell line containing the cloning vector backbone served as a negative control in this analysis (empty vector). As depicted in Figure $\mathbf{2}$ A and B, all four reporter cell lines displayed clear perinuclear reticular staining with the BirA antisera, consistent with an ER Iocalization for all BioID chimera. Ribophorin I and Sec61 $\beta$ are subunits of oligomeric protein complexes; to ensure correct localization of these chimeras we also compared the hydrodynamic behavior of the BirA* chimera with the respective natively expressed proteins in the engineered BiolD and empty vector cell lines by glycerol gradient velocity sedimentation (Nikonov, Snapp, Lippincott-Schwartz, \& Kreibich, 2002)(Figure 2 - figure supplement 1). The sedimentation patterns of all BiolD reporters and respective native proteins were similar to those of the empty vector-engineered cell lines and with sedimentation velocities consistent with their estimated complex sizes, suggesting that the chimera were appropriately assembled into native complexes (Harada et al., 2009). In yeast, such chimera complement genomic deletions of the parent gene, also indicative of native-like function (Jan, Williams, and Weissman 2014).

Intriguingly, streptavidin staining of proximal biotin labeled targets co-localized with the BirA staining patterns, suggesting that the primary interactomes are largely confined to the ER (Figure 2A,B). These findings were further validated in studies comparing the streptavidin staining patterns with the resident ER membrane protein TRAP $\alpha$ (Figure 2B). As with the data depicted in Figure 2A, we observed extensive overlap of streptavidin staining pattern with that of the resident ER protein marker. Surprisingly, after $16 \mathrm{~h}$ of 
200 induction/biotin labeling the biotin tagging pattern was highly restricted to the ER, with

201 little discernible tagging of cytosolic proteins.

202

203

204

205

206

207

208

209

210

211

212

213

214

215

216

217

218

219

220

221

222

The immunofluorescence data (Figure 2) were further evaluated in cell fractionation studies of the BirA* chimera and the biotin labeling patterns (Figure 3). Using a previously validated sequential detergent fractionation protocol (Jagannathan, Nwosu, \& Nicchitta, 2011; Stephens \& Nicchitta, 2007), where the cytosol fraction is released upon addition of a digitonin-supplemented buffer and the membrane fraction subsequently recovered by addition of a NP40/sodium deoxycholate/high-salt buffer, BiolD chimera distributions were assessed by SDS-PAGE/immunoblot analysis. These data are depicted in Figure 3 and demonstrate that all ER membrane protein reporters were wholly recovered in the membrane fraction (M) and displayed SDS-PAGE mobilities consistent with their predicted molecular weights. Mirroring the immunofluorescence data shown in Figure 2A and $\mathbf{B}$, proximal protein biotin labeling was highly enriched in the membrane fractions (M) (Figure 3B,C,TRAP $\alpha$ as ER marker), with only modest labeling of cytosolic proteins (C) (Figure 3B,C, $\beta$-tubulin as cytosolic marker). Interestingly, the biotin labeling patterns of the membrane fractions were readily distinguishable from one another, suggesting that the ER protein-reporters reside in distinct protein neighborhoods. The relatively paucity of biotinylated cytosolic proteins, visualized by both immunofluorescence staining and direct biochemical analysis, was unexpected. Because the reactive biotin-AMP intermediate diffuses from the BirA* active site to modify accessible lysine residues of proximal proteins (Choi-Rhee, Schulman, \& Cronan, 2004), we expected that membrane and cytosolic proteins would be similarly accessible to modification. The bias to biotin- 
conjugation of ER membrane proteins suggests that the labeling radius for the reactive biotin-AMP intermediate is highly restricted (Kim et al. 2014).

\section{Evidence for meso-organization of ER membrane protein assemblies.}

BiolD proximity labeling experiments are typically conducted over many hours (Varnaitè \& MacNeill, 2016) (e.g. 16-24h), a reflection of the slow release kinetics of the reactive biotin-AMP catalytic intermediate from the BirA* active site (Kwon \& Beckett, 2000). Because this time scale is substantially slower than that of most cellular processes, the specificity of the labeling reaction is formally a concern (Rees, Li, Perrett, Lilley, \& Jackson, 2015), though it has been demonstrated that neighboring proteins can be distinguished from random interactors by their higher relative labeling over non-specific controls (Rees et al. 2015; Kim et al. 2014; Roux et al. 2012; Ueda et al. 2015; Gupta et al. 2015). In the context of the experiments with ER membrane-localized BiolD reporters, we were concerned that reporter diffusion in the constrained $2 \mathrm{D}$ environment of the ER membrane over such extended labeling times could confound identification of nearneighbor and interacting proteins. To address this concern, we examined the BiolD reporter biotin labeling patterns as a function of labeling time. Our prediction was that the biotin labeling patterns would diversify as labeling times increased, a consequence of the expected random diffusion of the reporter chimera within the 2-D constraints of the ER membrane. The results of these experiments are shown in Figure 4A. Depicted are streptavidin blots of the cytosol and ER protein fractions from the four BiolD reporter cell lines, sampled over a time course of 0-6 hours. Two observations are highlighted here. First, as noted above, the relatively enhanced labeling of membrane proteins (M) to 
cytosolic proteins (C) is evident throughout the time course examined, with very modest levels of cytosolic protein labeling throughout the time course for all constructs. Second, contrary to our expectations, the membrane protein biotin labeling patterns did not substantially diversify over the labeling time course (Figure 4A). Rather, the labeling pattern intensified as labeling time increased. The biotin labeling patterns revealed by SDS-PAGE were further analyzed by densitometric analysis (Figure 4A), where it can be appreciated that the biotin labeling patterns intensify, but only modestly diversify, as a function of labeling time. These data suggest that the BiolD interactomes comprise largely stable membrane protein assemblies (Figure 4B), rather than the presumed randomizing interactomes expected of diffusion-based interactions (Figure 4B) (Goyette \& Gaus, 2017; Kusumi et al., 2012; Kusumi, Suzuki, Kasai, Ritchie, \& Fujiwara, 2011; Singer \& Nicolson, 1972).

The data presented above (Figure 4A) are consistent with a model where the mobility of the BiolD reporters is constrained (Figure 4B), perhaps reflecting mesoscale organization of the ER via biomolecular interactome networks, as has been extensively documented in the plasma membrane (Goyette \& Gaus, 2017; Kusumi et al., 2012, 2011). We also considered that the labeling patterns could be influenced by either ER distribution biases (e.g., tubules vs. sheets) or protein-specific differences in reactivity to the biotin-AMP reactive intermediate. To examine these scenarios, we performed proximity labeling time course experiments using canine pancreas rough microsomes (RM), which lack the native topological structure of the ER, and a soluble, recombinant BirA*. Using this system, the reactive intermediate was delivered in trans and accessible to the ER surface 
by solution diffusion. The results of these experiments are shown in Figure $\mathbf{5}$ and demonstrate that when accessible to RM proteins in trans, biotin labeling is pervasive and monotonic, with a diversity of proteins undergoing labeling and relative labeling intensities increasing as a function of labeling time (compare Figure 5B to Figure 5D). Combined, the data depicted in Figures $\mathbf{4}$ and $\mathbf{5}$ indicate that these BirA* chimera are restricted to protein interactome domains of the ER in vivo, as represented by the distinct labeling patterns identified in each cell line.

To gain molecular insight into the protein neighborhoods of the reporters, cell lines were supplemented with biotin for 3 hours, the time point at which labeling intensity was highest compared to background, as illustrated in Figure 4, and biotinylated proteins captured from membrane extracts by streptavidin-magnetic bead affinity isolation. Elution was performed by biotin competition at high $\mathrm{pH}$ to select against non-specific background, with protein composition determined by mass spectrometry of the eluted samples. A summary of the analysis schema is depicted in Figure 6A. In brief, spectral counts of proteins meeting high confidence ( $1 \%$ FDR) cutoffs were normalized to those of natively biotinylated proteins and the subset with enrichments of $\geq 2.5$-fold over an empty vector control were selected. For these, two categories were defined; "enriched", displaying an enrichment of $>2$-fold over the combined normalized value, and "shared", for those below this selection threshold. For all reporters, the majority of the labeled proteins meeting initial significance criteria were membrane proteins, corroborating the data presented in Figures 2-4. In the shared category, representing those proteins that met selection criteria and were present at similar normalized levels in two or more reporter datasets, 
about $80 \%$ were membrane proteins, $10 \%$ were cytoplasmic proteins, and $10 \%$ were nuclear proteins. Within the shared membrane protein category, a number of prominent ER resident membrane proteins were identified in the reporter datasets and included signal peptidase complex subunit 2 , the elF2 $\alpha$ kinase PERK, DNAJC1, the ERADassociated E3 ubiquitin ligase TRIM13, ERGIC-53, ER calcium ATPase 2, and reticulon4. Other prominent ER resident proteins present in at least 3 of the 4 reporter datasets included Sec63 homolog, calnexin, and NADPH cytochrome P450. With respect to the enriched datasets, the candidate ribosome interactors LRRC59 and Ribophorin I returned identical numbers of neighboring/candidate interacting proteins (35), with Sec61 $\beta$ returning 19 enriched hits, and Sec62 11 enriched hits; these specific interactomes are discussed further below. In summary, proteomic analysis of the neighboring proteins for the indicated BiolD chimera revealed a high enrichment in ER membrane proteins and within this category, proteins with established functions in canonical rough ER functions such as protein translocation/protein processing, the unfolded protein response (UPR), and ER-associated protein degradation (Cross, Sinning, Luirink, \& High, 2009; Gardner, Pincus, Gotthardt, Gallagher, \& Walter, 2013; Hayashi-Nishino et al., 2009; Vembar \& Brodsky, 2008).

\section{Candidate Ribosome Interactors Reside In Distinct ER-Protein Neighborhoods}

To further evaluate the subsets of neighboring proteins scoring in the enriched category, the datasets were visualized in Cytoscape (Shannon et al., 2003), cross-referenced via the STRING Protein-Protein Interaction Network resource (Szklarczyk et al., 2017), and functional enrichments for each reporter neighborhood determined by GO analysis. For 
clarity, the Cytoscape-generated plots depicted in Figure 7 include the top enriched hits, with screened, shared interactors included as Figure 8A-B. The plots provided in Figure 7 are coded to illustrate interactions with soluble proteins (yellow border) and membrane proteins (turquoise border). Centered and uncolored nodes indicate the chimera protein from each cell line and reporter spokes identify candidate interactor or near neighbor proteins. Direct protein-protein interactions that have been previously experimentally demonstrated via STRING annotation are represented by additional edges between colored nodes and, in the cases of Sec61 $\beta$ and Ribophorin I, green nodes for members of their native heterooligomeric complexes, which serve as important internal controls. Dark blue nodes and green nodes with asterisks by the gene name are proteins comprising the top GO category indicated underneath each plot and in the included table at the bottom of the figure. For Sec61 $\beta$ (Figure 7), a prominent interactor was Sec61 $\alpha$, as would be expected if the reporter was assembled into the native Sec61 translocon. The enriched BiolD neighborhood set for Sec61 $\beta$ also included membrane biogenesis enzymes, e.g., the stearoyl desaturase SCD, the $\mathrm{IP}_{3}$ receptor/calcium channel ITPR3, and the calcium ATPase ATP2B1. GO analysis of the enriched Sec61 $\beta$ BiolD interactome set yielded the category "organelle membrane" as a high probability functional gene set. The enriched interactome set for Ribophorin I (RPN1 in figures) (Figure 7) includes STT3A, STT3B, and RPN2, (subunits of the OST complex), accessory components of the translocation machinery, such as SSR1, the IP 3 receptor/calcium channel ITPR2, and the stearoyltransferase SOAT1. GO analysis of the enriched ribophorin I BiolD interactome set yielded the category "transport" as a high probability functional gene set. The LRRC59 (Figure 7) enriched interactome was particularly interesting as it included ER membrane 
proteins either predicted or demonstrated to function as RNA binding proteins, including MTDH (AEG-1), RRBP1 (p180), and CKAP4, as well as SRP68 (68 kDa subunit of the signal recognition particle) (Castello et al., 2012, 2016; Hentze, Castello, Schwarzl, \& Preiss, 2018). This functional enrichment is consistent with recently published work demonstrating a function for AEG-1 and RRBP1 in RNA anchoring to the ER, and implicate LRRC59 in translational regulation on the ER (Hsu et al. 2018; Cui, Zhang, and Palazzo 2012; Ueno et al. 2012); the GO category "poly(A)RNA-binding" reflects this enrichment. The Sec62 BiolD chimera dataset contained very few proteins that met the "enriched" cutoff criteria, with the few that did representing likely false positives (ER lumenal and mitochondrial matrix proteins) (see supplementary proteomic data set)(Figure 8B). Also, and whereas we predicted Sec63 in the Sec62 dataset, Sec63 appeared similarly labeled in the LRRC59 and Sec61 $\beta$ datasets and by selection criteria is shared (Figure 8B).

The binning scheme ("enriched" and "shared") is useful for highlighting near-neighbor interactions and their functional enrichments. As noted, however, the proteomics dataset also revealed crosstalk between the BioID chimera and the wild-type candidate ribosome interacting proteins, though these interactions were not above the high stringency cutoff used to define near proximity interactions. The Cytoscape plot illustrated in Figure $\mathbf{8 A}$ depicts these lower threshold interactions, with the reporter nodes illustrated in yellow, green and dark red, representing Sec61 $\beta$, LRRC59, and Ribophorin I, respectively, with the remaining "shared" dataset illustrated in Figure 8B. In summary, mass spectrometric analysis of the protein neighborhoods/interactomes identified by the BiolD method 
confirm that for two of the candidate ribosome interactors, Sec61 $\beta$ and Ribophorin I, the reporter chimera reside in proximity to their established native oligomeric complexes and intriguingly, three of the chimera reveal distinct protein neighborhoods whose residents are enriched for different ER functions, notably poly(A)RNA-binding (LRRC59), while sharing numerous ER resident proteins functioning in protein biogenesis and other ancillary ER functions (e.g., lipid synthesis and calcium transport).

\section{Proximity Labeling of ER-Bound Ribosomes by Candidate Ribosome Interactors}

In our initial mass spectrometric screens of candidate ribosome interacting proteins, biotinylated ribosomal proteins were largely absent from the datasets, which we subsequently determined reflected inefficient elution of densely biotinylated proteins from the Neutravidin beads. In addition, whereas we had presumed that ribosomal proteins, being highly basic and lysine-rich, would be very receptive to BiolD labeling, SDS-PAGE analyses of ER-derived biotinylated ribosomes revealed that only a small subset of ribosomal proteins were targets for BiolD labeling (Figure 9). As an alternative analytical strategy for analyzing candidate ribosomal proteins labeled via the BiolD method, we conducted labeling experiments as above but first enriched for the ribosome fraction by ultracentrifugation and analyzed ribosome BiolD patterns separately.

The Sec61 $\beta$ BiolD reporter, being a subunit of the Sec61 translocon, was found to efficiently label ER-bound ribosomes, as was the LRRC59 reporter, though itself not a translocon subunit (Figure 9, $6 \mathrm{hr}$ time points). Ribosome labeling was not observed at the shorter labeling periods for the Ribophorin I BiolD chimera, or at any of the time points 
examined for the Sec62 BiolD chimera (Figure 9), though both have been previously reported to bind ribosomes in vitro (Harada et al., 2009; Müller et al., 2010). As we report above for the protein interactomes, the restricted ribosome BiolD labeling patterns we observed are suggestive of a high degree of spatial organization and stability. Negative data must be interpreted with caution, however. In the case of the Ribophorin I reporter, the ribosome-OST interaction may be too short lived for efficient labeling. Consistent with this interpretation, recent cryoEM studies of ER microsomes have reported two distinct Sec61 translocon environments distinguished by the presence or absence of OST, where it is noted that OST recruitment to the translocon may be transient, being present for the brief interval of $\mathrm{N}$-linked sugar addition (Pfeffer et al., 2015; Wild et al., 2018). In addition and/or alternatively, the Ribophorin I chimera may be compromised in its ability to associate with the Sec61 translocon and thus to report on translocon-bound ribosomes (Braunger et al. 2018).

For the same rationale used in the studies of near-neighbor protein-protein interactions (Figure 4), we performed time course studies of ribosome labeling, and examined labeled ribosome distributions in the cytosol and ER compartments (Figure 9). As shown, the distinct ribosome labeling patterns seen for the LRRC59 and Sec61 $\beta$ BiolD reporters were evident within 0.5 to 1 hour of biotin addition, enriched in the ER-bound ribosome fraction, and with a small fraction of labeled ribosomes recovered in the cytosol. The labeling pattern and relative ratio of ER to cytosolic ribosome labeling, most evident in the LRRC59 BiolD reporter line, did not vary substantially over the 6 hour time course of the experiments (Figure 9). At present it is not known if the biotin-labeled cytosolic ribosomes 
408 represent ribosomes that were labeled in the ER-bound state and subsequently

409

410

411

412

413

414

415

416

417

418

419

420

421

422

423

424

425

426

427

428

429

430

exchanged to the cytosol, or if the BiolD chimera labeled both free cytosolic and ER-

bound ribosomes. That the ribosomal protein labeling patterns are nearly identical in the ribosomes from both compartments suggests the former. This phenomenon is currently

under investigation. As in the experiments illustrated in Figure 4, the patterns evident at early time points intensified as a function of labeling time, but did not diversify, suggesting

a highly restricted spatial orientation of the BiolD reporter-ribosome interface. This phenomenon is further characterized in the analysis depicted in Figure 9B, which illustrates the kinetics of the summed signal intensities of the biotinylated ribosomal proteins, for all BiolD reporters. Notably, the ribosomal protein labeling kinetics of the LRRC59 and Sec61 $\beta$ BiolD reporters are similar, suggesting that the two reporters undergo similar near-neighbor lifetime interactions with membrane-bound ribosomes.

To assess the functional impact of LRRC59 and Sec61 $\beta$ BiolD reporter-mediated biotinylation on ribosome function, sucrose gradient sedimentation experiments were performed (Figure 10A). The data in Figure 10B and $\mathrm{C}$ reveal the presence of biotinylated ribosomal proteins in the subunit (Figure 10B) and polysome (Figure 10C) fractions, where subunit identification was confirmed by sucrose gradient centrifugation and RNA gel analysis of $18 \mathrm{~S}$ and $28 \mathrm{~S}$ rRNA distributions, demonstrating that for both reporters, biotin-labeled ribosomes are functionally engaged in translation. The abundant biotin labeling present in the proteins at the top of the gradients represents the ER membrane proteins present in the detergent extracts. These data indicate that LRRC59 and Sec61 $\beta$ BiolD-mediated biotin labeling did not compromise ribosome function. 
Mass spectrometric analysis of the on-bead digested ribosome fraction revealed a small

subset of ribosomal proteins (Figure 10A, 11). Consistent with the overall streptavidin labeling patterns of gradient purified ribosomes, determined by streptavidin immunoblot analyses, both BiolD reporters labeled a common set of ribosomal proteins: L7a, L14, L23a, and LA2 (not shown) whose locations on the ribosome, illustrated in Figure 11A are regionally clustered. Intriguingly, these shared proteins distribute in regions adjacent to the peptidyl transferase and nascent peptide exit site (Wilson \& Doudna Cate, 2012). Two ribosomal proteins were highly enriched in only one dataset. RPL17, enriched in the Sec61 $\beta$ dataset, is located near the nascent chain exit site and has been demonstrated to serve important roles in transmembrane domain sensing and signaling to the peptidyl transferase, a function consistent with its appearance in the Sec61 $\beta$ interactome (Lin, Jongsma, Pool, \& Johnson, 2011; Zhang, Wölfle, \& Rospert, 2013). RPS3A, enriched in the LRRC59 dataset, is located near the mRNA exit site and has been shown to interact with the transcription factor CHOP (Cui et al. 2000). These data are consistent with

447 ribosome and the translocon, of particular relevance to the Sec61 $\beta$ BiolD reporter (Voorhees et al., 2014). The LRRC59 BiolD reporter, which resides in an ER membrane neighborhood enriched in integral membrane RNA binding proteins, also resides in proximity to bound ribosomes, consistent with a function in coupling translating ribosomes to translocons (Reid \& Nicchitta, 2015). These data place LRRC59 in an important ER 452 locale with complementary enrichments in poly(A)RNA binding and translation. The 453 precise role(s) performed by LRRC59 in this environment awaits further study. 
Domain-specific RNA-seq reveals regional mRNA enrichments and broad translation functions for ER-bound ribosomes.

457 A primary objective of this study was to examine the translational landscape of the ER,

458

459

460

461

462

463

464

465

466

467

468

469

470

471

472

473

474

475

476

using candidate ribosome interacting proteins as probes for identifying the composition, organization, and translation activities of ribosome-ER association sites. As noted above, we identified robust near-neighbor interactions between ER-bound ribosomes the translocon subunit Sec61 $\beta$, and the candidate ribosome receptor LRRC59. Intriguingly, the membrane protein neighborhoods for the two bound ribosome interactors displayed divergent functional enrichments, consistent with functions in protein translocation and mRNA translation, respectively. To extend these findings to the translational status of these domains, biotin-tagged, ER-associated ribosomes were purified from the Sec61 $\beta$ and LRRC59 BiolD cell lines and the associated mRNAs identified by RNA-seq (Figure 12). The experimental methodology is summarized in Figure 12A. Following the biotin labeling period, the cytosolic, free ribosome fraction was released via the sequential detergent extraction method noted above and the ER-bound ribosome fraction recovered by detergent solubilization of cytosol-depleted cells. The ribosome fraction was then separated from the co-solubilized membrane proteins by chromatography on Sephacryl S-400 gel filtration media. Biotinylated ribosomes, which are recovered in the S-400 void fractions, were isolated by avidin-magnetic bead capture, the total RNA fraction isolated, and cDNA libraries prepared for deep sequencing. To correct for background mRNA contributions, parallel isolations were performed with empty vector parental cell lines and cDNA libraries from these mock purifications deep sequenced in parallel. 
478 In Figure 12B, mRNA subcellular category distributions in the shared, Sec61 $\beta$-enriched, 479 and LRRC59-enriched pools are illustrated. As expected, the ER-associated mRNA 480 transcriptome (Figure 12B, Mem Fraction) differs substantially from the total cellular mRNA transcriptome, (Figure 12B, Total Cell) showing a substantial enrichment in secretory- and membrane protein-encoding transcripts. As previously reported, the ERassociated mRNA transcriptome contains a substantial representation of cytosolic protein-encoding mRNAs (Reid and Nicchitta 2012; Jan, Williams, and Weissman 2014; Chartron, Hunt, and Frydman 2016). This overall distribution is generally represented, per category, in the shared and Sec61 $\beta$ - and LRRC59-enriched categories, though with significant variations. These differences are further explored in Figure 12C and D, which depicts the TPM distributions of mRNA cohorts in the shared and enriched gene sets. As with the total ER-associated transcriptome, when expressed as a relative fraction of the total ER-associated mRNAs, the majority mRNA fraction in the shared category encodes cytosolic proteins (Reid \& Nicchitta, 2012). As reported previously, and although relatively abundant and broadly ER-represented, this mRNA cohort is about 2-fold de-enriched relative to the cytosol resident fraction, similar to the fractional distributions reported in yeast and mammalian cell lines (Reid and Nicchitta 2012; Jan, Williams, and Weissman 2014; Chartron, Hunt, and Frydman 2016). In comparison to the total ER-associated and reporter-enriched cohorts, the shared gene set has a somewhat higher representation of cytosolic protein-encoding mRNAs, indicating that in general, this cohort of mRNAs is not selected into either the Sec61 $\beta$ or LRRC59-translation domains. In contrast, membrane 499 protein-encoding mRNAs are substantially enriched in both translation domains (Figure 
500

501

502

503

504

505

506

507

508

509

510

511

512

513

514

515

516

517

518

519

520

521

12C,D). Furthermore, individual organelle categories showed unexpected and divergent enrichments. For example, the Sec61 $\beta$ translation domain is enriched for nuclear genes yet de-enriched for secreted genes. Intriguingly, the enriched gene sets for the two translation domains are divergent in mitochondrial genes, with the shared gene set being enriched in matrix (soluble) genes and the enriched sets in genes encoding mitochondrial membrane proteins. As with the cytosolic genes, these data indicate that mitochondrial matrix protein-encoding mRNAs are not selected into either of the translation domains whereas mitochondrial membrane protein-encoding mRNAs are. Furthermore, and quite unexpectedly, GO analysis of the mitochondrial genes in these categories revealed further specification, with the Sec61 $\beta$ translation domains being enriched for mitochondrial outer membrane protein genes and the LRRC59 translation domains being enriched for inner membrane electron transport membrane proteins (Table 2). Also displayed in Tables 1,2 are the highest confidence GO term enrichments for the principal divergent gene sets, which demonstrate that the two examined translation domains display both specification, in the enriched gene sets, and generalization, in the shared gene sets.

At present, the molecular basis for such enrichments are unknown. Intriguingly, for both translation domains, one of the most enriched genes is the parent reporter gene. Thus, ribosomes engaged in the translation of the reporter reside in proximity to their translation product (Figure 12F). Such an intimate association may arise if the reporter parent genes encode or associate with an interacting RNA binding protein. Consistent with this view, 
Sec61 $\beta$ has been identified as a poly(A) RNA binding protein (Baltz et al., 2012), and LRRC59 resides in an RNA binding protein-enriched domain (Figure 7).

In addition to the shared and divergent gene cohorts in coding mRNAs, discussed above, the sequencing data also revealed differences in non-coding mRNAs (Figure 12E). For the purposes of this study, we focused on the non-coding 7S RNA of the signal recognition particle (Walter \& Blobel, 1982). 7S RNA is enriched over control in the BiolD reporter translation domains, with a higher representation in the LRRC59 vs Sec61 $\beta$ translation domains. Consistent with the 7S RNA enrichment in the LRRC59 translation domain, SRP68, the 68kDa SRP protein subunit, was enriched in the LRRC59 proteomics dataset and serves as orthogonal validation for the enrichment of SRP in the two translation domains (Figure 7 and 12E). In summary, RNA-seq analyses of the mRNAs undergoing translation on ribosomes proximal to the Sec61 $\beta$ and LRRC59 BiolD reporters revealed translational specialization, where specific GO category gene sets were enriched in the two domains, and shared translation functions, where numerous genes were common to the two translation domains. Most noteworthy were divergencies in enrichments for genes encoding mitochondrial matrix or membrane proteins, and "self" genes, where the two translation domains enrich for their respective self RNAs. Combined with the membrane protein proteomic data reported above, these data reveal a higher order mesoorganization of the ER, with resident membrane proteins, ribosomes and mRNAs, displaying discrete and complementary enrichments, which is consistent with a model where the ER is comprised of both stable and interacting membrane domains functioning 
bioRxiv preprint doi: https://doi org/10 1101/398669; this version posted August 23, 2018. The copyright holder for this preprint (which was not certified by peer review) is the author/funder, who has granted bioRxiv a license to display the preprint in perpetuity. It is made available under aCC-BY 4.0 International license.

544 as local translation sites and which can be engaged in the translation of enriched subsets

545 of cytosolic and secretory/membrane protein-encoding RNAs.

546 


\section{Discussion:}

Here we report on the translational landscape of the ER from the perspective of candidate ribosome interacting proteins and their protein interactome networks. The rationale for this study is rooted in the growing number of reports demonstrating that cytosolic proteinencoding mRNAs undergo translation on ER-bound ribosomes. Indeed, recent analyses indicate that cytosolic protein-encoding mRNAs can comprise the majority of the translation activity of total ER-bound ribosomes (Reid and Nicchitta 2012; Jan, Williams, and Weissman 2014; Chartron, Hunt, and Frydman 2016). These reports raise a number of fundamental questions regarding mechanisms of RNA localization to the ER, the spatiotemporal regulation of ER-associated translation and in particular, and mechanisms of ribosome association and exchange on the ER in vivo, for which it is generally accepted that ribosome exchange on the ER are functionally linked to secretory/membrane protein synthesis (Hsu and Nicchitta 2018). An additional challenge is epistemological, where a dedicated role for the ER in the biogenesis of secretory and membrane proteins is well established, though the question of the exclusivity of this role has been raised for many decades and continues to be debated (Mueckler and Pitot 1981; Diehn et al. 2006; Reid and Nicchitta 2012; Reid and Nicchitta 2015; Jan, Williams, and Weissman 2015). Here we used an unbiased proximity labeling approach, BiolD, to investigate the near-neighbor environments of both established and candidate ribosome-interacting ER membrane proteins, including Sec61 $\beta$, a subunit of the Sec61 translocon, Ribophorin I, a subunit of the OST complex, which resides in proximity to the Sec61 translocon (Harada et al., 2009), and LRRC59 (p34), which displays ribosome binding activity in vitro (Tazawa et al., 1991). We draw three primary conclusions from these studies; i) the ribosome 
570 interactors examined reside in stable, interactome-ordered ER membrane domains; ii)

571 LRRC59 resides proximal to ER-bound ribosomes and thus likely contributes to the

572 totality of ribosome association on the ER; and iii) the mRNA compositions of ribosomes

573 residing in different membrane domains can be distinguished and comprise both

574 selectively enriched as well as shared transcriptome cohorts. Combined, these data

575 reveal a higher order organization of the ER, which we refer to as mesoscale organization

576 by analogy to current understanding of the domain organization of the plasma membrane

577 (Goyette \& Gaus, 2017; Kusumi et al., 2012, 2011), and provide early experimental 578 evidence for a "translation center-based" organization of the ER, where distinct ER 579 domains may function in the coordinated biogenesis of functionally related proteins.

Two largely unexpected observations from this work were the findings that the nearneighbor environments of the different BiolD reporter constructs did not diversify as a function of labeling time, and that the direct environments of the BiolD reporters were heavily biased to ER membrane proteins. We had initially expected that given the 2-D constraints of the ER membrane, the reporter interactomes would diversify as a function of labeling time to reflect random diffusion in the 2-D plane of the ER membrane. To the contrary, their environments became more densely labeled over labeling time courses of many hours, with only a modest increase in labeling diversity. The remarkable stability of the protein labeling patterns is consistent with a domain model where diverse, low affinity interactions between functionally related proteins enable a mesoscale organization of the membrane. In support of this interpretation, GO analysis of the enriched sets of labeled 
593 BiolD reporter chimera that are known to be subunits of oligomeric proteins (Sec61 $\beta$,

594 Ribophorin I) tagged key subunits, Sec61 $\alpha$ in the case of Sec61 $\beta$ and both STT3A and

595 STT3B in the case of Ribophorin I, indicating that the chimera assembled into native 596 oligomers and thus reported on the environments of the oligomeric complexes. Although by analogy, extensive studies of plasma membrane architecture have provided strong 598 evidence for mesoscale organization with roles for biophysical contributions from distinct 599 lipid species and interactions with cytoskeletal components as important organizing 600 determinants (Chiantia et al., 2008). Whether lipid species or cytoskeletal components

601

602

603

604

605

606

607

608

609

610

611

612

613

614

615

contribute to ER membrane organization remains to be determined, though there is evidence for ceramide/sphingolipid domains in the ER as well as both microtubule and actin cytoskeleton interactions with ER resident proteins (Jagannathan et al., 2014; Ogawa-Goto et al., 2007; Savitz \& Meyer, 1997).

Another unexpected observation from this work was the strong biotin labeling bias to the ER membrane over cytosolic proteins. Given the diffusion-based mechanism of BiolD labeling, we had expected significant labeling of both cytosolic and membrane proteins. While, the exact reason for this bias remains to be determined, we speculate that it reflects both high local concentrations of reactive sites and high residence lifetimes of ER membrane proteins proximal to the reporters, as contrasted with a soluble protein undergoing three-dimensional aqueous diffusion.

A particularly intriguing observation from these studies is the finding that LRRC59 is near translating ribosomes. Although LRRC59 had been previously reported to function as a 
616 ribosome binding protein in vitro, a function in ribosome association in vivo had not been

617 demonstrated (Ichimura et al., 1993; Ohsumi et al., 1993; Tazawa et al., 1991). Indeed,

618 after a decades long search for the ribosome receptor, which yielded the identification of

619 the Ribophorins, LRRC59, p180, and Sec61, among others, research interest has largely

620

621

622

623

624

625

626

627

628

629

630

631

632

633

634

635

636

637

638

focused on the Sec61 complex as the sole ribosome interacting ER protein (Gorlich et al., 1992; Kalies, Görlich, \& Rapoport, 1994; Pfeffer et al., 2015; Voorhees et al., 2014).

Indeed, substantial structural data supports this functional assignment, but do not exclude the possibility that additional ER proteins contribute to the totality of ribosome association with the ER (Blau et al., 2005; Müller et al., 2010; Shibatani, David, McCormack, Frueh, \& Skach, 2005; Ueno et al., 2012; Wang \& Stefanovic, 2014). In support of this conjecture, the BiolD interactome for LRRC59 was highly enriched in proteins with candidate or established RNA binding activity, including MTDH (AEG-1), which we recently demonstrated to be an ER RNA binding protein enriched in membrane protein-encoding mRNAs (Hsu et al. 2018), p180, which has also been demonstrated to have a poly(A)RNA binding function, and CKAP4, which was identified as a candidate RNA binding protein in a number of recent studies (Cui, Zhang, and Palazzo 2012; Ueno et al. 2012; Castello et al. 2012). These findings suggest that LRRC59 may have a previously unrecognized role in coupling ER-associated translation to translocon engagement of the translation product. These data fit with a previously proposed model suggesting ribosome interacting proteins might diffuse in the ER membrane to allow nascent chain engagement with unoccupied translocons (Benedix et al., 2010; Johnson \& van Waes, 1999; Reid \& Nicchitta, 2015). The data in this report demonstrates that LRRC59 resides in proximity to ER-associated ribosomes and engages an interactome enriched in RNA binding 
639 proteins suggesting previously unanticipated roles for this protein in translation on the 640 ER.

642 Since two BiolD reporter chimeras distinctly tagged ER membrane-bound ribosomes this provided an opportunity to investigate the transcriptome organization of the ER. As noted, a primary role for the ER in secretory/membrane protein biogenesis is very well established and both past and recent studies examining the subcellular distributions of mRNAs between the cytosol and ER compartments have strongly affirmed this role (Reid \& Nicchitta, 2012; Voigt et al., 2017). Although the interpretation of these data has been debated, studies of mRNAs distributions between the cytosol and ER compartments in yeast, by ER localized BirA-AVI tag labeling or by SRP-directed immunoprecipitation, demonstrate that many cytosolic protein-encoding mRNAs display $\log _{2}$ cytosol enrichments of < 1-2, and are thus substantially represented on the ER (Jan, Williams, and Weissman 2014; Chartron, Hunt, and Frydman 2016). This mRNA distribution is similar to data reported in mammalian cells (Reid \& Nicchitta, 2012; Voigt et al., 2017). In the current study, we examined the associated transcriptomes of biotin-tagged, ER-bound ribosomes. As with earlier studies, we report that although enriched over the cell transcriptome in secretory/membrane protein-encoding mRNAs, ribosomes residing in proximity to both the Sec61 $\beta$ and LRRC59 BiolD chimera contained a significant fraction

658 of cytosolic protein-encoding mRNAs and their respective populations of biotin-tagged 659 ribosomes displayed overlapping yet distinct biotin labeling patterns. The RNA 660 populations for the two cell lines displayed both shared and enriched transcripts and, of 661 high interest, the enriched transcript cohorts differed in GO enrichments, with the Sec61 $\beta$ 
662 cohort being enriched in mRNAs encoding ER proteins and the LRRC59 cohort being enriched in mRNAs encoding integral plasma membrane proteins. Particularly interesting was the finding that one of the most enriched transcripts for both reporters was the "self mRNA". These findings support the concept of translation centers on the ER, where mRNAs encoding proteins of related function are coordinately translated in a coherent,

667 localized manner. It remains to be determined how individual mRNAs are targeted to 668 distinct sites or whether mRNAs may be directly recruited to such sites via binding 669 interactions with ER RNA binding proteins such as AEG-1 or by stably associated 670 ribosomes potentially with heterogeneous composition (Hsu et al. 2018; Mauro and Edelman 2002; Wu et al. 2016; Gilbert 2011; Shi et al. 2017). translation on the ER, and the ER membrane itself, is subject to mesoscale organization where cohorts of interacting proteins, ribosomes, and mRNAs, are enriched in distinct domain environments. We suggest that such a mechanism may provide for the efficient assembly of functionally related and/or interacting protein complexes. These data also provide additional evidence in support of a transcriptome-wide function for the ER in proteome expression. The remaining questions are many, but given emerging data on the higher order structural organization and translational organization of different regions 681 and compartments of the cell, notably dendrites, mitochondria, stress granules, and P bodies, these data are consistent with higher organization of transcriptome expression and regulation as an evolutionarily conserved cellular strategy (Banani, Lee, Hyman, \& 
bioRxiv preprint doi: https://doi.org/10.1101/398669; this version posted August 23,2018 . The copyright holder for this preprint (which was not certified by peer review) is the author/funder, who has granted bioRxiv a license to display the preprint in perpetuity. It is made available under aCC-BY 4.0 International license.

684 Rosen, 2017; English \& Voeltz, 2013; Hudder, Nathanson, \& Deutscher, 2003; Uezu et

685 al., 2016; Vance, 2014; Youn et al., 2018).

686 
687

688

689

690

691

692

693

694

695

696

697

698

699

700

\begin{tabular}{|c|c|}
\hline Primer Name & Primer Sequence (5' to 3') \\
\hline Vector-RPN1-Fwd & CTCTAGCGTTTAAACTTAAGCTTATGGAGGCGCCAGCCGCC \\
\hline RPN1-BirA*-Rev & CCACTGCCCAGGGCATCCAGGATGTGGTCG \\
\hline RPN1-BirA*-Fwd & ATGCCCTGGGCAGTGGCAGTAAGGACAACACCGTGCCC \\
\hline BirA*-Vector-Rev & ATCCGAGCTCGGTACCTATGCGTAATCCGGTACATCG \\
\hline Vector-BirA*-Fwd & CTCTAGCGTTTAAACTTAAGCTTATGAAGGACAACACCGTGC \\
\hline BirA*-LRRC59-Rev & CCACTGCCCTCGAGCTTCTCTGCGCT \\
\hline BirA*-LRRC59-Fwd & AGCTCGAGGGCAGTGGCAGTACCAAGGCCGGTAGCAAG \\
\hline $\begin{array}{l}\text { LRRC59-Vector- } \\
\text { Rev }\end{array}$ & ATCCGAGCTCGGTACCTCACTGCTGAGAGTCGGTC \\
\hline BirA*-Sec61ß-Rev & CCACTGCCCTTCTCTGCGCTTCTCAG \\
\hline 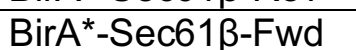 & CAGAGAAGGGCAGTGGCAGTCCTGGTCCGACCCCCAGT \\
\hline Sec61 $\beta-$ Vector-Rev & GGGTTTAAACGGGCCCTACGAACGAGTGTACTTGCCC \\
\hline Vector-Sec62-Fwd & GCGTTTAAACTTAAGCTTATGGCGGAACGCAGGAGA \\
\hline Sec62-BirA*-Rev & CTTACTGCCACTGCCTGATTTTTCATGTGAAGATTTAGGTGTTTCTC \\
\hline $\begin{array}{l}\text { Vector-C terminal- } \\
\text { BirA*-Rev }\end{array}$ & AAGCTTAAGTTTAAACGCTAGAGTC \\
\hline $\begin{array}{l}\text { Vector-C terminal- } \\
\text { BirA*-Fwd }\end{array}$ & GGCAGTGGCAGTAAGGA \\
\hline
\end{tabular}

\section{Materials and Methods}

\section{Generation of BiolD Chimera}

Plasmids were from the following sources: pCMV-Sport6-RPN1 (Transomic ID: pCS6BC010839, TransOMIC, Hunstsville, AL), pCMV-Sport6-LRRC59 (Transomic ID: pCS6BC017168), Sec61ß (Transomic ID: pOTB7-BC BC001734), Neo-IRES-GFP-Sec62 (Richard Zimmerman, Saarland University, Homburg, Germany), pEYFP-N1-BirA* (Scott Soderling, Department of Cell Biology, Duke University Medical Center). Gibson assembly master mix (NEB E2611S, Ipswich, MA) was used with the specified amplified fragments using the primers below to generate all constructs with the indicated Bir $A^{*}$ tag including a Gly-Ser-Gly-Ser linker between the protein of interest and BirA*. All resulting constructs were cloned into pcDNA5-FRT/TO for downstream generation of HEK293 FlpIn T-REx cell lines (Thermo Fisher Scientific, Waltham, MA). The BiolD tags were placed on the terminus facing the cytosol, for Sec62 we chose the C-terminus to avoid disrupting proposed ribosome interactions (Müller et al., 2010). 
702

703

704

705

706

707

708

709

710

711

712

713

714

715

716

717

718

719

720

721

722

723

724

725

Sequences were confirmed using a CMV-Forward and BGH-Reverse sequencing primers supplied by Eton Biosciences (Research Triangle Park, NC).

\section{Generation of HEK293 FIp-In T-Rex cell lines.}

HEK293 Flp-In T-REx cell lines were generated according to the manufacturer's instructions (Thermo Fisher Scientific). Cells were transfected in 6-well culture dishes at $80 \%$ confluence using $7.5 \mu \mathrm{L}$ of Lipofectamine 3000 (Thermo Fisher, L3000001) with 0.4 $\mu \mathrm{g}$ of plasmid containing the desired fusion protein and $4 \mu \mathrm{g}$ of pOGG4 plasmid. Selection with $100 \mu \mathrm{g} / \mathrm{mL}$ hygromycin (MediaTech, 30-240-CR, Manassas, VA) and $15 \mu \mathrm{g} / \mathrm{mL}$ blasticidin (Thermo Fisher, R21001) was started 48 hours after transfection and continued for 2 weeks at which point colonies were identified. A control cell line was generated by recombination of an empty vector pcDNA5-FRT/TO and antibiotic selection for an empty vector matched control.

\section{Expression of BirA fusion proteins}

Expression levels were examined by doxycycline (Sigma Aldrich, D9891, St. Louis, MO) titration and the following doxycycline concentrations were used for each construct: 10ng/mL LRRC59-BiolD, 5 ng/mL Sec61ß-BioID, 50 ng/mL Ribophorin I-BiolD, 100 $\mathrm{ng} / \mathrm{mL}$ Sec62-BiolD. Expression of BiolD constructs was performed for at least $16 \mathrm{hr}$ before addition of biotin unless otherwise noted.

\section{Immunofluorescence Analyses}

Cells were plated on poly-lysine coated 22 mm \#1.5 coverslips (Globe Scientific, 140415, Paramus, NJ). Reporter expression was induced by doxycycline addition and $50 \mu \mathrm{M}$ 
biotin added for an overnight labeling. After 16 hours, cells are washed twice with PBS, fixed in $4 \%$ paraformaldehyde for $10 \mathrm{~min}$ on ice and $10 \mathrm{~min}$ at room temperature then washed 3 times with PBS for 5 min each. Cells were permeabilized with a blocking solution of 3\% BSA and $0.1 \%$ saponin (Sigma Aldrich, S-2149) in PBS for $1 \mathrm{hr}$ at room temperature. Primary staining was performed in the identical solution supplemented with 1:200 BirA antibody (Sino Biological Inc., rabbit IgG, Wayne, PA) or 1:50 TRAPa antibody (Migliaccio, Nicchitta, \& Blobel, 1992) (polyclonal, rabbit lgG) at $4^{\circ} \mathrm{C}$ overnight. Following $5 \times 3$ min washes of $0.1 \%$ saponin in PBS, coverslips were incubated with 1:200 goat antirabbit IgG AlexaFluor488 (Thermo Fisher, A-11034), 1:1000 streptavidin-Alexafluor647 (Thermo Fisher, S21374) and 1:10000 DAPI $(0.5 \mathrm{mg} / \mathrm{mL}$ stock solution) mixed in blocking solution at room temperature for $45 \mathrm{~min}$ in the dark. Coverslips were washed $5 \mathrm{X}$ as above, rinsed and mounted in FluorSave hard mount (CalBioChem, 345789, Burlington, $\mathrm{MA}$ ) and cured at $4^{\circ} \mathrm{C}$ overnight prior to imaging.

\section{Fluorescence Imaging}

All imaging was performed on a DeltaVision deconvolution microscope (Applied Precision, Issaquah, WA) equipped with 100x NA 1.4 oil immersion objective (UPlanSApo 100XO; Olympus, Tokyo, Japan) and a high-resolution CCD camera (CoolSNAP HQ2; Photometrics, Tucson, AZ). Images were acquired as Z-stacks (at $0.2 \mu \mathrm{m}$ intervals) at identical exposure conditions across the samples for a given protein. The data were deconvolved using the c program (Applied Precision, Mississauga, ON) and processed further on ImageJ-FIJI software to render maximum intensity projections (as required), merge channels and pseudo color the images. Only linear changes were done to the 
brightness/contrast values of the images, as required and such changes were applied uniformly across all images in a given experiment.

\section{Sequential Detergent Fractionation and General Cell Lysis}

Cells were washed twice with ice-cold PBS containing $50 \mu \mathrm{g} / \mathrm{mL}$ of cycloheximide $(\mathrm{CHX})$ (VWR, 94271, Radnor, PA) for 3 min each wash. Permeabilization buffer (110 mM KOAc, $25 \mathrm{mM}$ HEPES pH 7.2, $2.5 \mathrm{mM} \mathrm{Mg(OAc)}$, $0.03 \%$ digitonin (Calbiochem, 3004010), $1 \mathrm{mM}$ DTT, $50 \mu \mathrm{g} / \mathrm{mL}$ CHX, 40U/mL RNAseOUT (Invitrogen, 10777-019, Carlsbad, CA), Protease Inhibitor Complex (PIC) (Sigma Aldrich, P8340)) was added to cells and incubations performed for $5 \mathrm{~min}$ at $4^{\circ} \mathrm{C}$. The supernatant fraction (cytosol) was collected and cells rinsed with wash buffer (110 mM KOAc, $25 \mathrm{mM}$ HEPES pH 7.2, $2.5 \mathrm{mM}$ $\mathrm{Mg}(\mathrm{OAc})_{2}, 0.004 \%$ digitonin, $1 \mathrm{mM}$ DTT, $50 \mu \mathrm{g} / \mathrm{mL} \mathrm{CHX}, 40 \mathrm{U} / \mathrm{mL}$ RNAseOUT, Protease Inhibitor Complex (PIC)). Cells were then lysed in NP-40 lysis buffer (400 mM KOAc, 25 $\mathrm{mM}$ HEPES $\mathrm{pH} 7.2,15 \mathrm{mM} \mathrm{Mg}(\mathrm{OAc})_{2}, 1 \% \mathrm{NP}-40,0.5 \%$ DOC, $1 \mathrm{mM}$ DTT, $50 \mu \mathrm{g} / \mathrm{mL}$ $\mathrm{CHX}, 40 \mathrm{U} / \mathrm{mL}$ RNAseOUT, Protease Inhibitor Complex (PIC)) for 5 min at $4^{\circ} \mathrm{C}$. Both cytosolic and membrane fractions were cleared by centrifugation (15,300 x $\mathrm{g}$ for $10 \mathrm{~min})$. Total cell lysis was performed in the ER lysis buffer by incubating cells at $4^{\circ} \mathrm{C}$ for $10 \mathrm{~min}$. Lysates were cleared by centrifugation as above.

\section{In Vitro BirA* Labeling of Microsomes}

Canine pancreas rough microsomes (RM) (Walter \& Blobel, 1980) were adjusted to a concentration of $4 \mathrm{mg} / \mathrm{mL}$ protein in $500 \mu \mathrm{L}$ of BirA reaction buffer $(20 \mathrm{mM}$ Tris $\mathrm{pH} 8,5$ $\mathrm{mM} \mathrm{CaCl} 2,100 \mathrm{mM} \mathrm{KCl} 2,10 \mathrm{mM} \mathrm{MgCl} 2,3 \mathrm{mM} \mathrm{ATP}, 1.5 \mathrm{mM}$ biotin, $5 \mathrm{mM}$ 
772 phosphocreatine (Sigma-Aldrich, P7936-1G) and $5 \mu \mathrm{g} / \mathrm{mL}$ of creatine kinase (Sigma-

773

774

775

776

777

778

779

780

781

782

783

784

785

786

787

788

789

790

791

792

793

794

Aldrich, C3755-3.5KU)). Purified recombinant BirA*-GST fusion protein was added to a concentration of $10 \mu \mathrm{g} / \mathrm{mL}$. At $0,1,3,6$, and $18 \mathrm{hrs}, 100 \mu \mathrm{L}$ of reaction was removed, flash frozen in an ethanol bath and stored at $-80^{\circ} \mathrm{C}$ prior to Western blot analysis.

\section{Western blotting}

Lysate protein concentrations were determined using a Pierce BCA Protein Assay Kit (ThermoFisher, 23225). SDS-PAGE was performed in $12 \%$ acrylamide gels containing $0.5 \%$ of trichloroethanol. Gels were UV irradiated for $5 \mathrm{~min}$ and imaged using an Amersham Imager 600 (GE Life Sciences, Pittsburgh, PA) to verify protein loading. Gels were then equilibrated in Tris-glycine transfer buffer for $5 \mathrm{~min}$ and transferred using a Trans Blot SD Semi-Dry Transfer apparatus (Biorad, Hercules, CA). Blots were blocked in PBS, 3\% BSA for $1 \mathrm{hr}$ before primary antibody was added at the indicated dilution and incubated for $2 \mathrm{hr}$ at RT or overnight at $4^{\circ} \mathrm{C}$. Goat secondary antibodies (Li-Cor, Lincoln, NE) were matched to the species of the primaries used and diluted 1:10,000. Streptavidin was used at a dilution of 1:20,000. Secondary reagents were incubated for $45 \mathrm{~min}$, washed 5x with TBST and imaged on the Odyssey Clx (Li-Cor). Primaries used: BirA (Abcam \#14002, polyclonal, chicken lgG), TRAPa (Migliaccio et al., 1992)(polyclonal, rabbit IgG), tubulin (lowa Hybridoma Bank, E7, monoclonal, mouse IgG, lowa City, IA), Sec61ß (Gift of Ramanujan Hegde, University of Cambridge, polyclonal, rabbit IgG), LRRC59 (Bethyl Labs A305-076A, polyclonal, rabbit IgG, Montgomery, TX), Sec62 (gift from Richard Zimmerman, polyclonal, rabbit lgG), Ribophorin I (Migliaccio et al., 1992)(polyclonal, rabbit lgG), streptavidin-RD680 (Li-Cor, P/N 925-68079). 


\section{RNA Extraction}

797

798

799

800

801

802

803

804

805

806

807

808

809

810

811

812

813

814

815

816

As adapted from (Chomczynski \& Sacchi, 2006), RNA was extracted from 1 volume of lysate using 2 volume of GT buffer to 0.5 volumes of water-saturated phenol, $\mathrm{pH} 4.5$ and incubated for $5 \mathrm{~min}$ at RT before adding 0.8 volume of chloroform. Following centrifugation for $15 \mathrm{~min}$ at $10,000 \times \mathrm{xg}, 4^{\circ} \mathrm{C}$ for $15 \mathrm{~min}$, the aqueous phase was recovered, and RNA precipitated by addition of 1.2 volumes of isopropanol and 0.15 volume of $3 \mathrm{M}$ sodium citrate $\mathrm{pH}$ 5.2. Following incubation at $-20^{\circ} \mathrm{C}$ for $1 \mathrm{hr}$, RNA was recovered by centrifugation at $10,000 \times \mathrm{xg}, 4^{\circ} \mathrm{C}$ for $20 \mathrm{~min}$. RNA pellets were washed in $70 \%$ ethanol, dried, and resuspended in TE buffer (10 mM Tris $\mathrm{pH} 8.0,1 \mathrm{mM}$ EDTA). RNA concentrations were determined using a NanoDrop ND-1000 Spectrophotometer (Thermo Fisher Scientific). RNA quality was examined by denaturing formaldehyde gel electrophoresis.

\section{Glycerol Gradients}

As adapted from (Nikonov et al., 2002), reporter construct expressing BiolD lines were lysed in $1 \mathrm{ml} / 10 \mathrm{~cm}$ dish of homogenization buffer $(20 \mathrm{mM}$ Tris $\mathrm{pH} 7.4,500 \mathrm{mM} \mathrm{NaCl}$, $1.5 \%$ digitonin, $1 \mathrm{mM} \mathrm{MnCl}_{2}, 1 \mathrm{mM} \mathrm{MgCl} 2,1 \mathrm{mM} \mathrm{DTT}, \mathrm{PIC}$ ) for $30 \mathrm{~min}$ at $4^{\circ} \mathrm{C}$. Lysates were cleared by centrifugation in a TLA 100.2 rotor at $40,000 \mathrm{rpm}$ for $10 \mathrm{~min}, 4^{\circ} \mathrm{C}$ (TL100 Ultracentrifuge, Beckman Coulter, Brea, CA). $850 \mu \mathrm{L}$ of the supernatant was then loaded onto a 8-30\% glycerol gradient and centrifuged in an SW-41 rotor at 35,000 rpm for $15.5 \mathrm{hr}, 4^{\circ} \mathrm{C}$ (L5-50B Ultracentrifuge, Beckman). Gradients were fractionated into 12 
817 fractions using a Teledyne Isco gradient fractionation system and analyzed by 818 immunoblot.

\section{Polysome Gradients}

Cells expressing BioID constructs were lysed in 50 mM HEPES, pH 7.2, 200 mM KOAc, $15,300 x g$ for $10 \mathrm{~min}, 4^{\circ} \mathrm{C}$. $0.8 \mathrm{~mL}$ of lysate was loaded onto $15-50 \%$ sucrose gradients and centrifuged for 3 hours at 35,000 rpm, $4^{\circ} \mathrm{C}$ (L5-50B Ultracentrifuge, Beckman). Gradients were fractionated into 12 fractions using a Teledyne Isco (Lincoln, NE) gradient fractionation system and analyzed by immunoblot and denaturing RNA gel electrophoresis.

\section{Biotin Pulldowns}

Adapted from (Firat-Karalar \& Stearnsx, 2015): Constructs were expressed as above, with biotinylation reactions performed for 3 hours prior to sequential detergent fractionation. The membrane fraction was obtained and volume adjusted to a protein concentration of ca. $1.3 \mathrm{mg} / \mathrm{ml}$ and diluted 1:1 with $100 \mathrm{mM} \mathrm{NaCl}, 50 \mathrm{mM}$ HEPES pH 7.4 to reduce detergent concentrations. Pierce NeutrAvidin Agarose (Thermo Fisher, 29200) resin was blocked for $1 \mathrm{hr}$ with $1 \% \mathrm{BSA}$ and washed three times in HEPES buffer.

837 Pulldown reactions were performed overnight at $4^{\circ} \mathrm{C}$. Beads were washed with the 838 following buffers twice each for $10 \mathrm{~min}$ at RT. Buffer 1: 2\% SDS in $50 \mathrm{mM} H E P E S \mathrm{pH}$ 8397.2 Buffer 2: 0.1\% DOC, 1\% Triton X-100, 1mM EDTA, 500 mM NaCl, 50 mM HEPES pH 
7.5 Buffer 3: 0.5\% DOC, 0.5\% NP-40, 1mM EDTA, $250 \mathrm{mM} \mathrm{LiCl,} 10 \mathrm{mM}$ Tris pH 7.4. Beads were then suspended in $50 \mu \mathrm{L}$ of biotin elution buffer, vortexed, and heated for 15 min at $70^{\circ} \mathrm{C}$. Supernatant fractions were combined and concentrated to $50 \mu \mathrm{L}$ in a Savant SpeedVac Concentrator (Thermo Fisher Scientific).

\section{Ribosome Pulldowns}

Cells were washed with PBS and lysed in NP-40 lysis buffer (as above). Lysates were cleared at $15,300 \times \mathrm{g}$ for $10 \mathrm{~min}$ and the supernatant fraction overlaid onto a $1 \mathrm{M}$ sucrose cushion (2:1, load:cushion). Samples were centrifuged at $80,000 \mathrm{rpm}$ for 25 min (TLA 100 rotor in TL-100 ultracentrifuge, Beckman). Ribosome pellets were washed with PBS before being suspended in $50 \mathrm{mM}$ HEPES, pH 7.4, $100 \mathrm{mM} \mathrm{NaCl}, 1 \%$ SDS, $10 \mathrm{mM}$ EDTA, 1 mM DTT, by Dounce homogenization. Ribosome concentration was determined by the $A_{260}$ absorbance and calculated using the extinction coefficient: $5 \times 10^{7} / \mathrm{cm}^{*} \mathrm{M}$ (Matasova et al., 1991). Equal amounts of ribosomes were used for pulldowns, as above. Binding reactions were performed by end-over-end mixing for 90 minutes at room temperature. Beads were washed as above and suspended in $20 \mu \mathrm{L}$ of HEPES buffer and submitted to the Duke Proteomics Core (DPMSR) for on-bead digestion.

\section{Mass Spectrometry}

On-Resin Trypsin Digestion. The Dynabead complexes in solution were washed three times with $500 \mu \mathrm{L}$ of $50 \mathrm{mM}$ ammonium bicarbonate (AmBic) (Millipore Sigma, Burlington, MA). Twenty microliters of $1.0 \%$ acid labile surfactant (RapiGest, Waters, Milford, MA) in AmBic was added to each sample followed by an additional twenty microliters of AmBic. 
863

864

865

866

867

868

869

870

871

872

873

874

875

876

877

878

879

880

881

882

883

884

885

Samples were subsequently reduced with $10 \mathrm{mM}$ dithiothreitol (DTT, Millipore Sigma) for 30 minutes at $40^{\circ} \mathrm{C}$ with shaking, and alkylated using $20 \mathrm{mM}$ iodoacetamide (IAM, VWR Scientific) for 30 minutes at room temperature. Digestion was performed using $500 \mathrm{ng}$ sequencing grade trypsin in AmBic ( $5 \mu \mathrm{L}$ at $0.1 \mu \mathrm{g} / \mu \mathrm{L}$, Promega, Madison, $\mathrm{WI})$, at $37^{\circ} \mathrm{C}$ overnight with shaking. Peptides were extracted by decanting supernatant into a separate $1.5 \mathrm{~mL}$ Eppendorf (Hamburg, Germany) LoBind tube, and washing the resin with $50 \mu \mathrm{L}$ additional AmBic, which was also combined with digested peptides. The combined extract was acidified to $1 \% \mathrm{v} / \mathrm{v}$ trifloroacetic acid (Thermo Fisher Scientific), heated to $60^{\circ} \mathrm{C}$ for 2 hours to cleave the RapiGest surfactant, and lyophilized to dryness.

Gel Electrophoresis. Samples were transferred to the DPMSR for one dimensional sodium dodecyl sulfate polyacrylamide gel electrophoresis (SDS-PAGE). $25 \mu \mathrm{L}$ of sample was combined with $5 \mu \mathrm{L}$ of $100 \mathrm{mM}$ DTT and $10 \mu \mathrm{L}$ of NuPAGE ${ }^{\mathrm{TM}}$ (Thermo Fisher Scientific) $4 \mathrm{X}$ loading buffer and samples were then heated to $70^{\circ} \mathrm{C}$ for ten minutes with shaking. SDS-PAGE separation was performed using $1.5 \mathrm{~mm} \mathrm{4-12 \%} \mathrm{Bis-Tris} \mathrm{pre-cast}$ polyacrylamide gels (Novex, Thermo Fisher Scientific), 1X MES SDS NuPAGE ${ }^{\text {TM }}$ Running Buffer (Thermo Fisher Scientific) including NuPAGE ${ }^{T M}$ antioxidant. SDS-PAGE separation was performed at a constant $200 \mathrm{~V}$ for five minutes, gels fixed for 10 minutes, stained for 3 hours, and destained overnight following manufacturer instructions.

Gel Band Isolation and Trypsin Digestion. Gel bands of interest were isolated using a sterile scalpel transferred to protein LoBind tubes (Eppendorf) and minced. Gel pieces were washed with $500 \mu \mathrm{L}$ of $40 \%$ LCMS grade acetonitrile (MeCN, Thermo Fisher 
886

887

888

889

890

891

892

893

894

895

896

897

898

899

900

901

902

903

904

905

906

907

908

Scientific) in AmBic, with shaking at $30^{\circ} \mathrm{C}$. Gel pieces were shrunk with LCMS grade $\mathrm{MeCN}$, the solution discarded, and the gel pieces dried at $50^{\circ} \mathrm{C}$ for $3 \mathrm{~min}$. Reduction of disulfides was performed using $100 \mu \mathrm{L}$ of $10 \mathrm{mM}$ DTT at $80^{\circ} \mathrm{C}$ for 30 min with shaking, followed by alkylation with $100 \mu \mathrm{L}$ of $55 \mathrm{mM}$ IAM at RT for $20 \mathrm{~min}$. This liquid was aspirated from the samples and discarded, and gel pieces were washed twice with 500 uL AmBic, and these washes were also discarded. LCMS grade MeCN was added to shrink the gel pieces in each sample, then samples were swelled in AmBic and this process was repeated a second time, finally the gel pieces were shrunk a final time by adding $200 \mu \mathrm{L}$ of LCMS grade $\mathrm{MeCN}$, and heating for $3 \mathrm{~min}$ at $50^{\circ} \mathrm{C}$ to promote evaporation. Trypsin digestion was performed with addition of $30 \mu \mathrm{L}$ of $10 \mathrm{ng} / \mu \mathrm{L}$ sequencing grade trypsin (Promega, Madison, WI) in AmBic followed by $30 \mu \mathrm{L}$ of additional AmBic. The samples were incubated overnight at $37^{\circ} \mathrm{C}$ with shaking at 750 rpm. Finally after overnight digestion $60 \mu \mathrm{L}$ of 1/2/97 v/v/v TFA/MeCN/water was added to each sample and incubated for $30 \mathrm{~min}$ at RT and $750 \mathrm{rpm}$ to extract peptides, and the combined supernatant was transferred to an autosampler vial (Waters). Gel pieces were shrunk in $50 \mu \mathrm{L}$ additional MeCN for 10 min to extract the maximum amount of peptides, which was combined with the previous supernatant. The samples were dried in the Vacufuge (Eppendorf) and stored at $-80^{\circ} \mathrm{C}$ until ready for LC-MS/MS analysis.

\section{Qualitative Analysis of On-Resin and Gel Electrophoresis Samples. All on-resin and} gel band samples were resuspended in $20 \mu \mathrm{L}$ of $1 / 2 / 97 \mathrm{v} / \mathrm{v} / \mathrm{v}$ TFA/MeCN/water. The samples were analyzed by nanoLC-MS/MS using a Waters nanoAcquity LC interfaced to a Thermo Q-Exactive Plus via a nanoelectrospray ionization source. $2 \mu \mathrm{L}$ of each on- 
909 resin sample, and $1 \mu \mathrm{L}$ of each gel band sample was injected for analysis. Each sample

910

911

912

913

914

915

916

917

918

919

920

921

922

923

924

925

926

927

928

929

930

931

was first trapped on a Symmetry C18, $300 \mu \mathrm{m} \times 180 \mathrm{~mm}$ trapping column $(5 \mu \mathrm{l} / \mathrm{min}$ at

99.9/0.1 v/v H2O/MeCN for $5 \mathrm{~min})$, after which the analytical separation was performed using a $1.7 \mu \mathrm{m}$ ACQUITY HSS T3 C18 $75 \mu \mathrm{m}$ x $250 \mathrm{~mm}$ column (Waters). The peptides

were eluted using a 90 min gradient of $5-40 \%$ MeCN with $0.1 \%$ formic acid at a flow rate of $400 \mathrm{nl} / \mathrm{min}$ with a column temperature of $55^{\circ} \mathrm{C}$.

Data collection on the $Q$ Exactive Plus mass spectrometer was performed with data dependent acquisition (DDA) MS/MS, using a 70,000 resolution precursor ion (MS1) scan followed by MS/MS (MS2) of the top 10 most abundant ions at 17,500 resolution. MS1 was performed using an automatic gain control (AGC) target of $1 \mathrm{e} 6$ ions and maximum ion injection (max IT) time of $60 \mathrm{msec}$. MS2 used AGC target of $5 \mathrm{e} 4$ ions, $60 \mathrm{~ms}$ max IT time, $2.0 \mathrm{~m} / \mathrm{z}$ isolation window, $27 \mathrm{~V}$ normalized collision energy, and $20 \mathrm{~s}$ dynamic exclusion. The total analysis cycle time for each sample injection was approximately $2 \mathrm{~h}$.

The sample run order was chosen to minimize potential carryover and is detailed as follows for the on-resin and gel band samples, respectively: 125-EV, 125-LR59, 125-S61, 1210-EV, 1210-LR59, 1210-S61, EV, LRRC59, SEC62, SEC61B, and RPN1.

Database searching. Proteome Discoverer (Thermo Fisher Scientific) was used to generate mgf files from the DDA analyses and the data was searched using Mascot v 2.5 (Matrix Science) with a custom database containing the human proteome downloaded from UniProt combined with common proteins found in BirA experiments and common contaminants. The data was searched using trypsin enzyme cleavage rules and a 
932 maximum of 4 missed cleavages, fixed modification carbamidomethylated cysteine,

933

934

935

936

937

938

939

940

941

942

943

944

945

946

947

948

949

950

951

952

953

954

variable modifications biotinylated lysine, deamidated asparagine and glutamic acid and

oxidated methionine. The peptide mass tolerance was set to $+/-5 \mathrm{ppm}$ and the fragment mass tolerance was set to +/- $0.02 \mathrm{Da}$. False discovery rate control for peptide and protein identifications was performed using Scaffold v4 (Proteome Software, Inc).

\section{Analysis of Scaffold data}

Method adapted from Ritchie, Cylinder, Platt, \& Barklis, 2015. For the membrane protein data sets of each biological replicate, hits with 1\% FDR at the protein level, $50 \%$ peptide match with a minimum of 2 peptides and 2 spectral counts were used for subsequent analysis. Each dataset is first normalized by summing spectral counts for the natively biotinylated proteins-acetyl-CoA carboxylase, propionyl CoA carboxylase, pyruvate carboxylase, and methyl crotonyl-CoA carboxylase subunits - and dividing all spectral counts by this number. Proteins less than 2.5 -fold above the same proteins in the respective control dataset were removed. The remaining protein spectral counts for each dataset were averaged and normalized by dividing by the BirA protein spectral counts to account for any differences in reporter expression. Analyses were performed so that any proteins with average normalized counts higher than 2-fold above the same protein in the three other datasets was assigned to the specific cell line as "enriched." Remaining proteins were analyzed by covariance of normalized counts with a cut-off of 40.0. These proteins were shared between at least two of the cell lines with higher than 2-fold normalized counts of the lowest count. For figure clarity, the Cytoscape plot in Figure 8B displays those shared proteins with a covariance of 50.0 or above. 
955 For localization prediction, a FASTA file containing the protein sequences was generated

956

957

958

959

960

961

962

963

964

965

966 967 translocon.

968

969

970

971

972

973

974

975

976

977

and processed on the TMHMM Server v2.0 (DTU Bioinformatics) to identify membrane

vs soluble proteins. Localization by organelle (Fig 6B) was determined by running the datasets through DeepLoc v1.0 (DTU Bioinformatics) using the Profiles algorithm.

For ribosomal protein data sets, spectral counts were retrieved for only ribosomal protein hits with $90 \%$ protein identity, $50 \%$ peptide identity with at least 2 peptides. Each experiment dataset was divided by the control, and those exceeding a 2-fold difference were further analyzed. For each candidate, sample spectral counts were divided by the control and proteins with greater than 2-fold difference are termed "enriched" and those below the cutoff are termed "shared". Those proteins with the same term between the two datasets are kept and mapped onto PDB file 37JR, of the translating ribosome on the

\section{Biotinylated Polysome Isolation and Sequencing}

Ribosomes were purified from the membrane fractions of sequential detergent fractionation of the indicated BioID cell lines by gel filtration chromatography, collecting the fraction of a Sephacryl S400 column operating at a flow rate of $0.7 \mathrm{~mL} / \mathrm{min}$. Dynabeads M-270 Streptavidin beads (ThermoFisher, 65305) and 0.05\% Triton X-100 are added to each sample and incubated overnight at $4^{\circ} \mathrm{C}$. Beads were washed three times for 10 min at $4^{\circ} \mathrm{C}$ in high-salt wash buffer followed by suspension in low-salt buffer and extraction of bound RNA using an RNAEasy Kit (Qiagen, 74104, Hilden, Germany).

RNA was quantified by Bioanalyzer 2100 analysis (Agilent, Santa Clara, CA) and like 
978

979

980

981

982

983

984

985

986

987

988

989

990

991

992

993

994

995

996

997

998

999

1000

samples combined to provide $10 \mathrm{ng}$ of total RNA total. RNA samples were concentrated to $12 \mu \mathrm{L}$ using E.Z.N.A. MicroElute RNA Cleanup Kit (Omega Bio-Tek, R6247, Norcross, GA) and libraries constructed using Ultra II RNA Library Kit (NEB, E7645S) for biological duplicates.

\section{Illumina Hi-Seq}

Libraries were submitted to the Duke Sequencing and Genomic Technologies for sequencing. Concentration of each library was estimated using Qubit assay and run on an Agilent Bioanalyzer for library size estimation. Libraries were then pooled into equimolar concentration. Final pool was clustered on a HiSeq 4000 Single-Read flow cell. Sequencing was done at 50bp Single-Read. Bcls files generated by the sequencer were then converted into fastq files using Illumina bcl2fastq v2.20.0.422 and reads demultiplexed using the molecular indexes incorporated during library preparation.

\section{Sequencing Analysis}

FASTA files were adapter trimmed using Trimmomatic v0.32 (Bolger, Lohse, \& Usadel, 2014), aligned to the human genome, build GRCh38/h38, using HISAT2.0.5 default options for unpaired reads (D. Kim, Langmead, \& Salzberg, 2015). Aligned read files were then counted using htseq-count v0.5.4p3 (Anders, Pyl, \& Huber, 2015) using options for non-stranded reads, intersection-strict mode, and 'exon' as the feature to be counted using a UCSC hg38 GTF annotation file. This GTF file with unique gene IDs and transcript IDs was generated to a genePred file for hg38 using the genePredtoGTF script from kentUtils. Data sets from the two cell lines were analyzed for differential expression 
1001 versus the control experiments using DESeq2v1.18.1 (Love, Huber, \& Anders, 2014).

1002 Gene lists were generated by taking the subset with greater than or equal to 2-fold change

1003 over the control data set with an adjusted p-value of 0.05 (Benjamini \& Hochberg, 1995).

1004 Genes coding for protein products were selected for interaction and GO analysis using

1005 the STRING database. Localization predication analysis was performed using the

1006 DeepLoc1.0 Profiles algorithm (Almagro Armenteros et al., 2017). Transcript per million

1007 (TPM) analysis was performed by first calculating reads per kilobase (RPK), summing the

1008 RPK values and dividing by 1 million to use as the scaling factor (SF). Individual RPK

1009 values were divided by the SF to obtain a gene specific TPM value for the given subset

1010 of data for better comparison of the datasets.

1011

1012

1013

1014

1015

1016

1017

1018

1019

1020

1021

1022

1023 


\section{Acknowledgements:}

1025 We thank the Duke University School of Medicine for the use of the Proteomics and Metabolomics Shared Resource which provided the proteomics service for this study. In particular, we would like to acknowledge Will Thompson, $\mathrm{PhD}$ and Sarah Raines of the Duke Proteomics Core facility for very helpful guidance and advice on experimental design and data analysis. We acknowledge key instrumental resources (QE Plus) supported by NIH S10OD012266-01A1. We also thank the Duke Sequencing and Genomic Technologies Shared Resource, in particular Nicolas Devos, PhD, for advice, guidance, and generous support of the deep sequencing studies. We especially thank members of the Nicchitta lab, in particular Jessica Childs, Heather Vincent, and Jason Arne for insightful discussions throughout this project. The E7 monoclonal antibody was obtained from the Developmental Studies Hybridoma Bank, created by the NICHD of the $\mathrm{NIH}$ and maintained at The University of lowa, Department of Biology, lowa City, IA

1037 52242. This research was supported by funding from the NIH (GM101533-A1, 1038 GM118630-A1, CVN). 


\section{References}

Almagro Armenteros, J. J., Sønderby, C. K., Sønderby, S. K., Nielsen, H., Winther, O., \& Hancock, J. (2017). DeepLoc: prediction of protein subcellular localization using deep learning. Bioinformatics, 33(21), 3387-3395.

http://doi.org/10.1093/bioinformatics/btx431

Anders, S., Pyl, P. T., \& Huber, W. (2015). HTSeq-A Python framework to work with high-throughput sequencing data. Bioinformatics, 31(2), 166-169. http://doi.org/10.1093/bioinformatics/btu638

Baltz, A. G., Munschauer, M., Schwanhäusser, B., Vasile, A., Murakawa, Y., Schueler, M., ... Landthaler, M. (2012). The mRNA-Bound Proteome and Its Global Occupancy Profile on Protein-Coding Transcripts. Molecular Cell, 46(5), 674-690. http://doi.org/10.1016/j.molcel.2012.05.021

Banani, S. F., Lee, H. O., Hyman, A. A., \& Rosen, M. K. (2017). Biomolecular condensates: Organizers of cellular biochemistry. Nature Reviews Molecular Cell Biology, 18(5), 285-298. http://doi.org/10.1038/nrm.2017.7

Becker, T., Bhushan, S., Jarasch, A., Armache, J.-P., Funes, S., Jossinet, F., ... Beckmann, R. (2009). Structure of monomeric yeast and mammalian Sec61 complexes interacting with the translating ribosome. Science, 326(5958), 13691373. http://doi.org/10.1126/science. 1178535

Benedix, J., Lajoie, P., Jaiswal, H., Burgard, C., Greiner, M., Zimmermann, R., ... Dudek, J. (2010). BiP Modulates the Affinity of Its Co-chaperone ERj1 for Ribosomes. Journal of Biological Chemistry, 285(47), 36427-36433. http://doi.org/10.1074/jbc.M110.143263

Benjamini, Y., \& Hochberg, Y. (1995). Controlling the False Discovery Rate: A Practical and Powerful Approach to Multiple Controlling the False Discovery Rate: a Practical and Powerful Approach to Multiple Testing. Source Journal of the Royal Statistical Society. Series B (Methodological), 57(1), 289-300. http://doi.org/10.2307/2346101 Blau, M., Mullapudi, S., Becker, T., Dudek, J., Zimmermann, R., Penczek, P. A., \& Beckmann, R. (2005). ERj1p uses a universal ribosomal adaptor site to coordinate the $80 \mathrm{~S}$ ribosome at the membrane. Nature Structural and Molecular Biology, 12(11), 1015-1016. http://doi.org/10.1038/nsmb998

Bolger, A. M., Lohse, M., \& Usadel, B. (2014). Trimmomatic: a flexible trimmer for Illumina sequence data. Bioinformatics, 30(15), 2114-20.

http://doi.org/10.1093/bioinformatics/btu170

Braunger, K., Pfeffer, S., Shrimal, S., Gilmore, R., Berninghausen, O., Mandon, E. C., Becker, T., Förster, F, Beckmann, R. (2018). Structural basis for coupling protein transport and $\mathrm{N}$-glycosylation at the mammalian endoplasmic reticulum, Science 360(6385), 215-219. doi: 10.1126/science.aar7789

Castello, A., Fischer, B., Eichelbaum, K., Horos, R., Beckmann, B. M., Strein, C., ... Hentze, M. W. (2012). Insights into RNA biology from an atlas of mammalian mRNA-binding proteins. Cell, 149(6), 1393-406.

http://doi.org/10.1016/j.cell.2012.04.031

Castello, A., Fischer, B., Frese, C. K., Horos, R., Alleaume, A.-M., Foehr, S., ... Hentze, M. W. (2016). Comprehensive Identification of RNA-Binding Domains in Human 
Cells. Molecular Cell, 63(4), 696-710. http://doi.org/10.1016/j.molcel.2016.06.029

Chartron, J. W., Hunt, K. C. L., \& Frydman, J. (2016). Cotranslational signalindependent SRP preloading during membrane targeting. Nature, 536(7615), 2248. http://doi.org/10.1038/nature19309

Chiantia, S., Ries, J., Chwastek, G., Carrer, D., Li, Z., Bittman, R., \& Schwille, P. (2008). Role of ceramide in membrane protein organization investigated by combined AFM and FCS. Biochimica et Biophysica Acta (BBA) - Biomembranes, 1778(5), 13561364. http://doi.org/10.1016/J.BBAMEM.2008.02.008

Choi-Rhee, E., Schulman, H., \& Cronan, J. E. (2004). Promiscuous protein biotinylation by Escherichia coli biotin protein ligase. Protein Science, 13(11), 3043-3050. http://doi.org/10.1110/ps.04911804

Chomczynski, P., \& Sacchi, N. (2006). The single-step method of RNA isolation by acid guanidinium thiocyanate-phenol-chloroform extraction: twenty-something years on. Nature Protocols, 1(2), 581-585. http://doi.org/10.1038/nprot.2006.83

Cross, B. C. S., Sinning, I., Luirink, J., \& High, S. (2009). Delivering proteins for export from the cytosol. Nature Reviews Molecular Cell Biology, 10(4), 255-264. http://doi.org/10.1038/nrm2657

Cui, K., Coutts, M., Stahl, J., \& Sytkowski, A. J. (2000). Novel interaction between the transcription factor CHOP (GADD153) and the ribosomal protein FTE/S3a modulates erythropoiesis. Journal of Biological Chemistry, 275(11), 7591-6. http://doi.org/10.1074/JBC.275.11.7591

Cui, X. A., Zhang, H., \& Palazzo, A. F. (2012). p180 Promotes the RibosomeIndependent Localization of a Subset of mRNA to the Endoplasmic Reticulum. PLoS Biology, 10(5). http://doi.org/10.1371/journal.pbio.1001336

de Brito, O. M., \& Scorrano, L. (2010). An intimate liaison: spatial organization of the endoplasmic reticulum-mitochondria relationship. The EMBO Journal, 29(16), 2715-23. http://doi.org/10.1038/emboj.2010.177

Deshaies, R. J., Sanders, S. L., Feldheim, D. A., \& Schekman, R. (1991). Assembly of yeast $\mathrm{Sec}$ proteins involved in translocation into the endoplasmic reticulum into a membrane-bound multisubunit complex. Nature, 349(6312), 806-808. http://doi.org/10.1038/349806a0

Diehn, M., Bhattacharya, R., Botstein, D., \& Brown, P. O. (2006). Genome-Scale Identification of Membrane-Associated Human mRNAs. PLoS Genetics, 2(1), e11. http://doi.org/10.1371/journal.pgen.0020011

Diehn, M., Eisen, M. B., Botstein, D., \& Brown, P. O. (2000). Large-scale identification of secreted and membrane-associated gene products using DNA microarrays. Nature Genetics, 25(1), 58-62. http://doi.org/10.1038/75603

English, A. R., \& Voeltz, G. K. (2013). Endoplasmic reticulum structure and interconnections with other organelles. Cold Spring Harbor Perspectives in Biology, 5(4), 1-16. http://doi.org/10.1101/cshperspect.a013227

Fawcett, D. W. (1966). An Atlas of Fine Structure: the cell, its organelles, and inclusions (Reprint Edition). Philadelphia: WB Suanders Co.

Firat-Karalar, E. N., \& Stearnsx, T. (2015). Probing mammalian centrosome structure using BiolD proximity dependent biotinylation. In Methods in Cell Biology (Vol. 129, pp. 153-170). http://doi.org/10.1016/bs.mcb.2015.03.016

Gardner, B. M., Pincus, D., Gotthardt, K., Gallagher, C. M., \& Walter, P. (2013). 
Endoplasmic reticulum stress sensing in the unfolded protein response. Cold Spring Harbor Perspectives in Biology, 5(3), a013169.

http://doi.org/10.1101/cshperspect.a013169

Gilbert, W. V. (2011). Functional specialization of ribosomes? Trends in Biochemical Sciences, 36(3), 127-32. http://doi.org/10.1016/j.tibs.2010.12.002

Gorlich, D., Prehn, S., Hartmann, E., Kalies, K. U., \& Rapoport, T. A. (1992). A mammalian homolog of SEC61p and SECYp is associated with ribosomes and nascent polypeptides during translocation. Cell, 71, 489-503. Retrieved from http://dx.doi.org/10.1016/0092-8674(92)90517-G

Goyette, J., \& Gaus, K. (2017). Mechanisms of protein nanoscale clustering. Current Opinion in Cell Biology, 44, 86-92. http://doi.org/10.1016/J.CEB.2016.09.004

Gupta, G. D., Coyaud, É., Gonçalves, J., Mojarad, B. A., Liu, Y., Wu, Q., ... Pelletier, L. (2015). A Dynamic Protein Interaction Landscape of the Human Centrosome-Cilium Interface. Cell, 163(6), 1484-99. http://doi.org/10.1016/j.cell.2015.10.065

Harada, Y., Li, H., Li, H., \& Lennarz, W. J. (2009). Oligosaccharyltransferase directly binds to ribosome at a location near the translocon-binding site. Proceedings of the National Academy of Sciences, 106(17), 6945-6949. http://doi.org/10.1073/pnas.0812489106

Hayashi-Nishino, M., Fujita, N., Noda, T., Yamaguchi, A., Yoshimori, T., \& Yamamoto, A. (2009). A subdomain of the endoplasmic reticulum forms a cradle for autophagosome formation. Nature Cell Biology, 11(12), 1433-1437. http://doi.org/10.1038/ncb1991

Helle, S. C. J., Kanfer, G., Kolar, K., Lang, A., Michel, A. H., \& Kornmann, B. (2013). Organization and function of membrane contact sites. Biochimica et Biophysica Acta - Molecular Cell Research, 1833(11), 2526-2541.

http://doi.org/10.1016/J.BBAMCR.2013.01.028

Hentze, M. W., Castello, A., Schwarzl, T., \& Preiss, T. (2018). A brave new world of RNA-binding proteins. Nature Reviews Molecular Cell Biology, 19(5), 327-341. http://doi.org/10.1038/nrm.2017.130

Hsu, J. C.-C., \& Nicchitta, C. V. (2018). Proteome Expression: The Subcellular Organisation of Protein Synthesis. ELS, 1-8. http://doi.org/10.1002/9780470015902.a0005718

Hsu, J. C. C., Reid, D. W., Hoffman, A. M., Sarkar, D., \& Nicchitta, C. V. (2018). Oncoprotein AEG-1 is an endoplasmic reticulum RNA-binding protein whose interactome is enriched in organelle resident protein-encoding mRNAs. RNA, 24(5), 688-703. http://doi.org/10.1261/rna.063313.117

Hudder, A., Nathanson, L., \& Deutscher, M. P. (2003). Organization of Mammalian Cytoplasm. Molecular and Cellular Biology, 23(24), 9318-9326.

http://doi.org/10.1128/MCB.23.24.9318-9326.2003

Hung, V., Lam, S. S., Udeshi, N. D., Svinkina, T., Guzman, G., Mootha, V. K., ... Ting, A. Y. (2017). Proteomic mapping of cytosol-facing outer mitochondrial and ER membranes in living human cells by proximity biotinylation. ELife, 6 . http://doi.org/10.7554/eLife.24463

Ichimura, T., Shindo, Y., Uda, Y., Ohsumi, T., Omata, S., \& Sugano, H. (1993). Anti(p34 protein) antibodies inhibit ribosome binding to and protein translocation across the rough microsomal membrane. FEBS Letters, 326(1-3), 241-245. 
http://doi.org/10.1016/0014-5793(93)81799-6

Jagannathan, S., Hsu, J. C. C., Reid, D. W., Chen, Q., Thompson, W. J., Moseley, A. M., \& Nicchitta, C. V. (2014). Multifunctional Roles for the Protein Translocation Machinery in RNA Anchoring to the Endoplasmic Reticulum. Journal of Biological Chemistry, 289(37), 25907-25924. http://doi.org/10.1074/jbc.M114.580688 Jagannathan, S., Nwosu, C., \& Nicchitta, C. V. (2011). Analyzing mRNA Localization to the Endoplasmic Reticulum via Cell Fractionation. In J. E. Gerst (Ed.), RNA Detection and Visualization: Methods and Protocols (Vol. 714, pp. 301-321). http://doi.org/10.1007/978-1-61779-005-8_19

Jan, C. H., Williams, C. C., \& Weissman, J. S. (2014). Principles of ER cotranslational translocation revealed by proximity-specific ribosome profiling. Science, 346(6210), 1257521. http://doi.org/10.1126/science.1257521

Jan, C. H., Williams, C. C., \& Weissman, J. S. (2015). Response to Comment on "Principles of ER cotranslational translocation revealed by proximity-specific ribosome profiling." Science, 348(6240), 1217-b.

http://doi.org/10.1126/science.1257521

Jing, J., He, L., Sun, A., Quintana, A., Ding, Y., Ma, G., ... Zhou, Y. (2015). Proteomic mapping of ER-PM junctions identifies STIMATE as a regulator of $\mathrm{Ca}(2+)$ influx. Nature Cell Biology, 17(10), 1339-1347. http://doi.org/10.1038/ncb3234

Johnson, A. E., \& van Waes, M. A. (1999). The translocon: a dynamic gateway at the ER membrane. Annual Review of Cell and Developmental Biology, 15, 799-842. http://doi.org/10.1146/annurev.cellbio.15.1.799

Kalies, K.-U., Görlich, D., \& Rapoport, T. A. (1994). Binding of ribosomes to the rough endoplasmic reticulum mediated by the Sec61p-complex. The Journal of Cell Biology, 126(4), 925-934. http://doi.org/10.1083/jcb.126.4.925

Kim, D. I., Birendra, K., Zhu, W., Motamedchaboki, K., Doye, V., \& Roux, K. J. (2014). Probing nuclear pore complex architecture with proximity-dependent biotinylation. Proceedings of the National Academy of Sciences, 111(24), E2453-E2461. http://doi.org/10.1073/pnas.1406459111

Kim, D., Langmead, B., \& Salzberg, S. L. (2015). HISAT: a fast spliced aligner with low memory requirements. Nature Methods, 12(4), 357-360. http://doi.org/10.1038/nmeth.3317

Kreibich, G., Freienstein, C. M., Pereyra, B. N., Ulrich, B. L., \& Sabatini, D. D. (1978). Proteins of rough microsomal membranes related to ribosome binding. II. Crosslinking of bound ribosomes to specific membrane proteins exposed at the binding sites. The Journal of Cell Biology, 77(2), 488-506. http://doi.org/10.1083/jcb.77.2.488

Kusumi, A., Fujiwara, T. K., Chadda, R., Xie, M., Tsunoyama, T. A., Kalay, Z., ... Suzuki, K. G. N. (2012). Dynamic Organizing Principles of the Plasma Membrane that Regulate Signal Transduction: Commemorating the Fortieth Anniversary of Singer and Nicolson's Fluid-Mosaic Model. Annual Review of Cell and Developmental Biology, 28(1), 215-250. http://doi.org/10.1146/annurev-cellbio100809-151736

Kusumi, A., Suzuki, K. G. N., Kasai, R. S., Ritchie, K., \& Fujiwara, T. K. (2011). Hierarchical mesoscale domain organization of the plasma membrane. Trends in Biochemical Sciences, 36(11), 604-615. http://doi.org/10.1016/j.tibs.2011.08.001 
Kwon, K., \& Beckett, D. (2000). Function of a conserved sequence motif in biotin holoenzyme synthetases. Protein Science, 9(8), 1530-1539. http://doi.org/10.1110/ps.9.8.1530

Lang, S., Benedix, J., Fedeles, S. V, Schorr, S., Schirra, C., Schäuble, N., ... Haßdenteufel, S. (2012). Different effects of Sec61a, Sec62 and Sec63 depletion on transport of polypeptides into the endoplasmic reticulum of mammalian cells. Journal of Cell Science, 125(8), 1958-1969. http://doi.org/10.1242/jcs.096727

Levy, R., Wiedmann, M., \& Kreibich, G. (2001). In Vitro Binding of Ribosomes to the $\beta$ Subunit of the Sec61p Protein Translocation Complex. Journal of Biological Chemistry, 276(4), 2340-2346. http://doi.org/10.1074/jbc.M004867200

Lin, P. J., Jongsma, C. G., Pool, M. R., \& Johnson, A. E. (2011). Polytopic membrane protein folding at $\mathrm{L} 17$ in the ribosome tunnel initiates cyclical changes at the translocon. Journal of Cell Biology, 195(1), 55-70. http://doi.org/10.1083/jcb.201103118

Love, M. I., Huber, W., \& Anders, S. (2014). Moderated estimation of fold change and dispersion for RNA-seq data with DESeq2. Genome Biology, 15(12), 550. http://doi.org/10.1186/s13059-014-0550-8

Lynes, E. M., \& Simmen, T. (2011). Urban planning of the endoplasmic reticulum (ER): how diverse mechanisms segregate the many functions of the ER. Biochimica et Biophysica Acta - Molecular Cell Research, 1813(10), 1893-905. http://doi.org/10.1016/j.bbamcr.2011.06.011

Matasova, N. B., Myltseva, S. V, Zenkova, M. A., Graifer, D. M., Vladimirov, S. N., \& Karpova, G. G. (1991). Isolation of ribosomal subunits containing intact rRNA from human placenta: Estimation of functional activity of $80 \mathrm{~S}$ ribosomes. Analytical Biochemistry, 198(2), 219-223. http://doi.org/10.1016/0003-2697(91)90416-Q

Mauro, V. P., \& Edelman, G. M. (2002). The ribosome filter hypothesis. Proceedings of the National Academy of Sciences, 99(19), 12031-12036. http://doi.org/10.1073/pnas.192442499

Migliaccio, G., Nicchitta, C. V, \& Blobel, G. (1992). The signal sequence receptor, unlike the signal recognition particle receptor, is not essential for protein translocation. The Journal of Cell Biology, 117(1), 15-25. http://doi.org/10.1083/JCB.117.1.15

Mueckler, M. M., \& Pitot, H. C. (1981). Structure and function of rat liver polysome populations. I. Complexity, frequency distribution, and degree of uniqueness of free and membrane-bound polysomal polyadenylate-containing RNA populations. The Journal of Cell Biology, 90(2), 495-506. http://doi.org/10.1083/jcb.90.2.495

Müller, L., de Escauriaza, M. D., Lajoie, P., Theis, M., Jung, M., Müller, A., ... Zimmermann, R. (2010). Evolutionary Gain of Function for the ER Membrane Protein Sec62 from Yeast to Humans. Molecular Biology of the Cell, 21(5), 691703. http://doi.org/10.1091/mbc.E09-08-0730

Nikonov, A. V, Snapp, E., Lippincott-Schwartz, J., \& Kreibich, G. (2002). Active translocon complexes labeled with GFP-Dad1 diffuse slowly as large polysome arrays in the endoplasmic reticulum. The Journal of Cell Biology, 158(3), 497-506. http://doi.org/10.1083/jcb.200201116

Ogawa-Goto, K., Tanaka, K., Ueno, T., Tanaka, K., Kurata, T., Sata, T., \& Irie, S. (2007). p180 Is Involved in the Interaction between the Endoplasmic Reticulum and Microtubules through a Novel Microtubule-binding and Bundling Domain. Molecular 
Biology of the Cell, 18(10), 3741-3751. http://doi.org/10.1091/mbc.E06-12-1125 Ohsumi, T., Ichimura, T., Sugano, H., Omata, S., Isobe, T., \& Kuwano, R. (1993). Ribosome-binding protein p34 is a member of the leucine-rich-repeat-protein superfamily. Biochemical Journal, 294(2), 465-472. http://doi.org/10.1042/bj2940465

Pfeffer, S., Burbaum, L., Unverdorben, P., Pech, M., Chen, Y., Zimmermann, R., ... Förster, F. (2015). Structure of the native Sec61 protein-conducting channel. Nature Communications, 6, 8403. http://doi.org/10.1038/ncomms9403

Pfeffer, S., Dudek, J., Gogala, M., Schorr, S., Linxweiler, J., Lang, S., ... Förster, F. (2014). Structure of the mammalian oligosaccharyl-transferase complex in the native ER protein translocon. Nature Communications, 5, 3072. http://doi.org/10.1038/ncomms4072

Potter, M. D., \& Nicchitta, C. V. (2000). Ribosome-independent regulation of translocon composition and Sec61 alpha conformation. Journal of Biological Chemistry, 275(3), 2037-2045. http://doi.org/10.1074/jbc.275.3.2037

Prinz, A., Behrens, C., Rapoport, T. A., Hartmann, E., \& Kalies, K. (2000). Evolutionarily conserved binding of ribosomes to the translocation channel via the large ribosomal RNA. European Molecular Biology Organization, 19(8), 1900-1906. http://doi.org/10.1093/emboj/19.8.1900

Rees, J. S., Li, X.-W., Perrett, S., Lilley, K. S., \& Jackson, A. P. (2015). Protein Neighbors and Proximity Proteomics. Molecular \& Cellular Proteomics, 14(11), 2848-2856. http://doi.org/10.1074/mcp.R115.052902

Reid, D. W., \& Nicchitta, C. V. (2012). Primary Role for Endoplasmic Reticulum-bound Ribosomes in Cellular Translation Identified by Ribosome Profiling. Journal of Biological Chemistry, 287(8), 5518-5527. http://doi.org/10.1074/jbc.M111.312280

Reid, D. W., \& Nicchitta, C. V. (2015). Diversity and selectivity in mRNA translation on the endoplasmic reticulum. Nature Reviews Molecular Cell Biology, 16(4), 221231. http://doi.org/10.1038/nrm3958

Ritchie, C., Cylinder, I., Platt, E. J., \& Barklis, E. (2015). Analysis of HIV-1 Gag Protein Interactions via Biotin Ligase Tagging. Journal of Virology, 89(7), 3988-4001. http://doi.org/10.1128/JVI.03584-14

Roux, K. J., Kim, D. I., Raida, M., \& Burke, B. (2012). A promiscuous biotin ligase fusion protein identifies proximal and interacting proteins in mammalian cells. The Journal of Cell Biology, 196(6), 801-810. http://doi.org/10.1083/jcb.201112098

Savitz, A. J., \& Meyer, D. I. (1990). Identification of a ribosome receptor in the rough endoplasmic reticulum. Nature, 346(6284), 540-544. http://doi.org/10.1038/346540a0

Savitz, A. J., \& Meyer, D. I. (1997). Receptor-mediated Ribosome Binding to Liposomes Depends on Lipid Composition. Journal of Biological Chemistry, 272(20), 1314013145. http://doi.org/10.1074/jbc.272.20.13140

Schaletzky, J., \& Rapoport, T. A. (2006). Ribosome Binding to and Dissociation from Translocation Sites of the Endoplasmic Reticulum Membrane. Molecular Biology of the Cell, 17(9), 3860-3869. http://doi.org/10.1091/mbc.E06-05-0439

Schwarz, D. S., \& Blower, M. D. (2016). The endoplasmic reticulum: structure, function and response to cellular signaling. Cellular and Molecular Life Sciences, 73(1), 7994. http://doi.org/10.1007/s00018-015-2052-6 
Shannon, P., Markiel, A., Ozier, O., Baliga, N. S., Wang, J. T., Ramage, D., ... Ideker, T. (2003). Cytoscape: a software environment for integrated models of biomolecular interaction networks. Genome Research, 13(11), 2498-504. http://doi.org/10.1101/gr.1239303

Shi, Z., Fujii, K., Kovary, K. M., Genuth, N. R., Röst, H. L., Teruel, M. N., \& Barna, M. (2017). Heterogeneous Ribosomes Preferentially Translate Distinct Subpools of mRNAs Genome-wide. Molecular Cell, 67(1), 71-83.e7. http://doi.org/10.1016/j.molcel.2017.05.021

Shibatani, T., David, L. L., McCormack, A. L., Frueh, K., \& Skach, W. R. (2005). Proteomic Analysis of Mammalian Oligosaccharyltransferase Reveals Multiple Subcomplexes that Contain Sec61, TRAP, and Two Potential New Subunits $†$. Biochemistry, 44(16), 5982-5992. http://doi.org/10.1021/bi047328f

Singer, A. S. J., \& Nicolson, G. L. (1972). The Fluid Mosaic Model of the Structure of Cell Membranes. Science, 175(4023), 720-731. http://doi.org/10.1126/science.175.4023.720

Stephens, S. B., \& Nicchitta, C. V. (2007). In vitro and tissue culture methods for analysis of translation initiation on the endoplasmic reticulum. In J. Lorsch (Ed.), Translation Initiation: Cell Biology, High-Throughput Methods, and Chemical-Based Approaches (Vol. 431, pp. 47-60). http://doi.org/10.1016/s0076-6879(07)31004-5

Stephens, S. B., \& Nicchitta, C. V. (2008). Divergent regulation of protein synthesis in the cytosol and endoplasmic reticulum compartments of mammalian cells. Molecular Biology of the Cell, 19(2), 623-632. http://doi.org/10.1091/mbc.E07-070677

Szklarczyk, D., Morris, J. H., Cook, H., Kuhn, M., Wyder, S., Simonovic, M., ... von Mering, C. (2017). The STRING database in 2017: quality-controlled proteinprotein association networks, made broadly accessible. Nucleic Acids Research, 45(D1), D362-D368. http://doi.org/10.1093/nar/gkw937

Tazawa, S., Unuma, M., Tondokoro, N., Asano, Y., Ohsumi, T., Ichimura, T., \& Sugano, H. (1991). Identification of a Membrane Protein Responsible for Ribosome Binding in Rough Microsomal Membranes. Journal of Biochemistry, 109(1), 89-98. Retrieved from http://jb.oxfordjournals.org/content/109/1/89.abstract

Ueda, S., Blee, A. M., Macway, K. G., Renner, D. J., \& Yamada, S. (2015). Force Dependent Biotinylation of Myosin IIA by a-Catenin Tagged with a Promiscuous Biotin Ligase. PLoS ONE, 10(3), e0122886. http://doi.org/10.1371/journal.pone.0122886

Ueno, T., Kaneko, K., Sata, T., Hattori, S., \& Ogawa-Goto, K. (2012). Regulation of polysome assembly on the endoplasmic reticulum by a coiled-coil protein, p180. Nucleic Acids Research, 40(7), 3006-3017. http://doi.org/10.1093/nar/gkr1197

Uezu, A., Kanak, D., Bradshaw, T., Soderblom, E., Catavero, C., Burette, A., ... Soderling SH. (2016). Identification of an elaborate complex mediating postsynaptic inhibition. Science, 353(6304), 1123-1129. http://doi.org/10.1126/science.aaf1836

Valm, A. M., Cohen, S., Legant, W. R., Melunis, J., Hershberg, U., Wait, E., ... Lippincott-Schwartz, J. (2017). Applying systems-level spectral imaging and analysis to reveal the organelle interactome. Nature, 546(7656), 162-167. http://doi.org/10.1038/nature22369

Vance, J. E. (2014). MAM (mitochondria-associated membranes) in mammalian cells: 
Lipids and beyond. Biochimica et Biophysica Acta - Molecular and Cell Biology of Lipids, 1841(4), 595-609. http://doi.org/10.1016/J.BBALIP.2013.11.014

Varnaitè, R., \& MacNeill, S. A. (2016). Meet the neighbors: Mapping local protein interactomes by proximity-dependent labeling with BioID. PROTEOMICS, 16(19), 2503-2518. http://doi.org/10.1002/pmic.201600123

Vembar, S. S., \& Brodsky, J. L. (2008). One step at a time: endoplasmic reticulumassociated degradation. Nature Reviews Molecular Cell Biology, 9(12), 944-957. http://doi.org/10.1038/nrm2546

Voigt, F., Zhang, H., Cui, X. A., Triebold, D., Liu, A. X., Eglinger, J., ... Palazzo, A. F. (2017). Single-Molecule Quantification of Translation-Dependent Association of mRNAs with the Endoplasmic Reticulum. Cell Reports, 21(13), 3740-3753. http://doi.org/10.1016/j.celrep.2017.12.008

Voorhees, R. M., Fernández, I. S., Scheres, S. H., \& Hegde, R. S. (2014). Structure of the Mammalian Ribosome-Sec61 Complex to $3.4 \AA$ Resolution. Cell, 157(7), 16321643. http://doi.org/10.1016/j.cell.2014.05.024

Walter, P., \& Blobel, G. (1980). Purification of a membrane-associated protein complex required for protein translocation across the endoplasmic reticulum. Proceedings of the National Academy of Sciences, 77(12), 7112-6. http://doi.org/10.1073/pnas.77.12.7112

Walter, P., \& Blobel, G. (1982, October 21). Signal recognition particle contains a $7 S$ RNA essential for protein translocation across the endoplasmic reticulum. Nature. Nature Publishing Group. http://doi.org/10.1038/299691a0

Wang, H., \& Stefanovic, B. (2014). Role of LARP6 and Nonmuscle Myosin in Partitioning of Collagen mRNAs to the ER Membrane. PLoS ONE, 9(10), e108870. http://doi.org/10.1371/journal.pone.0108870

Wild, R., Kowal, J., Eyring, J., Ngwa, E. M., Aebi, M., \& Locher, K. P. (2018). Structure of the yeast oligosaccharyltransferase complex gives insight into eukaryotic $\mathrm{N}$ glycosylation. Science, 359(6375), 545-550. http://doi.org/10.1126/science.aar5140

Wilson, D. N., \& Doudna Cate, J. H. (2012). The structure and function of the eukaryotic ribosome. Cold Spring Harbor Perspectives in Biology, 4(5), a011536. http://doi.org/10.1101/cshperspect.a011536

Wu, B., Eliscovich, C., Yoon, Y. J., \& Singer, R. H. (2016). Translation dynamics of single mRNAs in live cells and neurons. Science, 352(6292), 1430-1435. http://doi.org/10.1126/science.aaf1084

Youn, J.-Y., Dunham, W. H., Hong, S. J., Knight, J. D. R., Bashkurov, M., Chen, G. I., ... Gingras, A.-C. (2018). High-Density Proximity Mapping Reveals the Subcellular Organization of mRNA-Associated Granules and Bodies. Molecular Cell, 1-16. http://doi.org/10.1016/j.molcel.2017.12.020

Zhang, Y., Wölfle, T., \& Rospert, S. (2013). Interaction of nascent chains with the ribosomal tunnel proteins Rpl4, Rpl17, and Rpl39 of Saccharomyces cerevisiae. Journal of Biological Chemistry, 288(47), 33697-707. http://doi.org/10.1074/jbc.M113.508283 
SOURCE DATA FILES:

1406

REVIEWER ACCESS TO GEO ARCHIVED FASTQ FILES: $A$ secure token has been

created to allow review of record GSE118873 while it remains in private status:

1408

1409

1410

1411

1412

Figure 8-linked proteomics: Files containing all membrane protein raw MS data are provided as Scaffold files, file name: Figure 8 - source data 1 and 2.

Figure 11-linked proteomics: File containing all ribosomal protein raw MS data is contained in a Scaffold file, file name: Figure 11 - source data 1 


\section{Figure Legends:}

Figure 1. Experimental approach to the analysis of ribosome interactors and localized translation on the endoplasmic reticulum (ER). A) Schematic of experimental goals. Stable cell lines expressing inducible BirA* fusion proteins of previously identified ribosome associated membrane proteins, listed in (B), were prepared and used to determine the near-neighbor protein interactomes for each via the BiolD method. In addition to determining candidate ribosome interactor protein neighborhoods, reporter-mediated ribosome labeling was examined. To define the transcriptomes present at each of the postulated ER translation centers, biotin-tagged, ER-associated ribosome were recovered by detergent solubilization and avidin affinity isolation. Transcriptome compositions were determined by RNA-seq. B) Summary listing of candidate ribosome-interacting proteins, proposed functions, and linked citation.

Figure 2. BioID reporters display ER-restricted subcellular localization and biotinlabeling activity. A) Immunofluorescence micrographs of each reporter cell line after 24 hours of doxycycline-induced expression (BirA channel) and overnight biotin treatment (streptavidin channel). The merged images reveal high coincidence of ER membrane figures and proximity labeling. Scale bar $=10 \mu \mathrm{m}$. B) Immunofluorescence micrographs of each reporter cell line showing colocalization of the resident ER membrane protein marker (TRAPa) and the biotin labeling pattern. Scale bar $=10 \mu \mathrm{m}$. Data shown are representative of two biological replicates.

Figure 3. Biochemical fractionation of BiolD reporter cell lines demonstrates localization of the reporter constructs to the membrane fraction and highly enriched biotin tagging of membrane proteins. A) BirA immunoblot depicting the localization of each construct to the membrane fraction of the detergent fractionated cells. B) BirA*-mediated biotin labeling, depicted by streptavidin blot, reveals distinct labeling patterns for each cell line and high enrichment of the ER fraction over the cytosolic fraction. C) Cytosol and ER marker protein distribution in the cytosol and membrane fractions derived from the four BioID reporter cell lines. Cytosol marker $=\beta$-tubulin; ER marker $=$ TRAP $\alpha$. Data shown are representative of two biological replicates.

Figure 3 - figure supplement 1 . BiolD constructs display similar hydrodynamic behavior to native complexes in glycerol gradient sedimentation analyses. A) Immunoblot analysis of BiolD reporter construct migration in glycerol gradient velocity sedimentation experiments, comparing migration behavior of native and BiolD chimera for each BirA*-chimera cell line. Analysis of native proteins. B) As in (A) but using BirA antisera to compare migration patterns of the BiolD fusion proteins with the native protein. C) As in (A) but using an empty-vector control cell line, to compare migration patterns of native proteins as in panels $\mathbf{A}$ and $\mathbf{B}$.

Figure 4. The BiolD labeling patterns of the reporter cell lines largely intensify, rather than diversify, over time. A) Streptavidin blots of biotin labeling time courses are shown for each reporter cell lines. Also provided are line-intensity plots of selected time 
points through the six hour (hr) labeling period. Indicated are the biotin treatment time periods. -Doxy represents a six hr biotin treatment without prior doxycycline treatment, to test for leaky expression. B) Cartoons depicting the two predicted models of membrane protein diffusion. The leftward schematic (random diffusion) model depicts a biological membrane in which proteins diffuse freely in the 2-D membrane plane, encountering targets by random collision. The rightward schematic (constrained diffusion model), predicts that an organizing force, be it protein-protein interaction, lipid-enriched domains, or both, enables the formation of distinct compartments where protein diffusion is restricted. Data depicted in $\mathbf{A}$ ) is representative of two biological replicates.

Figure 5. In the absence of in situ-like ER membrane organization and with transdelivery of the reactive biotin intermediate, proximity-based selective labeling is abolished. A) SDS-PAGE gel depicting an in vitro labeling experiment conducted with canine rough microsomes (RM) incubated in the presence of soluble, recombinant BirA*. RM were incubated in the presence of an ATP regenerating system, biotin, and either $\mathrm{Bir}^{*}$ or PBS as indicated. Note that the general avidin labeling pattern mirrors the total protein when the reporter is present in trans. Asterisk indicates the BirA*-GST fusion protein, which is biotinylated during its induction in E.coli. B) Lane intensity plots demonstrate a general increase at all molecular weights, indicating loss of specificity when the reporter is presented in trans. C) India ink stain of the blot above demonstrating equivalent protein loading for all samples. D) Lane intensity plot of the India ink stain, illustrating the overall similarity in the labeling of total accessible protein. Data shown are representative of two biological replicates.

Figure 6. MS analysis of BiolD-labeled proteins demonstrates a high labeling enrichment of membrane vs. cytoplasmic proteins. A) Schematic depicting the data analysis pipeline and significance selection criteria. All MS experiments were performed in biological duplicate. B) Stack plots depicting the relative distributions of cellular localization for enriched and shared proteins from each cell line. The number of genes in each category is embedded in each bar, to enable comparisons between reporter cell lines.

Figure 7. BiolD reporters reside in distinct protein neighborhoods. Cytoscape plots of enriched proteins for the Sec61 $\beta$, LRRC59 and Ribophorin I BiolD reporter cell lines reveal different functional enrichments for proximally labeled proteins. Center nodes indicate the chimera protein from each cell line while the surrounding nodes develop from the proteomic datasets. Sizes indicate ranked normalized counts with the largest nodes having the highest values. Green nodes indicate stable, well-characterized protein oligomeric complexes, dark blue nodes are proteins comprising the top GO category indicated underneath each plot and in the appended table. Asterisks denote proteins that are in both established oligomeric complexes and GO categories. Borders indicate whether the protein is a membrane or soluble protein.

Figure 8. Shared proteins comprise the majority of the proteomic datasets and define common components of mesoscale-ordered ER membrane domains. A) The 
three chimera proteins, Ribophorin I (RPN1), LRRC59 and SEC61ß (SEC61B), implicated in ribosome binding, with common, shared proteins. B) Cytoscape plot of shared proteins confirms several established protein-protein interactions from experimental evidence (dotted edge lines, bold lines if connected to a reporter node). Size of the nodes are based on highest normalized count from the shared reporters. Proteins shared by specific chimera are distinguished by the indicated color scheme. LRRC59 share more proteins with the SEC61B and RPN1 reporters than SEC62. Files containing all membrane protein raw MS data is contained in Scaffold files as Figure 8 source data 1 and 2 .

Figure 9. BiolD labeling kinetics of cytosolic and ER-bound ribosomes. A) Streptavidin blots and related total protein analysis (india ink stains) of the ribosome pellets prepared from samples depicted in Figure 4. B) Quantification of the summed lane intensity from membrane-bound ribosome lanes, plotted against time of added biotin using data from the blots shown in panel $\mathbf{A}$. $\mathbf{C}=$ cytosol, $\mathbf{M}=$ membrane, $\mathbf{M W}=$ relative molecular weight in $\mathrm{kDa}$. Data depicted is representative of two biological replicates.

Figure 10. BiolD reporter labeling of ER-associated ribosomes in LRRC59 and Sec61 $\beta$ BiolD reporter cell lines does not impair translation function. A) Experimental schematic illustrating the biotin-tagged ribosome isolation and analysis protocol. B) Velocity sedimentation analysis of ribosomal small and large subunits derived from LRRC59 and Sec61 $\beta$ BioID reporter cell lines. Illustrated are the $A_{254}$ traces, RNA gel micrographs depicting $18 \mathrm{~S}$ and $28 \mathrm{~S}$ rRNAs. Also illustrated are streptavidin blots of the small and large ribosomal subunits from the reporter cell lines, with $80 \mathrm{~S}$ ribosomes as comparison. C) To determine if BiolD-mediated biotinylation altered ribosome function, polyribosomes were fractionated by sucrose gradient velocity sedimentation and biotinlabeled protein distributions analyzed by streptavidin blots of the precipitated gradient fractions. RNA gels of the gradient fractions are included to confirm ribosome migration.

Figure 11. MS analysis of biotin-labeled ribosomal proteins reveals distinct BiolD labeling patterns, suggestive of restricted steric interactions with the BiolD reporters. A) MS/MS identified ribosomal proteins were mapped onto a PDB structure of the ribosome bound to the translocon (PDB: 3J7R). High confidence biotin labeled ribosomal proteins are mapped to the ribosome and several ribosomal features are labeled for orientation. MS experiments were performed in biological duplicate. B) Table of the five ribosomal proteins identified from the mass spec datasets with high confidence. Files containing all membrane protein raw MS data is contained in Scaffold files as Figure 11 - source data 1

Figure 12. RNA-seq analysis of BiolD reporter-labeled polysomes shows divergent transcriptomes and demonstrates that ER ribosomes engage in the translation of cytosolic and secretory protein-encoding RNAs. A) Schematic of experimental protocol for capturing biotin-labeled polysomes. B) Final subcellular distributions of proteins encoded by ribosome-associated RNAs. Stack plots of RNA-seq TPM reveal an enrichment for organellar membrane proteins (DeepLoc1.0) compared to the total 
mRNA distribution by TPM for membrane and total cell (LocTree3, using datasets from (Reid and Nicchitta, 2012). The transcriptomes from Sec61 $\beta$ and LRRC59 labeled ribosomes diverge from the total and secretory/membrane distributions, and from one another. C) TPM analysis of the enriched and shared mRNAs for the Sec61 $\beta$ datasets showing both subcellular distributions and membrane prediction of the encoded proteins. D) TPM analysis of the enriched and shared mRNAs for the LRRC59 datasets showing both subcellular distributions and membrane prediction of the encoded proteins. Plasma membrane (PM); Transcripts per million (TPM). E) Read count analysis of raw counts shown for each of the datasets by percentage of those that aligned to the human genome and counted by htseq-count as described in the methods. F) Table of top ten genes by fold change value for enriched and shared datasets color coded by fold enrichment over the control datasets.

Figure 12 - figure supplement 1. Quality control checks for replicates in RNA-seq libraries. (A-C) $\log _{2}$ transformed counts from RNA-Seq datasets of biological replicates in the analysis are plotted, revealing high similarity between biological duplicated. Red lines represent regression lines plotted to reveal variation from the midline (black). Pearson correlation coefficient at $95 \%$ confidence is shown in upper left part of the graph. (D) Raw counts of datasets aligned to the humanized BirA construct sequence used for the BiolD chimera demonstrating expression of the BiolD chimera and background mapping frequencies in the empty vector lines. 
A aCC-BY 4.0 International license.

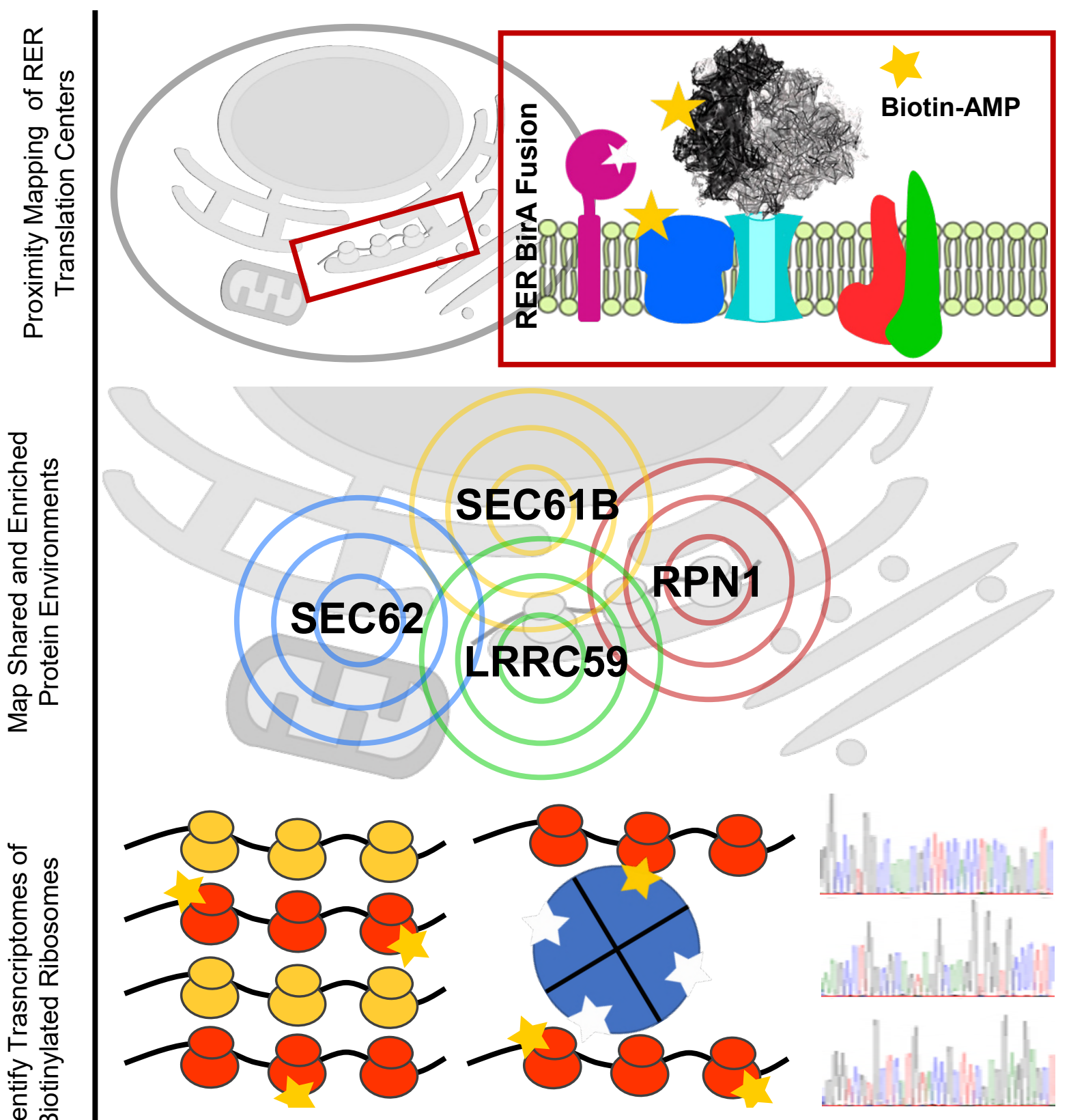

Isolated Rough ER Polysomes
Streptavidin Purification of Labeled Polysomes
Sequencing of ER bound polysomes

B

\section{BirA-Fusion}

Sec61 $\alpha /$ Translocon

Sec61 $\beta$

Ribophorin I

LRRC59

Sec62

\section{Proposed Cellular Function}

Translocon Complex

Translocon Complex

Oligosaccharyl transferase

Ribosome receptor

Post-translational translocation

\section{Citation}

Gorlich D et al (1992) Cell. 71:489-503.

Levy $R$ et al. (2001) JBC. 4:2340-2346.

Kreibich G et al. (1978) JCB. 77: 488-506.

Tazawa S et al. (1991) JBC. 109: 89-98.

Muller L et al. (2010). Mol Biol Cell. 21: 691-703 

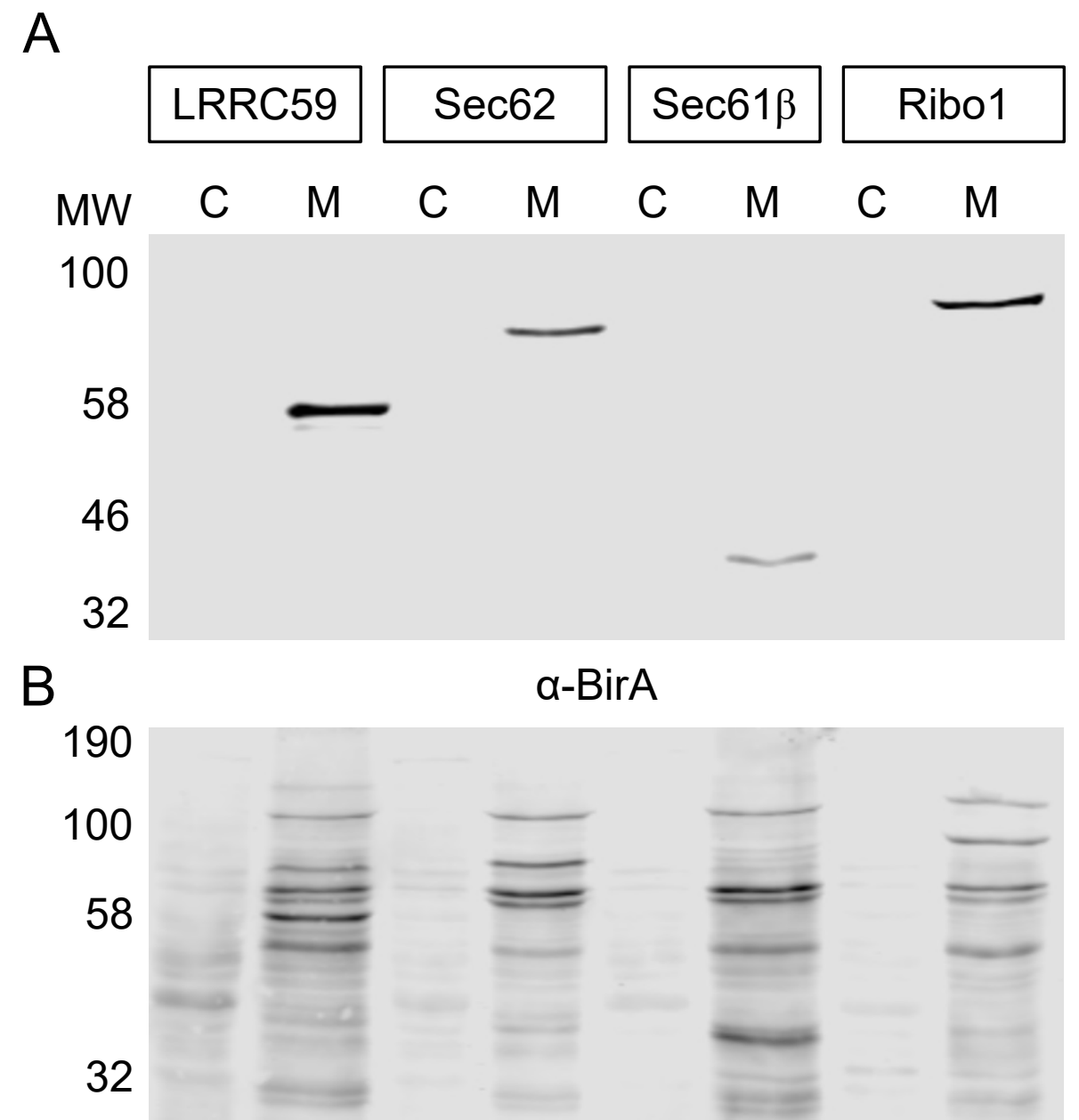

25

17

11

C

\section{Streptavidin}

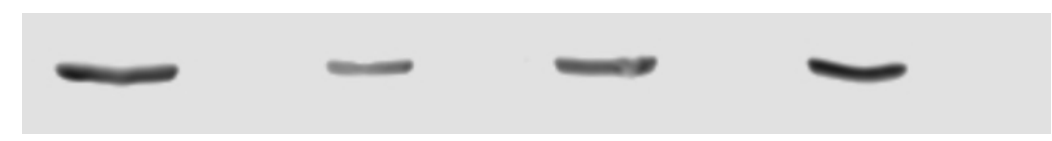

$\alpha-T u b u l i n$

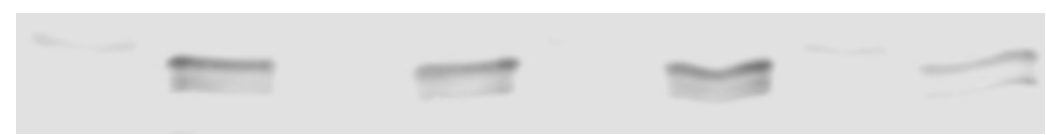

$\alpha-T R A P \alpha$ 
Figure 3 - figure supplement 1 , Hoffman an̊d Píc $^{4}$ Chitternational license.

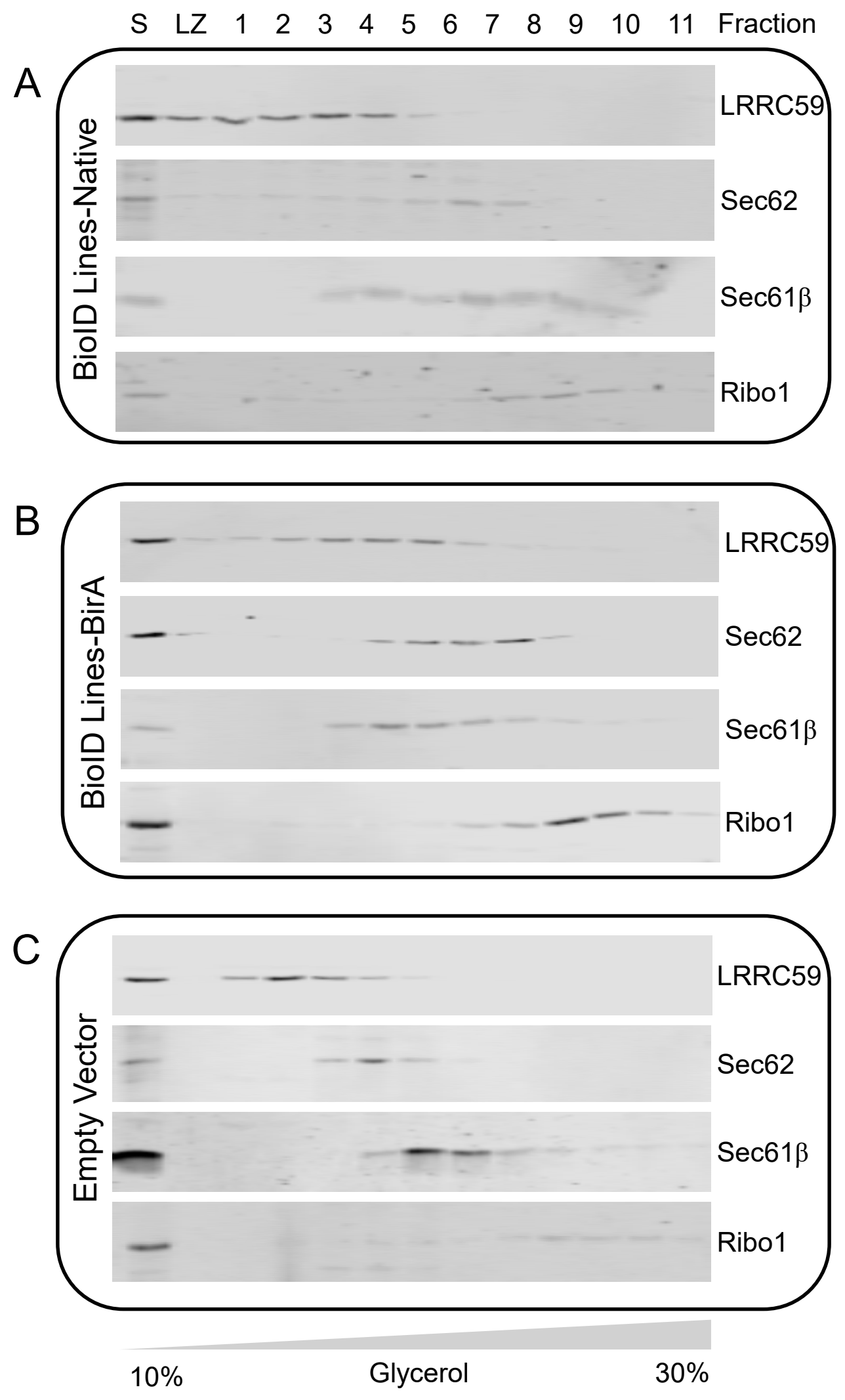




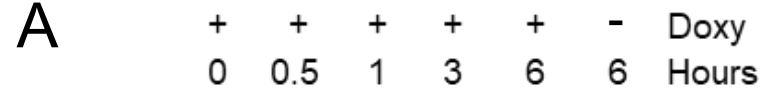
MWCM C M CMCM CM C M
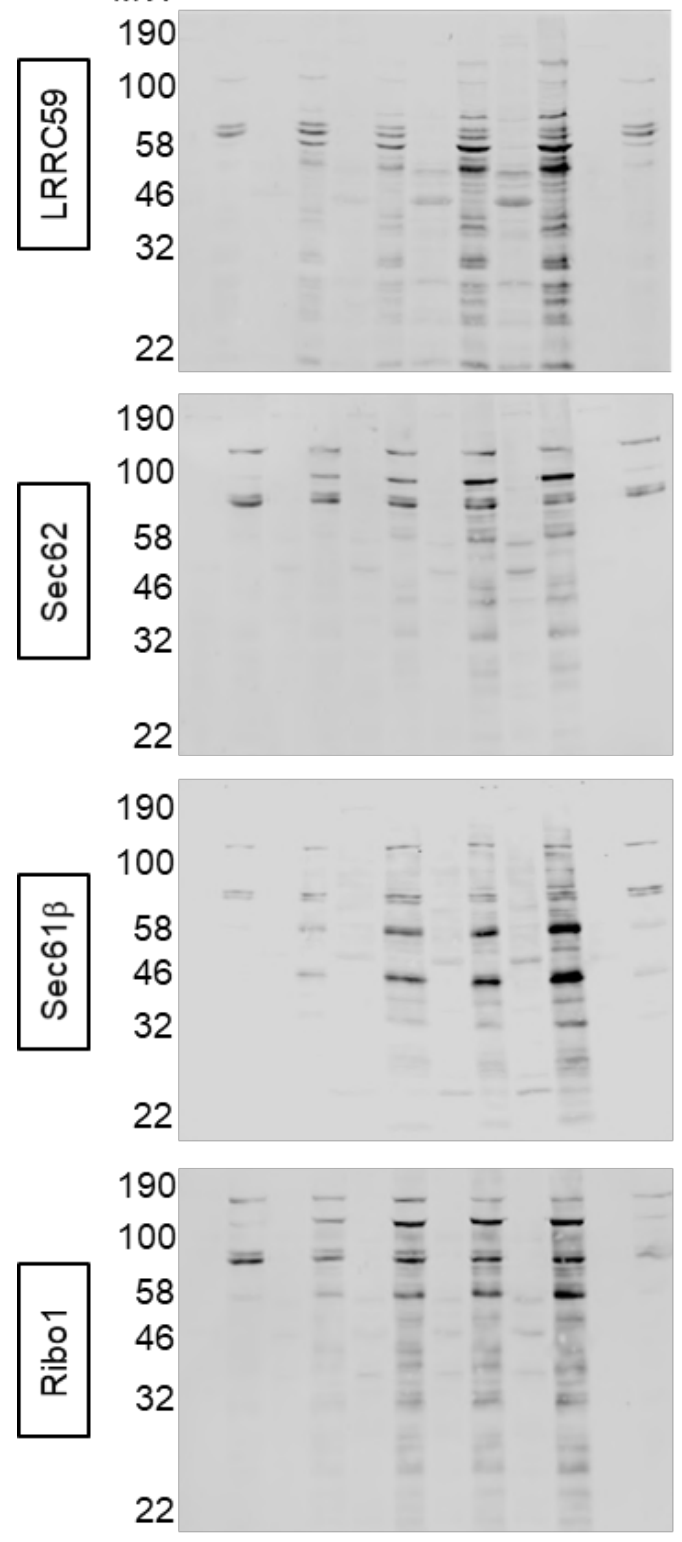

B

\section{Random Diffusion Model}
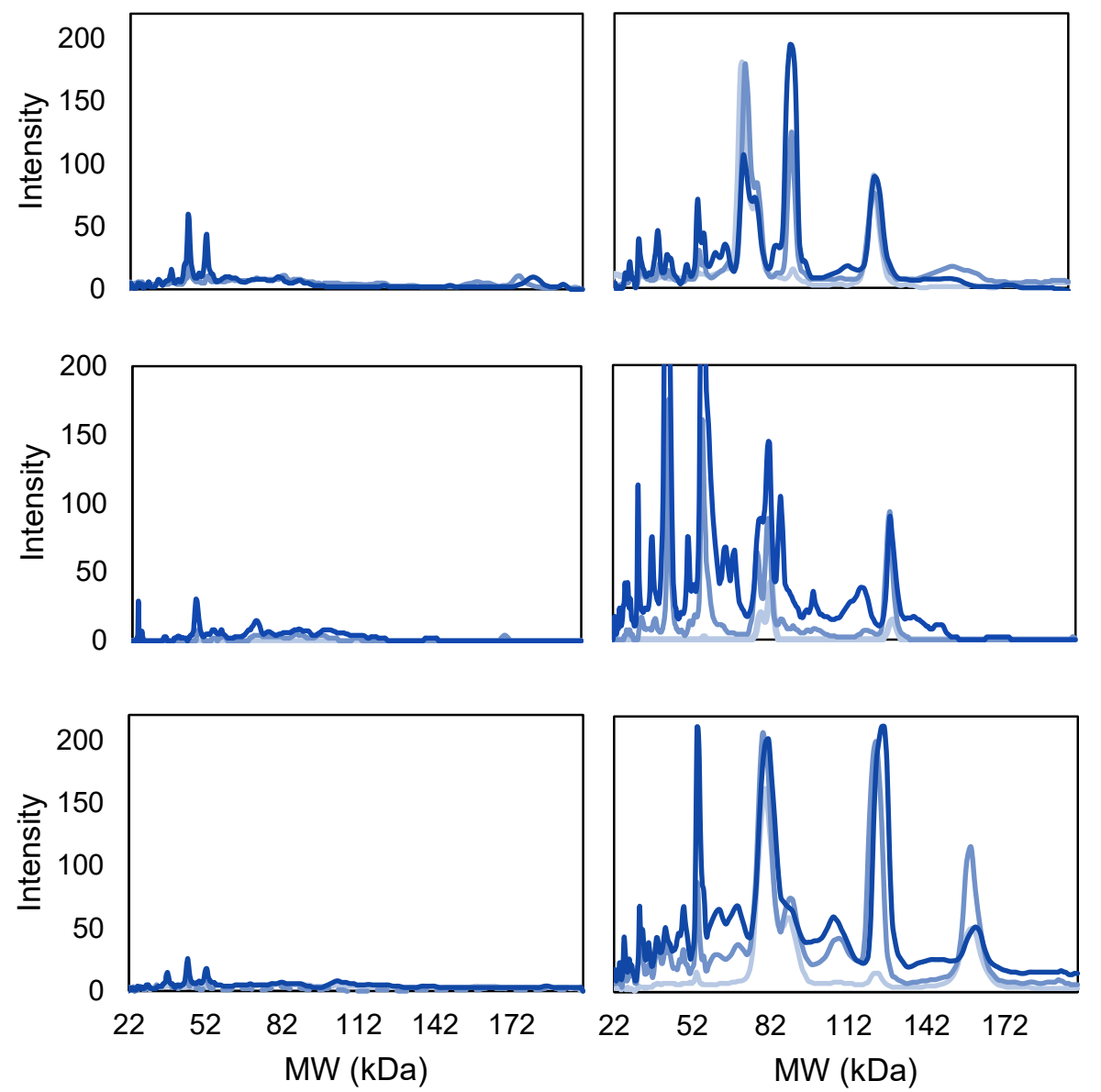
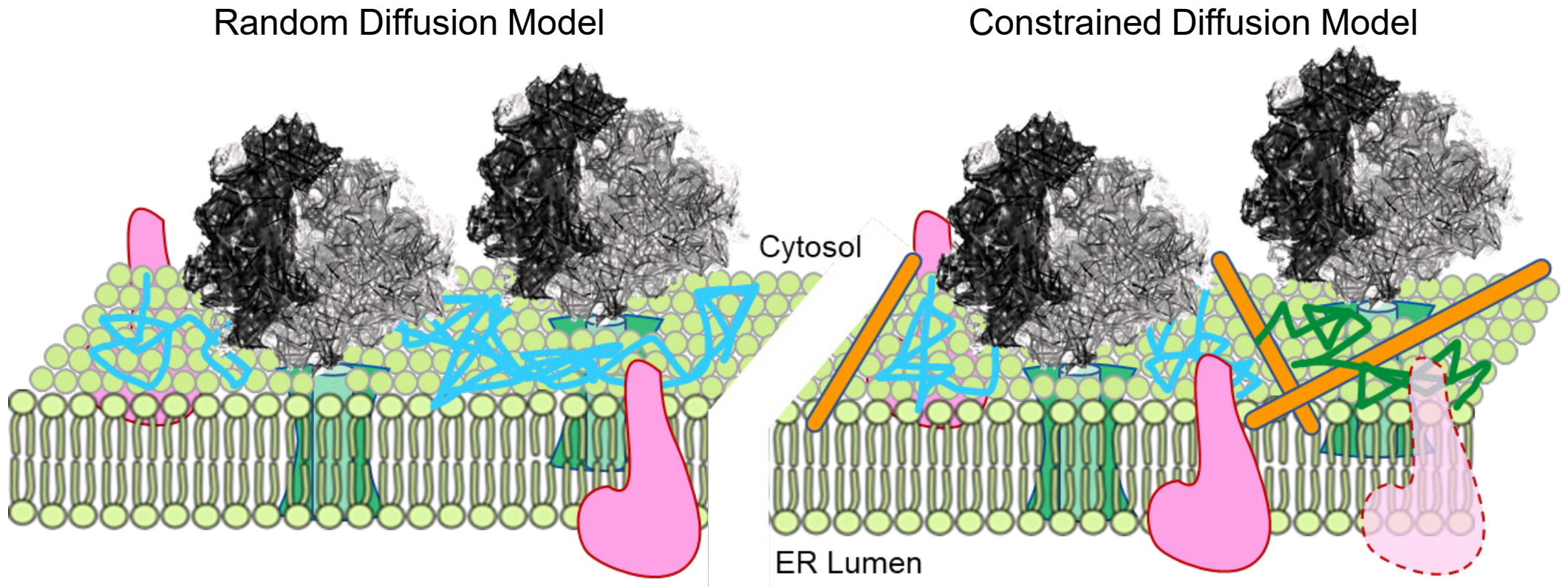


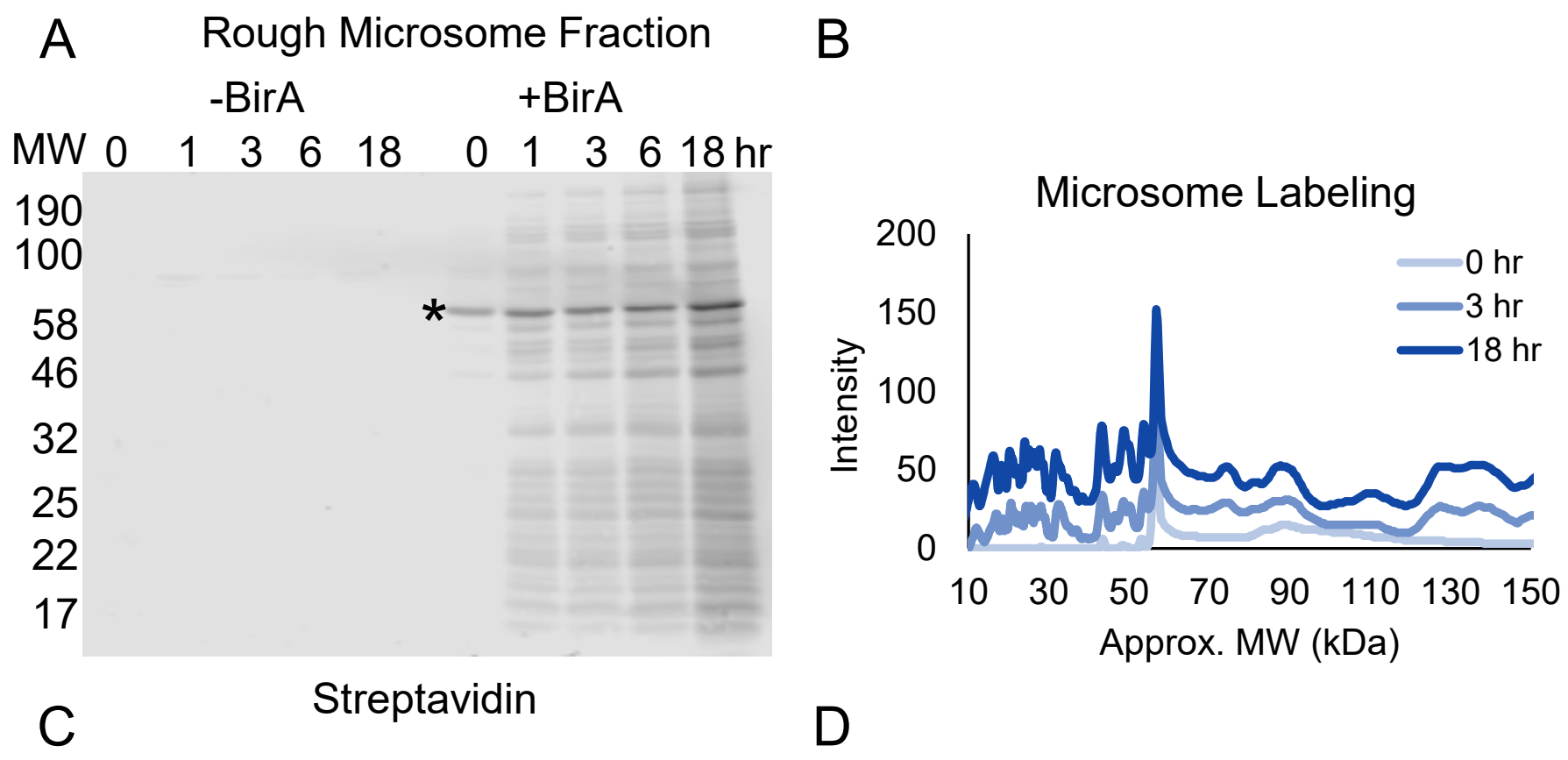

\section{MW}

190

100

58

46

32

25

22

17

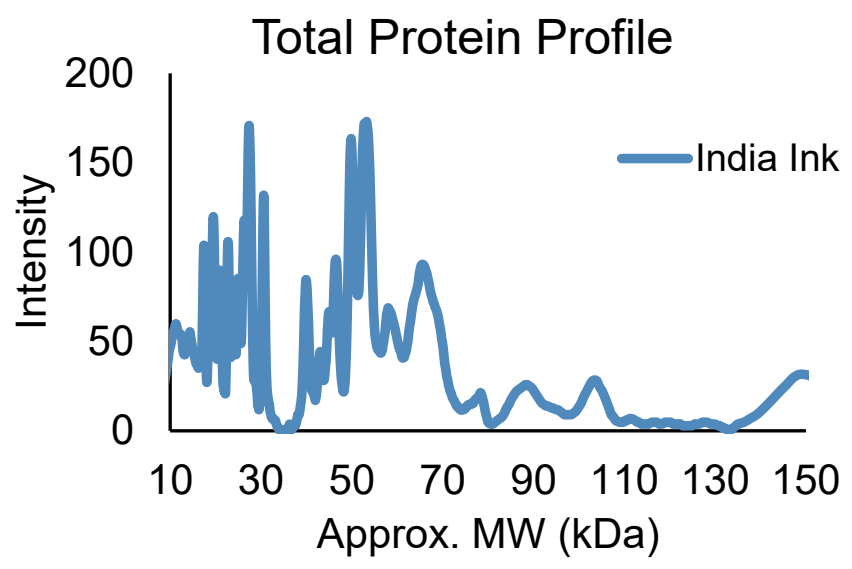

India Ink 


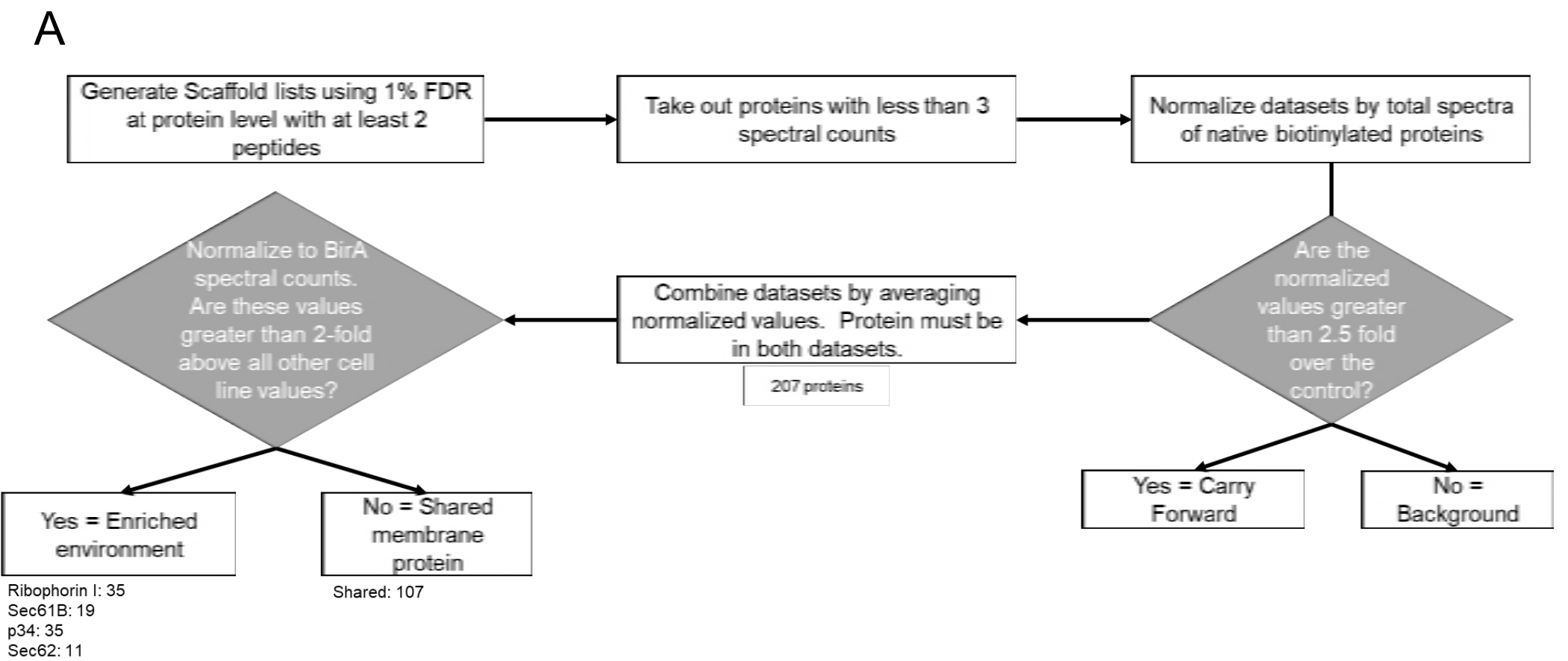

B

\section{Subcellular Localization by GeneID}

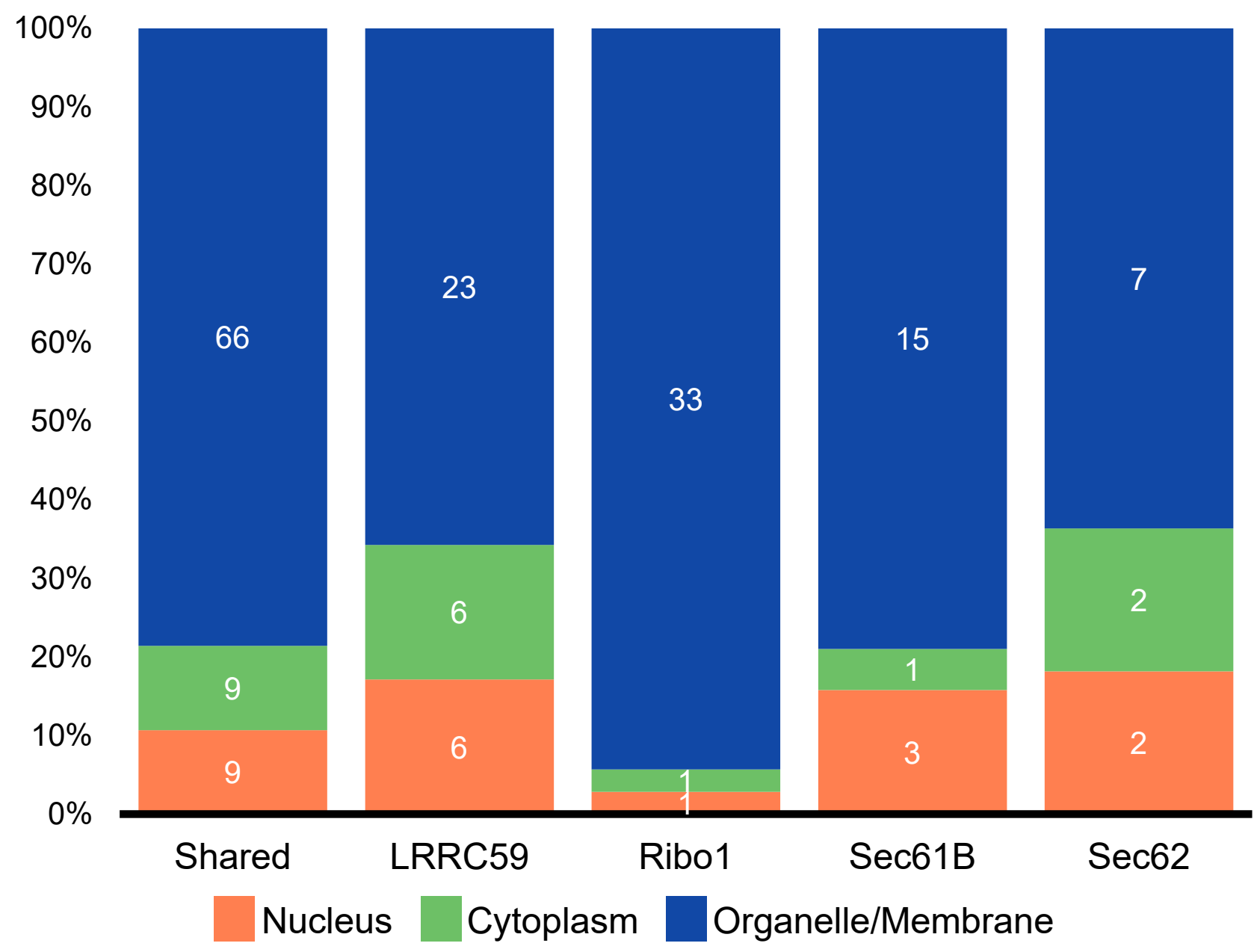




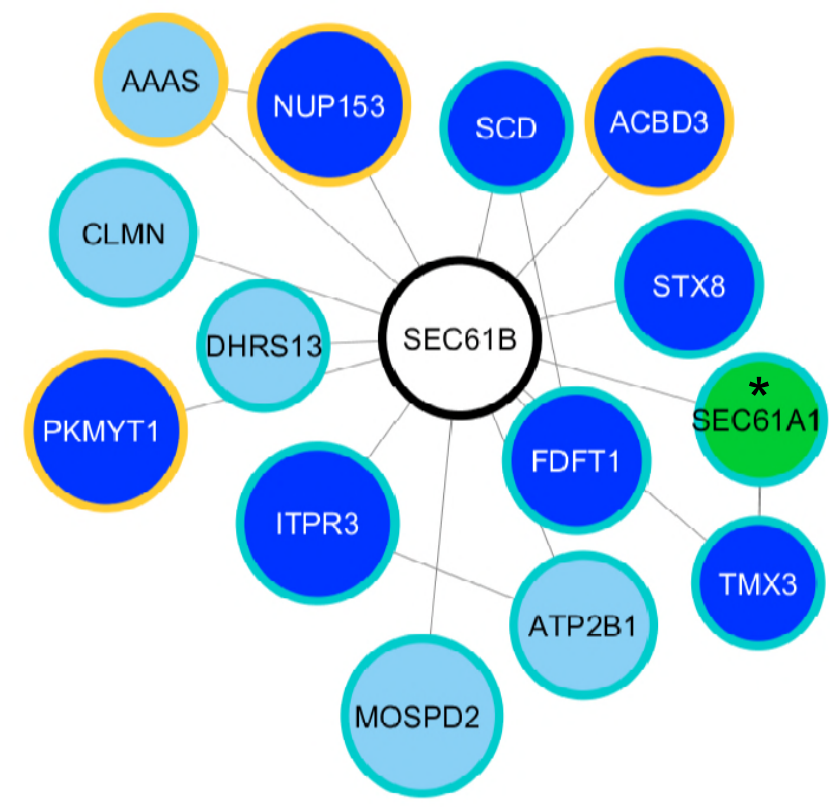

GO: Organelle Membrane

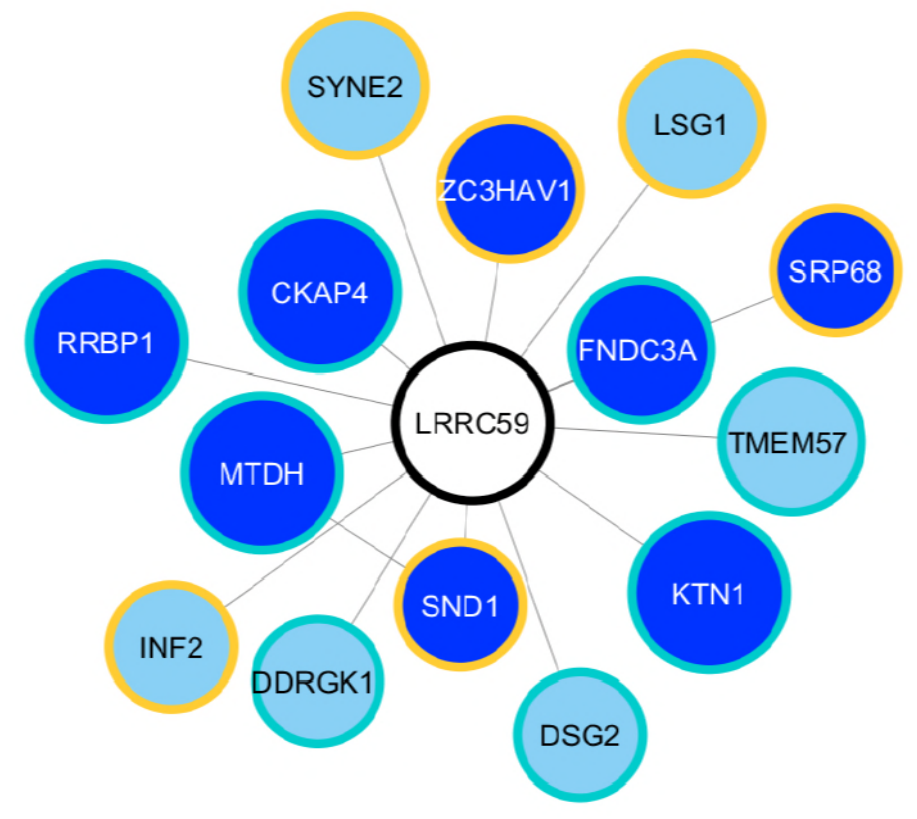

GO: Poly(A)RNA-binding

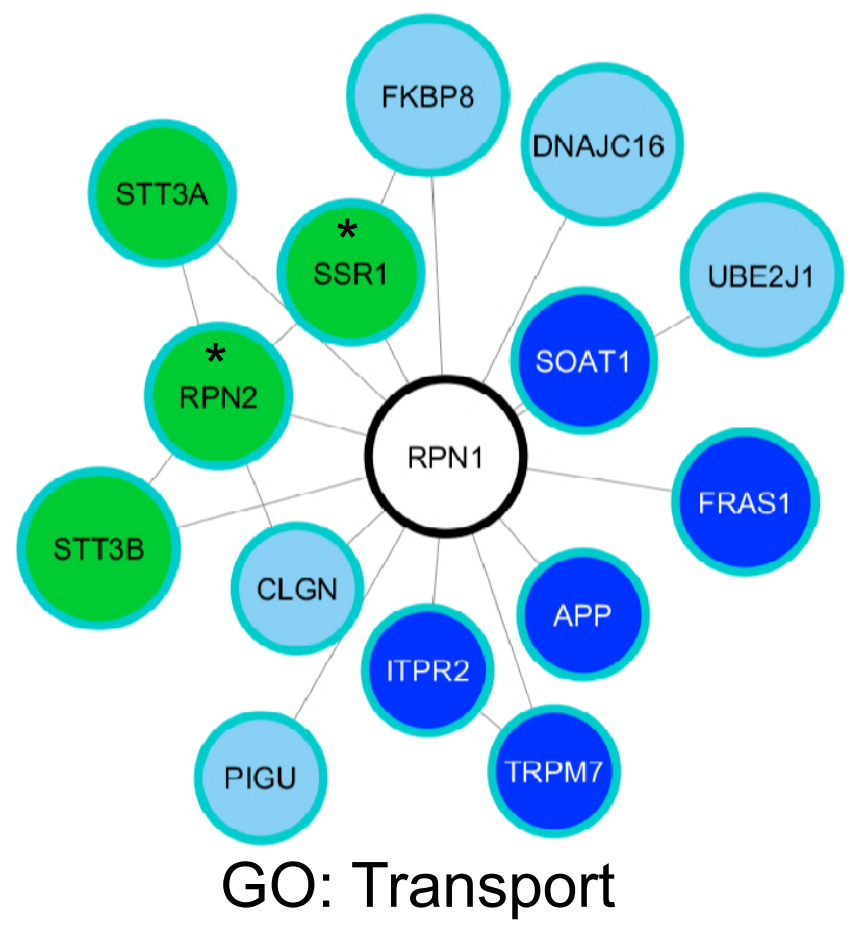

Soluble

Membrane

\section{BiolD Cell Line}

LRRC59

$\operatorname{Sec61\beta }$

Ribophorin I
Top GO Enrichment

Poly(A) RNA-Binding

Organelle Membrane

Transport

\section{FDR}

$7 \times 10^{-5}$

$1 \times 10^{-4}$

$9 \times 10^{-3}$ 
A

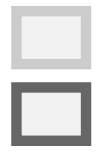

Soluble

Membrane

\section{RPN1-SEC61B-LRRC59 Shared Proteins}

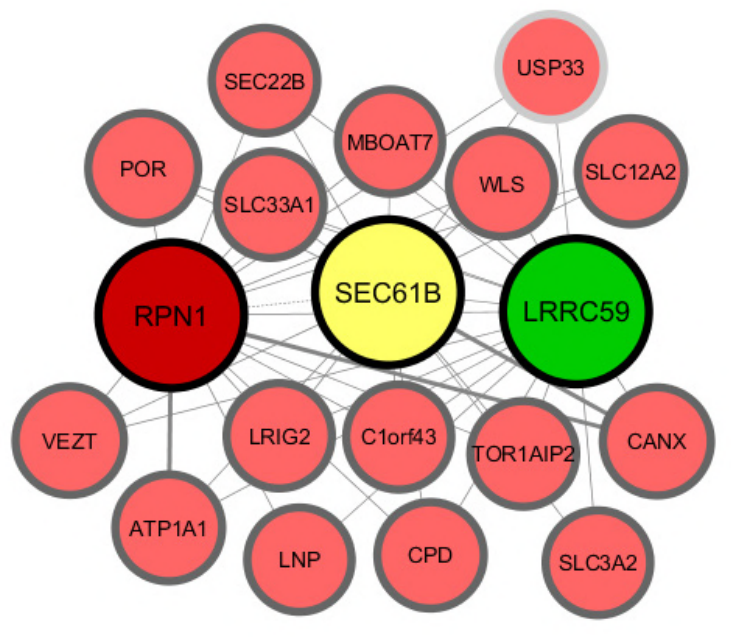

B

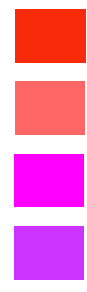

RPN1-SEC61B

RPN1-SEC61B-LRRC59

RPN1-LRRC59

RPN1-SEC62

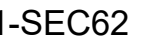

SEC61B-LRRC59

SEC61B-LRRC59-SEC62

SEC61B-SEC62

LRRC59-SEC62

\section{All Shared Proteins}

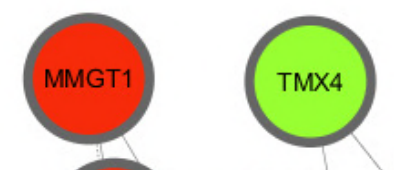

EMC7
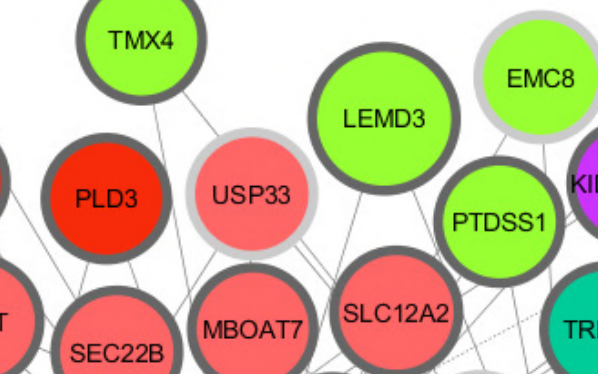

RANGAP1
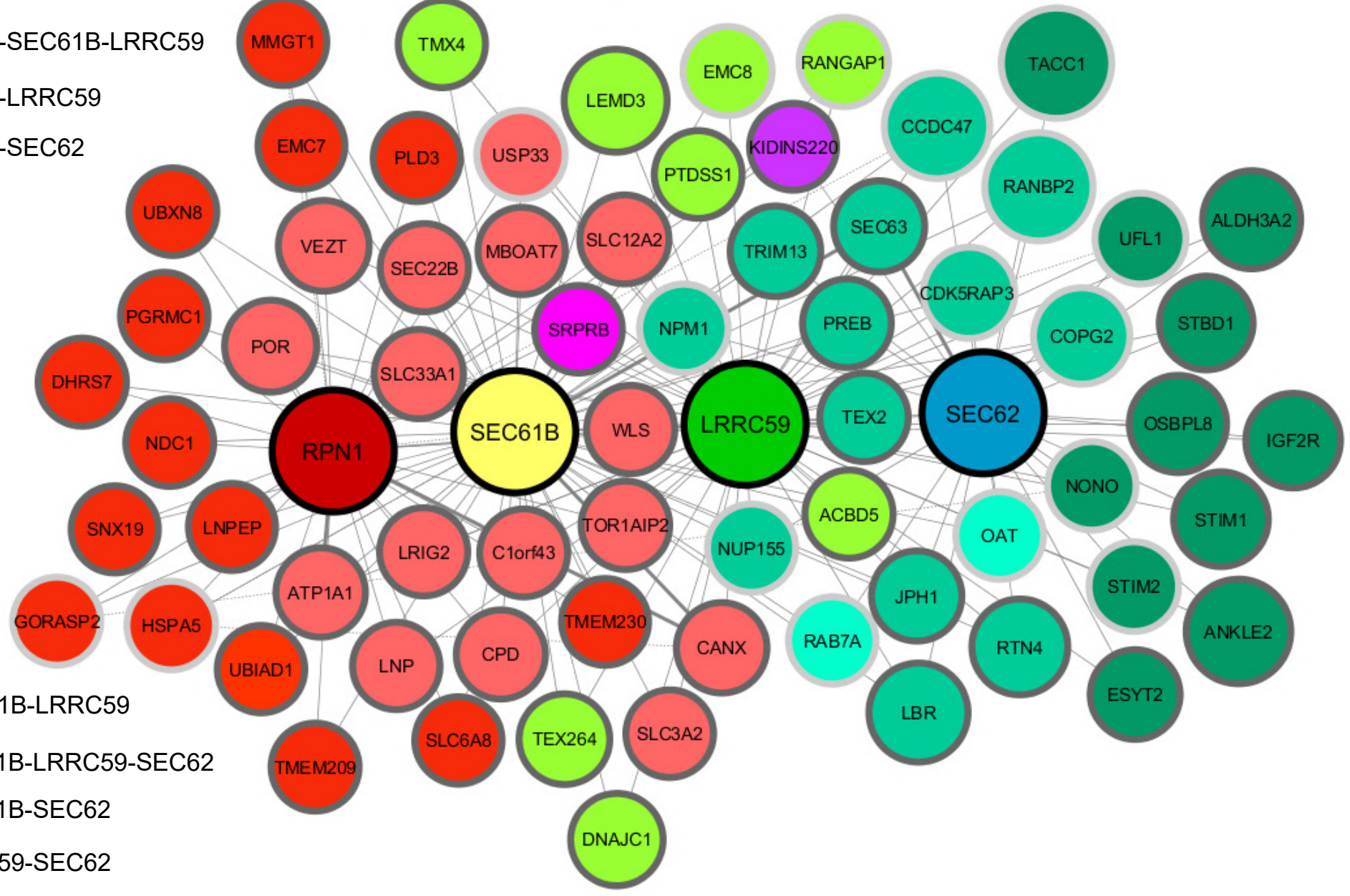


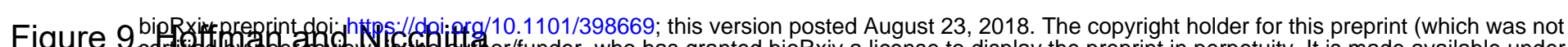
certilied by gee review) IS the wthor/funder, who has granted bioRxiv a license to display the preprint in perpetuity. It is made available under

A Streptavidin Blots

Total Protein
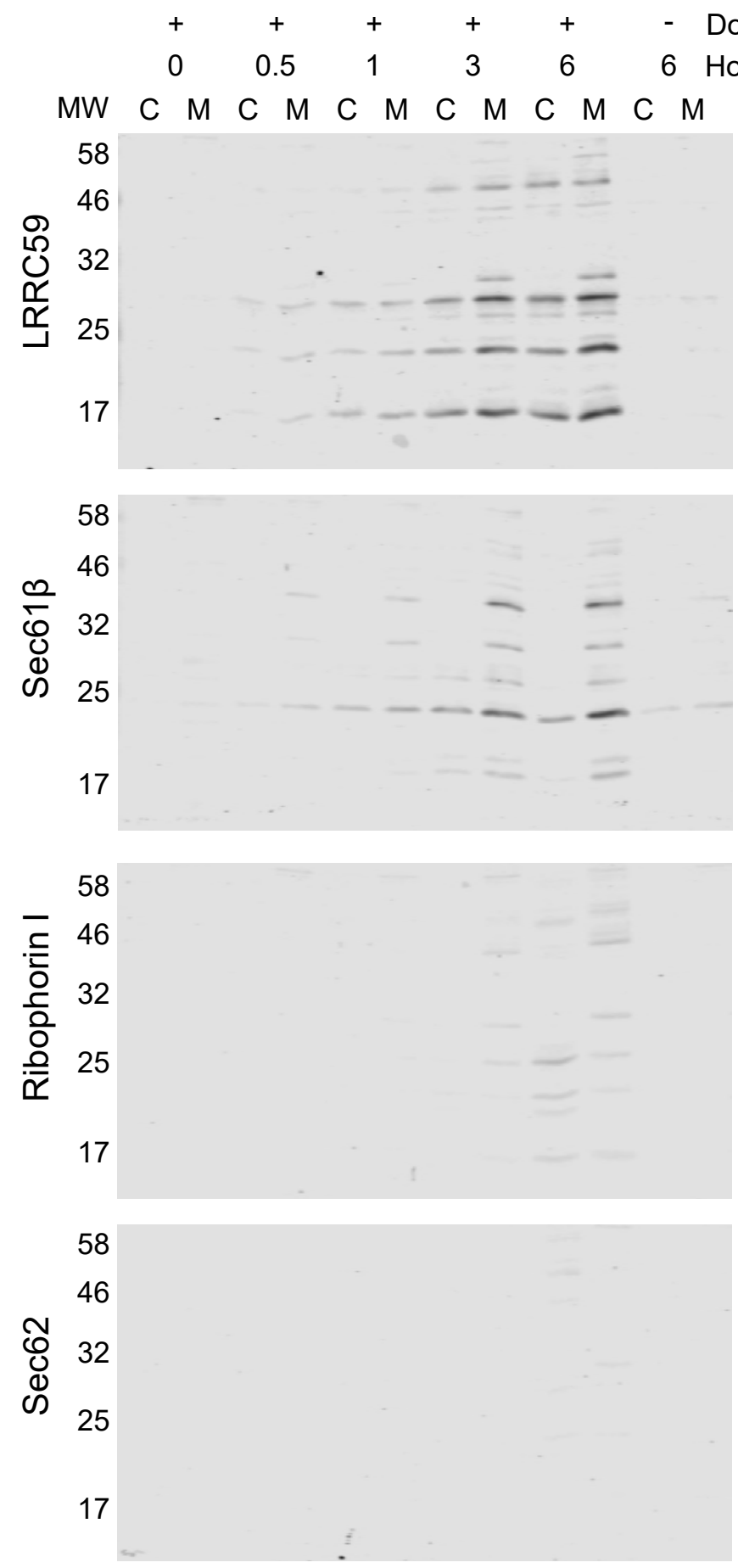

B

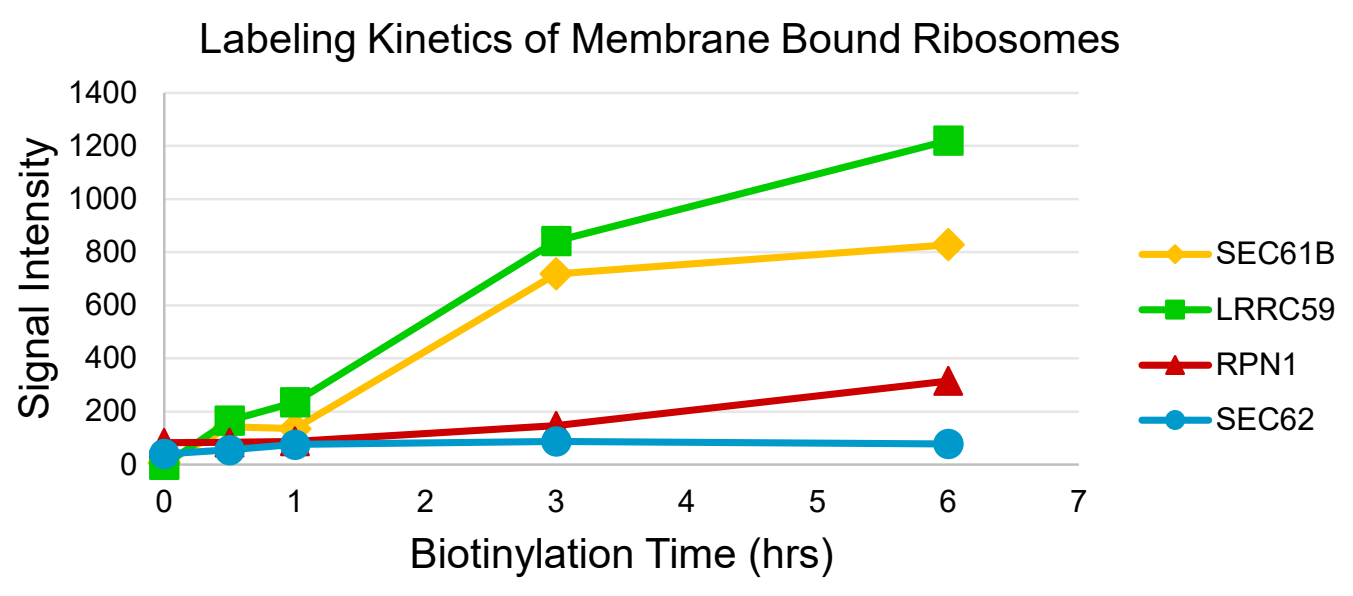



aCC-BY 4.0 International license.
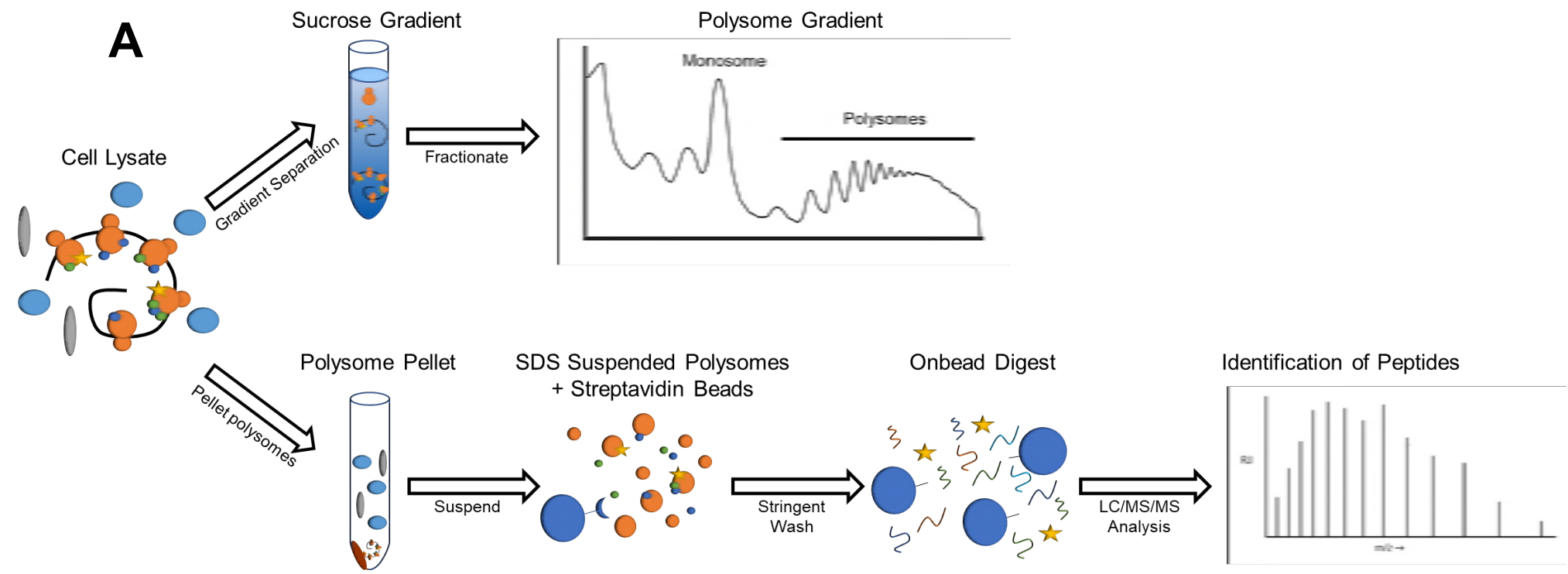

B
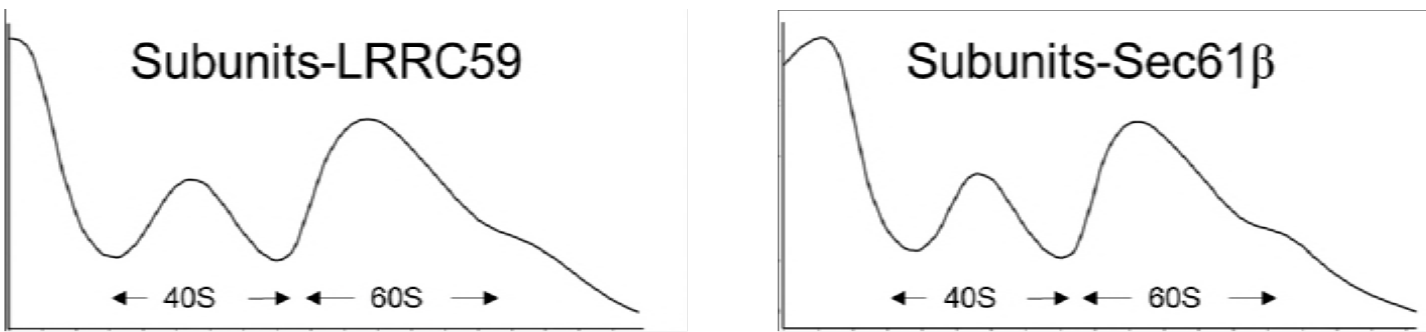

28S
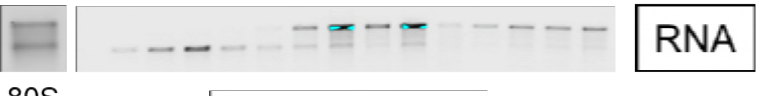

805

80S 40S 605
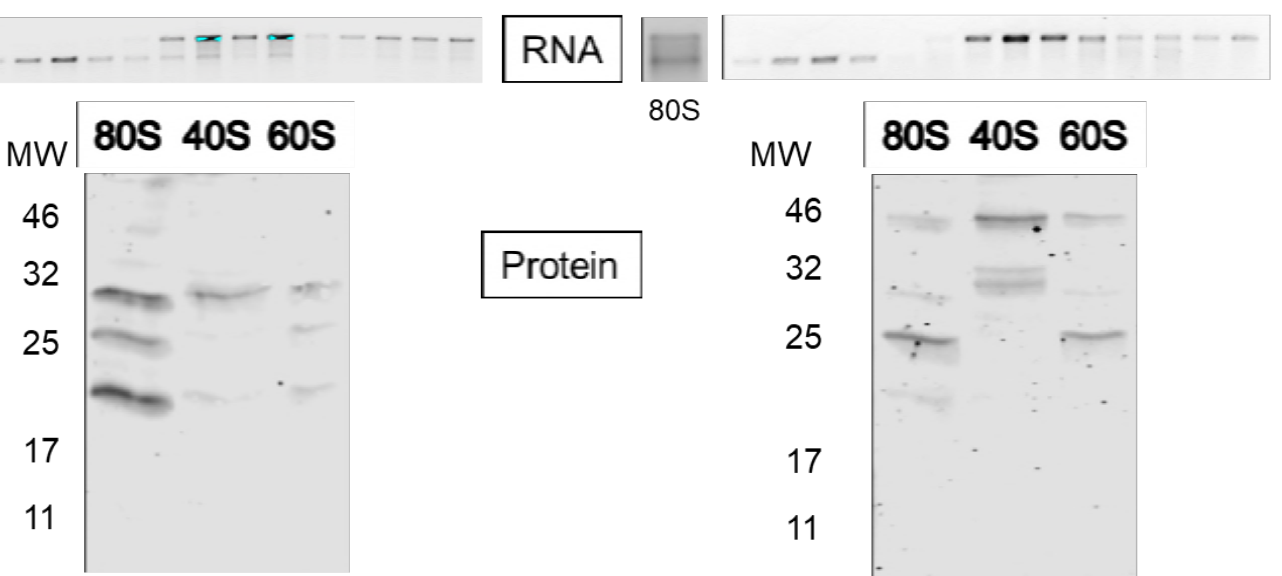

C
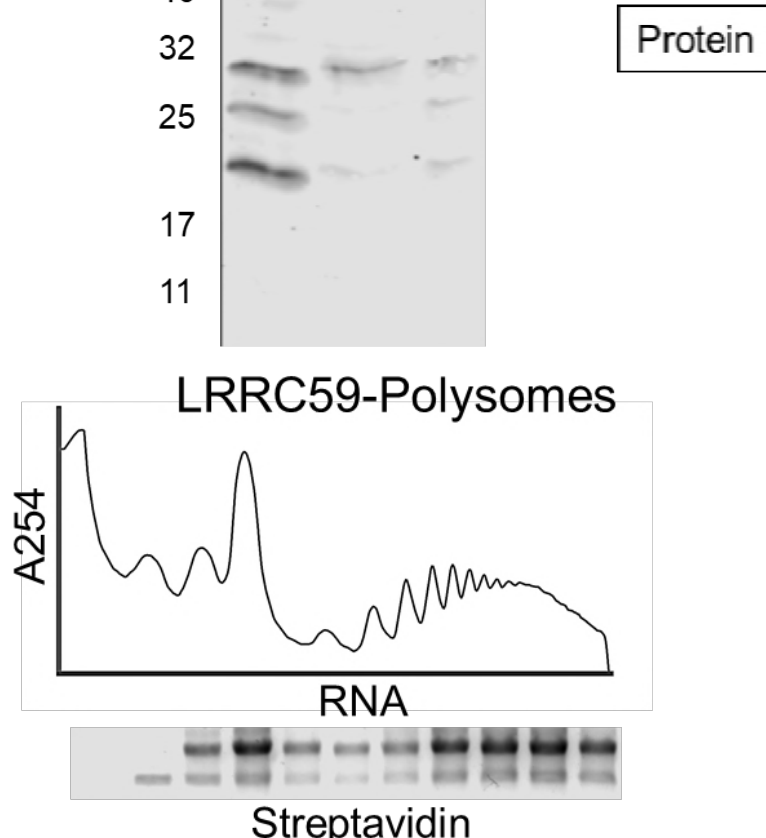

$80 S$
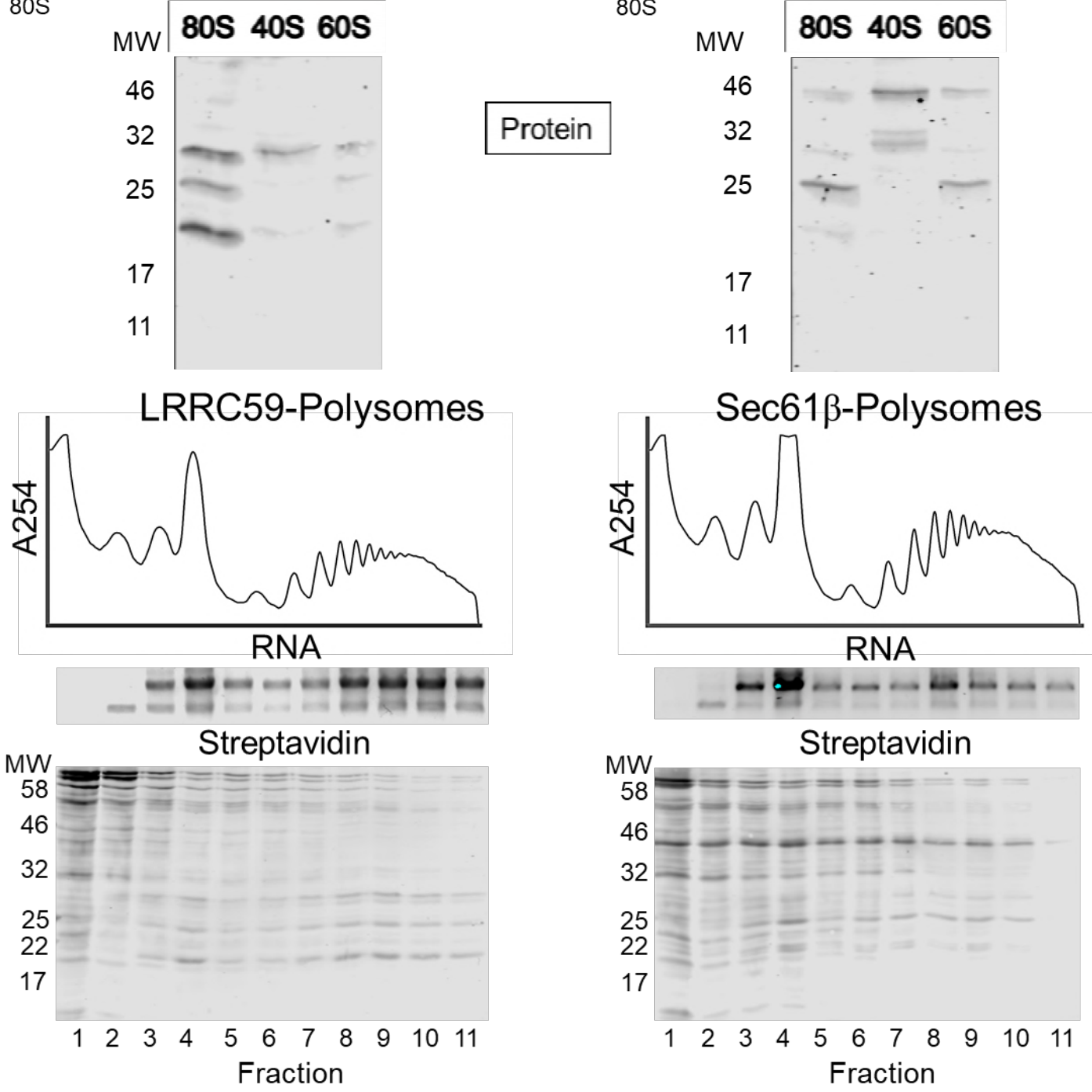

\section{Sec61 1 -Polysomes}

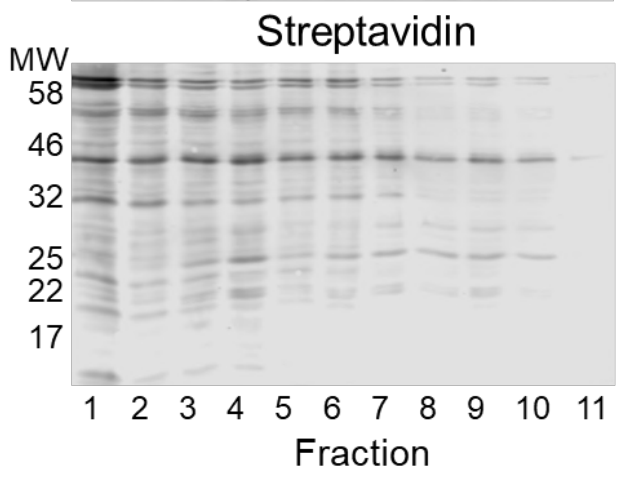



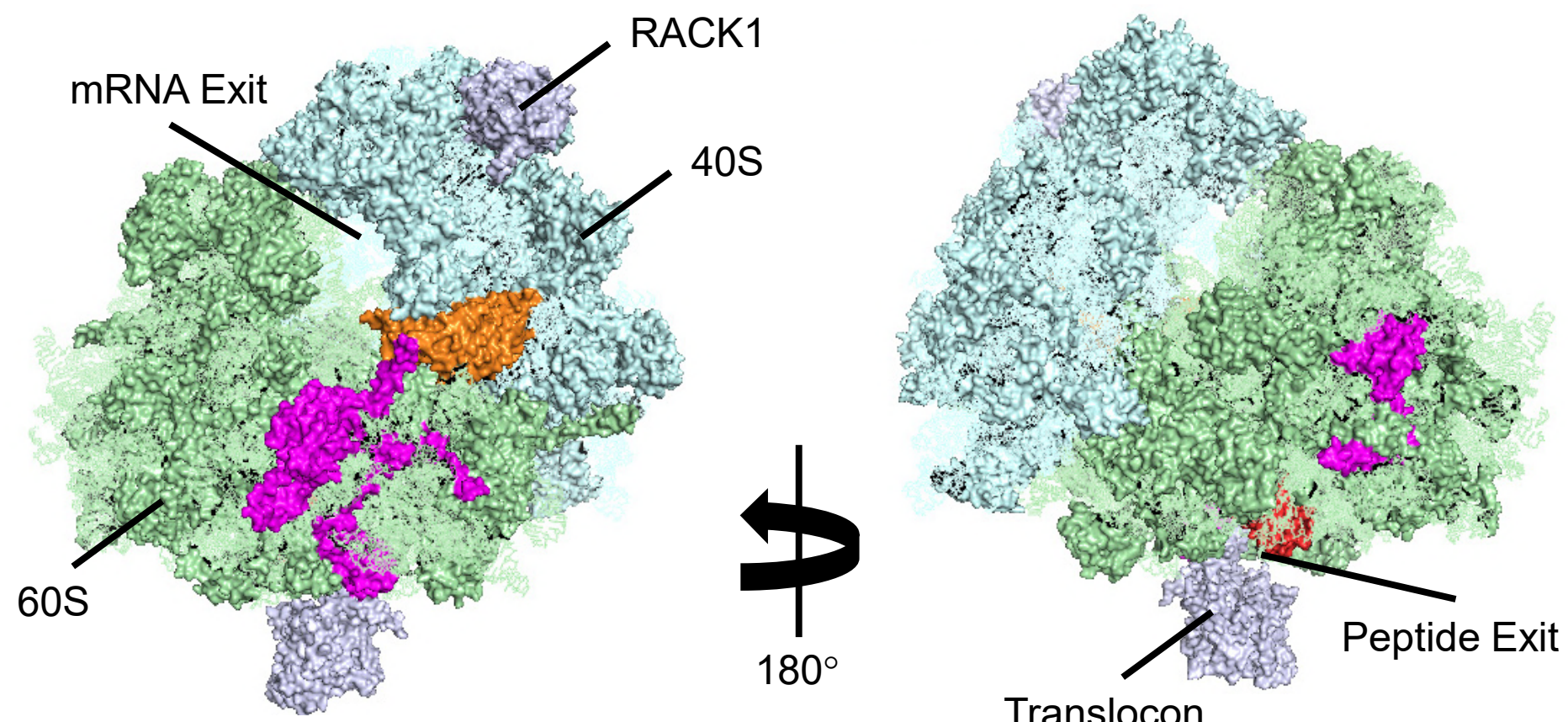

B

\begin{tabular}{|l|l|l|l|}
\hline $\begin{array}{l}\text { Dataset Enriched } \\
\text { in: }\end{array}$ & $\begin{array}{l}\text { MW } \\
\mathbf{( k D a )}\end{array}$ & $\begin{array}{l}\text { Ribosomal } \\
\text { Protein }\end{array}$ & Color \\
\hline LRRC59 & 30 & S3A & Orange \\
\hline Sec61 $\beta$ & 21 & L17 & Red \\
\hline Shared & 30 & L7a & Magenta \\
\hline Shared & 23 & L14 & Magenta \\
\hline Shared & 18 & L23a & Magenta \\
\hline Shared & 12 & LA2 & Not shown
\end{tabular}


A

\section{Labeled Polysome Purification}

Whole Cell Cytosol Extraction ER Extraction
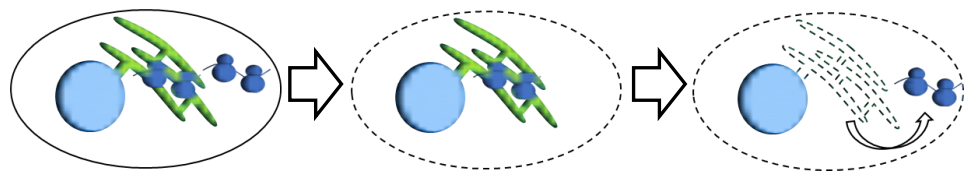

$80 \%$

$60 \%$

Sephacryl

Purification

Capture Biotinylated

Polysomes

$\Rightarrow \sum_{8}^{0}$
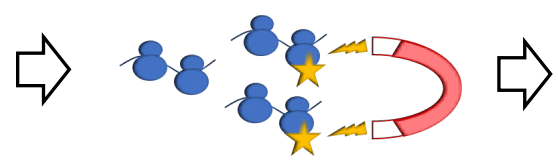

xtract RNA and

Sequence

$40 \%$

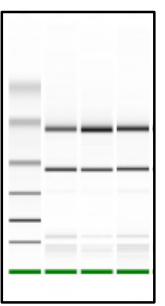

$20 \%$

$0 \%$

Sec61ß Shared

Soluble: $55.8 \%$ Membrane: $44.2 \% \quad$ Soluble: $27.7 \%$ Membrane: $72.3 \%$

Organelles

Organelles
Secreted

Other

ER/PM

Cytoplasm

Nucleus

$\mathrm{D}$

LRRC59 Enriched

Soluble: $41.0 \%$

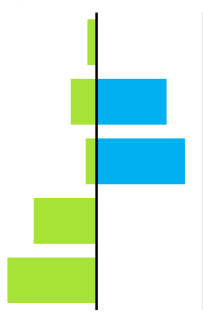

Secreted

Other

ER/PM

Cytoplasm

Nucleus

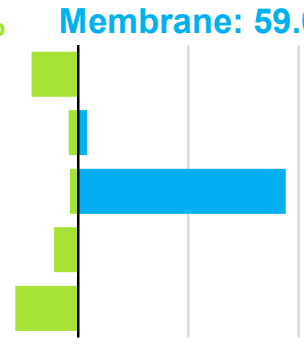

$300 \quad 600$

TPM (thousands)

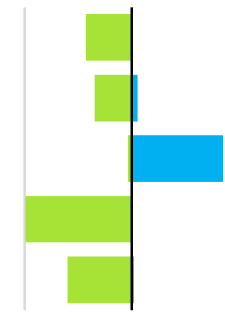

LRRC59 Shared

$73.7 \% \quad$ Membrane: $26.3 \%$

E

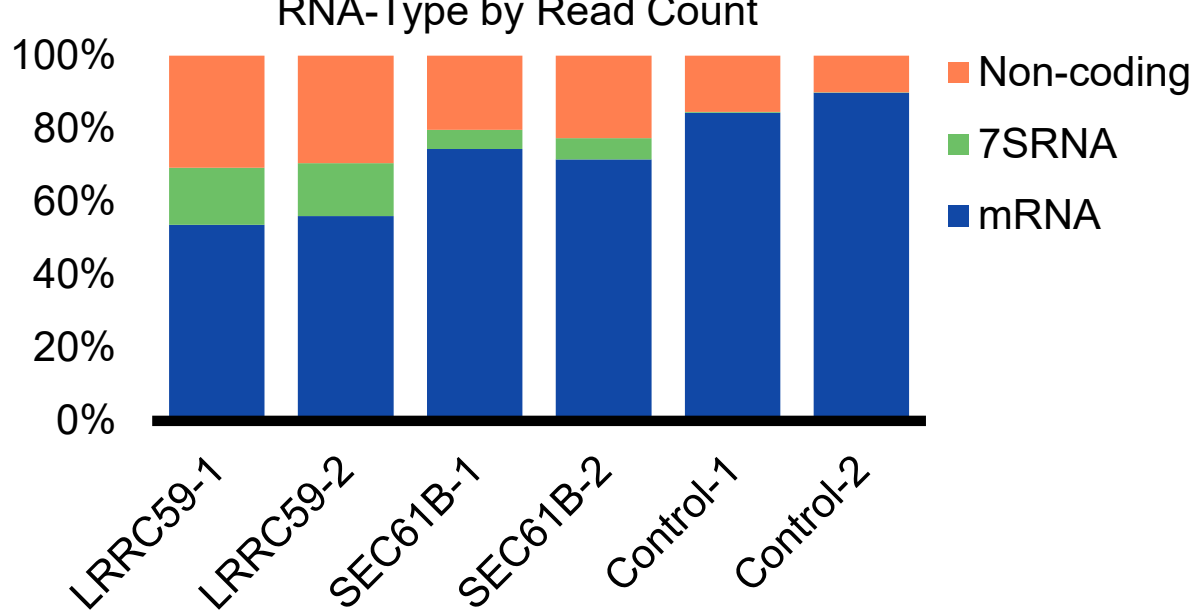

TPM by Localization
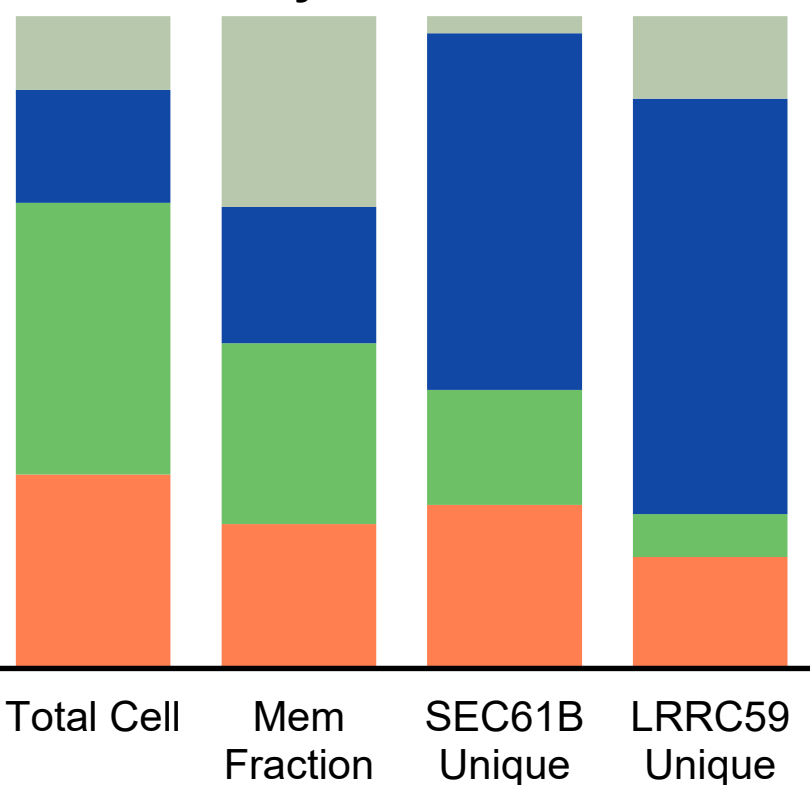

Secreted $\square$ Organelle Cyto $\square$ Nucleus
$\mathrm{F}$

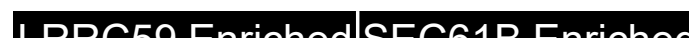

LRRC59 Enriched SEC61B Enriched Gene Name

\begin{tabular}{l|l}
\hline AC004556 & EEF1D \\
\hline
\end{tabular}

\begin{tabular}{l|l} 
LRRC59 & CD99 \\
\hline
\end{tabular}

\begin{tabular}{l|l}
\hline COLCA2 & BMP2 \\
\hline
\end{tabular}

\begin{tabular}{|l|l}
\hline ATAD3C & SEC61B \\
\hline RAB32 & COL3A1 \\
\hline
\end{tabular}

\begin{tabular}{l|l}
\hline RAB32 & COL3A1 \\
\hline
\end{tabular}

\begin{tabular}{|l|l}
\hline DDX39B & STAC2 \\
\hline
\end{tabular}

\begin{tabular}{|l|l}
\hline PGR & GOS2 \\
\hline
\end{tabular}

\begin{tabular}{|l|l}
\hline RAB3C & TNFSF12 \\
\hline
\end{tabular}

\begin{tabular}{l|l}
\hline MYRIP & TMEM130 \\
\hline
\end{tabular}

\begin{tabular}{l|l}
\hline DNER & TENM1 \\
\hline
\end{tabular}

LRRC59 Shared ISEC61B Shared Gene Name

\begin{tabular}{|l|l|}
\hline NRSN1 & ISL1 \\
\hline MAP7D2 & LSAMP \\
\hline PTPRO & SLC24A3 \\
\hline ISL1 & NRSN1 \\
\hline
\end{tabular}

\begin{tabular}{l|l}
\hline SLC24A3 & PTPRK \\
\hline
\end{tabular}

\begin{tabular}{|l|l|}
\hline PTPRK & PRPRO \\
\hline
\end{tabular}

\begin{tabular}{|l|l}
\hline MARS & NPR1 \\
\hline
\end{tabular}

\begin{tabular}{l|l}
\hline GABRA5 & ATP2B3 \\
\hline
\end{tabular}

\begin{tabular}{|l|l|}
\hline CHST9 & RAC2 \\
\hline
\end{tabular}

VCL

SYT1 
A $\quad$ B

$\operatorname{Sec} 61 \beta$

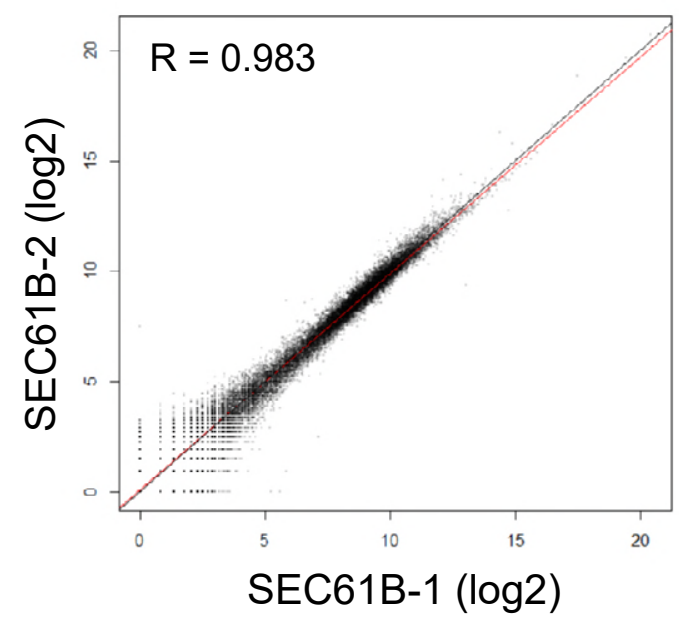

B C

LRRC59

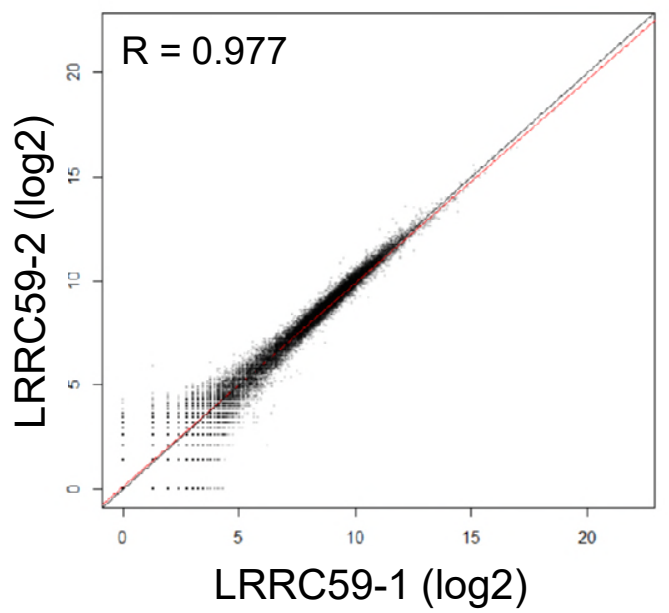

Empty Vector

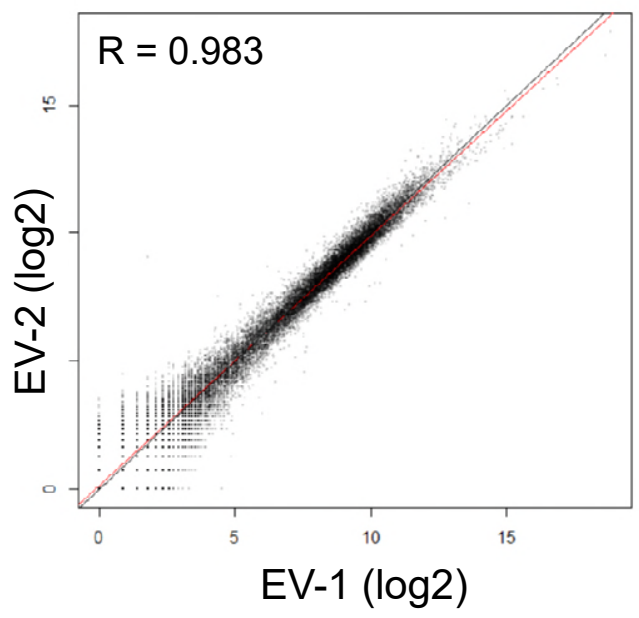

\section{Sample}

\section{BirA Raw Counts}

SEC61B-1

18059

SEC61B-2

5621

LRRC59-1

15761

LRRC59-2

16236

Empty Vector-1

175

Empty Vector-2

142 


\section{Table 1: GenelD Unique and Shared}

\begin{tabular}{|l|l|l|}
\hline Dataset & GO Term & FDR \\
\hline Shared (306) & System development & $3.31 \times 10-11$ \\
\hline & Membrane & $3.87 \times 10-12$ \\
\hline LRRC59 Unique (145) & Calcium ion binding & $4.77 \times 10-2$ \\
\hline & Plasma membrane & $2.03 \times 10-2$ \\
\hline SEC61B Unique (155) & Regulation of signaling & $1.60 \times 10-3$ \\
\hline & Endoplasmic reticulum & $3.60 \times 10-4$ \\
\hline
\end{tabular}

\section{Table 2: GeneID TPM Enriched Subcellular Components}

\begin{tabular}{|l|l|l|}
\hline Dataset & GO Term & FDR \\
\hline LRRC59 - Cell membrane & Cell-cell signaling & $3.37 \times 10-2$ \\
\hline LRRC59 - Extracellular & Extracellular matrix organization & $2.25 \times 10-4$ \\
\hline SEC61B - Nucleus & Negative regulation of transcription & $4.07 \times 10-2$ \\
\hline SEC61B - Cytosol & Neurotrophin signaling pathway & $5.99 \times 10-4$ \\
\hline LRRC59-mitochondria & Electron transport & $4.63 \times 10-4$ \\
\hline SEC61B-mitochondria & Mitochondrial membrane & $6.34 \times 10-7$ \\
\hline Shared - mitochondria & Mitochondrial matrix & $3.27 \times 10-2$ \\
\hline
\end{tabular}

